\title{
Mitochondrial prutein import
}

\author{
Franz-Ulrich Hartl, Nikolaus Pfanner, Donald W. Nicholson and Walter Ncupert \\ Instirut für Phvsiologische Chemie der Univessitüt München, München (F.R.G.)
}

(Received 2 June 1988)

\section{Contents}

I. Summary $\ldots \ldots \ldots \ldots \ldots \ldots \ldots \ldots \ldots \ldots \ldots \ldots \ldots \ldots \ldots \ldots \ldots \ldots \ldots \ldots$ ?

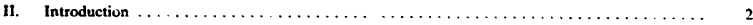

111. Cytosolic precursors of mitochondrial proteins $\ldots \ldots \ldots \ldots \ldots \ldots \ldots \ldots \ldots \ldots \ldots$;

A. Co- vs. posttranslatinnal translocation $\ldots \ldots \ldots \ldots \ldots \ldots \ldots \ldots \ldots \ldots \ldots \ldots \ldots \ldots \ldots$

B. Properties of cyloplusmic precursor pioteins $\ldots \ldots \ldots \ldots \ldots \ldots \ldots \ldots \ldots \ldots \ldots$ s

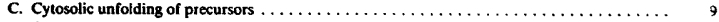

D. Cytosolic cofactors $\ldots \ldots \ldots \ldots \ldots \ldots \ldots \ldots \ldots \ldots \ldots \ldots \ldots \ldots \ldots \ldots \ldots \ldots$

IV. Mitochondrial targetiug signals $\ldots \ldots \ldots \ldots \ldots \ldots \ldots \ldots \ldots \ldots \ldots \ldots \ldots \ldots \ldots$

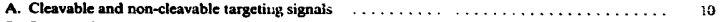

B. Structural properties of targeting sequences $\ldots \ldots \ldots \ldots \ldots \ldots \ldots \ldots \ldots \ldots \ldots \ldots$

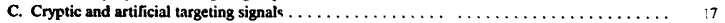

D. Heterologous impori $\ldots \ldots \ldots \ldots \ldots \ldots \ldots \ldots \ldots \ldots \ldots \ldots \ldots \ldots \ldots \ldots \ldots$

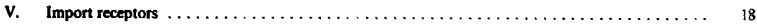
A. Proteinase-sensitive comperents on the mitochondrial surface for tie impori of precursor

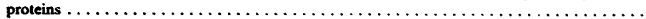
B. Binding of precursors to mitochondria and import from the bound state $\ldots \ldots \ldots \ldots \ldots$
C. Distinct steps in the binding of the ADP/ATP carrier and of porin $\ldots \ldots \ldots \ldots \ldots \ldots \ldots$
D. Titration of binding sites and competition of different precursors for specific binding sites ....
E. Role of specific binding sites

VI. Membrane translocation of precursor proteins $\ldots \ldots \ldots \ldots \ldots \ldots \ldots \ldots \ldots \ldots \ldots \ldots$ 21

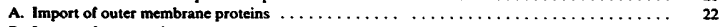

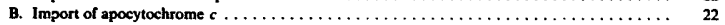

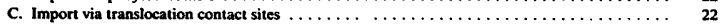

vil. Energy requirement of protein import $\ldots \ldots \ldots \ldots \ldots \ldots \ldots \ldots \ldots \ldots \ldots \ldots \ldots \ldots \ldots$

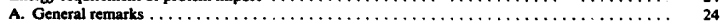

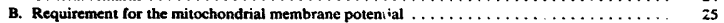

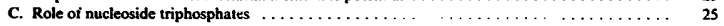

D. Energy requirement for protein transport across other biological membranes $\ldots \ldots \ldots \ldots$

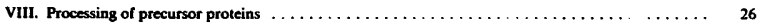

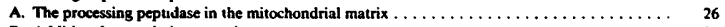

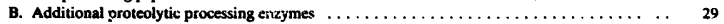

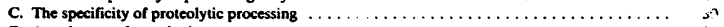

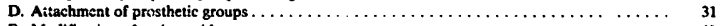

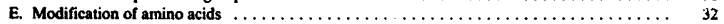

Abbreviations: ADH, alcohol dehydrogenase (EC 1.1.1.1); CCCP, carbonylcyanide-m-chlorophenylhydrazone; Cox, cytochrome oxidase; DHFR, dihydrofolate reductase; $\Delta \psi$, membrane potantial across the inner mitochondias memb:ane; ER, endoplusmic reticulum; FCCP, carbonylcyanide-

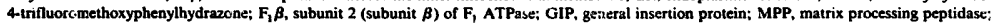
NTPs, nucleoside triphosphates; OTC, omithine transcarbamoylase; PEP, processing enhancing protein, hsp, hrat-shock prot:sin. 
IX. Intramitochondrial protein sorting and assembly $\ldots \ldots \ldots \ldots \ldots \ldots \ldots \ldots \ldots \ldots \ldots \ldots \ldots$

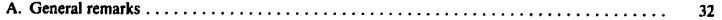

B. The 'conservative sorting' of intermembrane space proteins $\ldots \ldots \ldots \ldots \ldots \ldots \ldots \ldots \ldots$

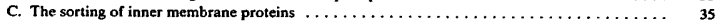

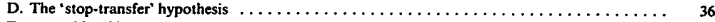

E. Assembly of imported mitochondrial proteins $\ldots \ldots \ldots \ldots \ldots \ldots \ldots \ldots \ldots \ldots \ldots$

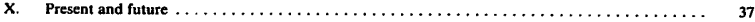

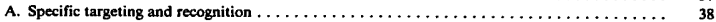

B. Translocation across the mitochondrial membranes $\ldots \ldots \ldots \ldots \ldots \ldots \ldots \ldots \ldots \ldots$

C. Processing and intramitochondrial sorting $\ldots \ldots \ldots \ldots \ldots \ldots \ldots \ldots \ldots \ldots \ldots \ldots \ldots$

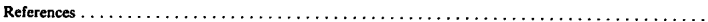

\section{Summary}

Most mitochondrial proteins are synthesized as precursor proteins on cytosolic polysomes and are subsequently imported into mitochondria. Many precursors carry amino-terminal presequences which contain information for their targeting to mitochondria. In several cases, targeting and sorting information is also contained in non-amino-terminal portions of the precursor protein. Nucleoside triphosphates are required to keep precursors in an import-competent (unfolded) conformation. The precursors bind to specific receptor proteins on the mitochondrial surface and interact with a general insertion protein (GIP) in thc outer membrane. The initial interaction of the precursor with the inner membrane requires the mitochondrial membrane potential $(\Delta \psi)$ and occurs at contact sites between outer and inner membranes. Completion of translocation into the inner membrane or matrix is independent of $\Delta \psi$. The presequences are cleaved off by the processing peptidase in the mitochondrial matrix. In several cases, a second proteolytic processing event is performed in either the matrix or in the intermembrane space. Other modifications can occur such as the addition of prosthetic groups (e.g., heme or $\mathrm{Fe} / \mathrm{S}$ clusters). Some precursors of proteins of the intermembrane space or the outer surface of the inner membrane are retranslocated from the matrix space across the inner membrane to their functional destination ('conservative sorting'). Finally, many proteins are assembled in multi-subunit complexes.

Exceptions to this general import pathway are known. Precursors of outer membrane proteins are transported directly into the outer membrane in a receptor-dependent manner. The precursor of cytochrome $c$ is directly translocated across the outer membrane and thereby reaches the intermembrane space.

In addition to the general sequence of events which occurs during mitochondrial protein import, current research focuses on the molecules themselves that are involved in these processes.

\section{Introduction}

A great deal of new information on how mitochondria import proteins has been gathered over the last few years (see Table I for a historical overview). Research in this area has been aided mainly by the introduction of gene-fusion techniques providing insight into the specific targeting of precursor proteins to mitochondria, and by the further refinement of in vitro assays resolving intermediate steps during the translocation of proteins across mitochondrial membranes. It is becoming more and more evident that the protein translocation processes across distinct cellular membranes are similar in several regards. For example, it has been demonstrated that protein transport across the membraries of mitochondria, chloroplasts, the endoplasmic reticulum, peroxisomes, and across the plasma membrane of Escherichia coli all require ATP and can occur posttranslationally (see Sections III-A and VII-C).

Mitochondria are not formed de novo. During the process of growth and division of preexisting organelles, newly synthesized components (e.g., proteins and lipids) have to be introduced into preformed structures. A number of processes take place to guarantee the functional identity of the organelles, which is sustained by a specific set of several hundred proteins. Mitochondria contain their own DNA and a unique system for repiication and protein synthesis (for review see Refs. 1-3). Only a small percentage of total mitochondrial proteins, however, are synthesized within the organelles. The bulk of mitochondrial proteins have to be imported from their site of synthesis in the cytoplasm.

The scope of the present review is to outline the general principles underlying the incorporation of cytoplasmically synthesized proteins into mitochondria. For ease of understanding, this highly complex process will be roughly subdivided into the following steps: (i) Mitochondrial proteins are synthesized on free polysomes, in most cases as larger precursors carrying $\mathbf{N}$ terminal extensions, and are subsequently released into a cytoplasmic precursor pool as soluble species. The 


\section{TABLE I}

\section{Historical overview}

Beginning from 1975, the main findings in the field of mitochondrial protein import are briefly summarized. In most cases we tried to select only those references reporting a certain observation for the first time. As a consequence, many contributions important to our present understanding of import are not cited here.

\section{Year Observation}

1975 Ribosomes attached to the outer mitochondrial membrane, especially at sites of close contact between outer and inner membranes, are visualized suggesting cotrarslational import of proteins via contact sites [209].

1976 Posttranslational import of precursor proteins into mitochondria is demonstrated in vivo. Translocation requires energy [31].

1977 Posttranslational import of precursors into mitochondria is established in an in vitro cell-free system [38].

1979 Uptake of precursor proteins into mitochondria is accompanied by proteolytic processing $[40,55,320,328]$.

Precursors of ADP/ATP carrier and cytochrome $c$ are synthesized without a cleavable presequence $[57,60]$.

1980 Cytosolic precursors are transported as high molecular weight aggregates [41].

Hypotonic extracts of mitochondria contain the activity for proteolytic processing of precursor proteins [226].

1981 Binding of precursors to mitochondria is demonstrated [192].

1982 An energized inner membrane is required for transport of precursors in,o or across the inner membrane $[172,182,213]$.

Presequences of mitochondrial precursor proteins are hydrophilic and positively charged $[72,215]$.

The processing peptidase is localized in the mitochondrial matrix. The enzyme is inhibited by metal chelators and stimulated by divalent cations [227-229].

Proteins destined for the intermembrane space are proteolytically processed in two steps $[35,51,52]$.

Binding sites for apocytochrome c can be titrated [193]

1983 Precursors of ADP/ATP carrier and of cytochrome $b_{2}$ specifically bind to de-energized mitochondria in vitro. Upon re-energization import from the binding sites takes place $[183,184,191]$.

Proteolytic processing is not essential for translocation of a cleavable precursor across both mitochondrial membranes [248].

Assembly of in vitro imported proteins is demonstrated $[73,300]$.

1984 The presequence of a mitochondrial precursor protein si sufincient to direct a cytosolic 'passenger' protein into mitochondria $[110,111]$.

In addition to information for targeting, information for sorting to the correct mitochondrial subcompartment can lie in the amino-terminal region of a precursor ('stop-transfer' hypothesis) [135].

1985 Sufficient information for targeting to mitochondria and for import into the matrix can be contained in the aminoterminal half of a presequence [114].

Positive charges contained in the presequence are important for import of a precursor protein [151]

Import of precursor proteins occurs at contact sites between outer and inner mitochondrial membranes [45].

Only the electrical component $\Delta \psi$ of the total proton motive force is required for translocation of precursors into the mitochondrial inner membrane [171].
TABLE I (continued)

\section{Year Observation}

1986 Precursor proteins must be at least partially unfolded to be translocated across the mitochondrial membranes 990 ].

Intramitochondrial sorting of a precursor protein to the outer surface of the inner membrane is proposed to occur by a 'stop-transfer' domain specific for the inner membrane [278].

Intramitochondrial sorting of a precursor protein to the oute: surface of the inner membrane is demonstrated to cocur via the matrix space ('conservative sorting' hypothesis) [36].

In addition to the membrane poiential. nucleoside triphosphates are required for import [98].

An amphiphilic a-helix is proposed to be a common secondary structure of mitochondrial presequences $[144,144 a, 156]$.

Positively charged artificial amino acid sequences can direct 'passenger' proteins into mitochondria [160].

1987 Nucleoside triphosphates are necessary to bep prorursor proteins in a translocation competent conformation [100,101. 217].

Translocation into and out of the mitochondrial matrix by a bipartite targeting signal is demonstrated [187].

Specific import information can reside in non-amino-terminal (carboxy-terminal) precursor parts [145,147].

1988 Mitochondrial processing peptidase (MPP) and the 'processing enhancing protein' (PEP), are purified and identified as essential components involved in import and asse:nbly of proteins into mitochondria [233].

PEP is identical with the product of the MAS 1 gene $[236]$ and MPP is identical with the product of the MAS 2 gene [236a]. which can complement the respective yeast mutants defective in proteolytic processing of precursors.

GIP, 'a general insertion protein', is proposed to be a common insertion site in the outer membrane receiving precursor proteins from different classes of surface receptors [169].

Members of the hsp 70-ramily of heat-shock proteins appear to be involved in keeping precursor proteins destined for different organclles in a translocation-competent conformation [107-109].

amino-terminal presequences apparently carry information for the targeting of precursor proteins to mitochondria. Nucleoside triphosphates are required for the unfolding of the precursor proteins prior to import. (ii) Precursor molecules specifically bind to proteinaceous receptors on the surface of mitochondria. (iii) Precursor molecules are then translocated across the membrane(s) and sorted to one of the four mitochondrial compartments (outer membrane, intermembrane space, inner membrane or matrix). Transport into or across the inner membranc occurs at contact sites between outer and inner membranes and is dependent on the membrane potential $(\Delta \psi)$ across the inner membrane. (iv) Processing of precursor proteins to their mature size or to an intermediate form in the case of several intermembrane space proteins - by the metal-ion dependent processing peptidase takes place in the matrix. (v) Additional processing steps occur during import including covalert and non-covalent modifications such as hemi- 
attachment, iron-sulfur cluster formation and conformational changes. The intermediate-sized forms of intermembrane space proteins have to undergo a second proteolytic event by a so far uncharacterized proteinase(s). (vi) Finally, many imported proteins are assembled into supranolecular protein complexes. The principles underlying these final assembly processes are poorly understood and are complicated by the fact that several protein complexes, like the proton translocating complexes of the respiratory chain and the $F_{0} F_{1}$ ATPase, are formed by cytoplasmically as well as mitochondrially synthesized subunits.

\section{Cytosolic precursors of mitochondrial proteins}

\section{III-A. Co- vs. posttranslational translocation}

Two principle mechanisms for the translocation of proteins across biological membranes have been discussed during the last decade. In both cases, protein syntiesis starts on free cytoplasmic polysomes. During cotranslational transport, the nascent polypeptide chain is directed to the target membrane as it emerges from. the ribosome. Translocation then takes place while synthesis continues. For example, translocation across the endoplasmic reticulum (ER) membrane can be dissected into the following steps [4-13]: following synthesis of a critical length of the polypeptide, the signal recognition particle (SRP) - a ribonucleoprotein complex - binds to the peptide chain. Under certain conditions the binding of SRP causes elongation arrest which is subsequently released after the complex (consisting of polysomes, polypeptide and SRP) has bound to the ER via the docking protein (SRP receptor). Insertion and translocation of the polypeptide across the ER membrane then occurs after synthesis is resumed. Aminoterminal signal peptides, if present, are cleaved off by the signal peptidase, a six-subunit protein complex residing on the luminal face or in the membrane of the ER [14].

In posttranslational transport, proteins bind to and are inserted into the target membrane after their synthesis is completed and the polypeptide has been released from the polysome. This type of membrane insertion is predominant in mitochondria and chloroplasts, as well as in peroxisomes and glyoxisomes [15-17]. It is noteworthy that cotranslational and posttranslational modes of insertion can coexist and are not mutually exclusive. Recently, reports from several laboratories have described posttranslational translocation across the ER membrane for a number of proteins [18-25]. The concept of mechanistic coupling between synthesis and translocation was primarily due to the temporal correlation of both processes. Even the translocation that occurs during synthesis has been shown to be independent of elongation if suitable experimental conditions were chosen $[26,27]$. On the other hand, protein transport into mitochondria could also occur during chain elongation (see below and Section VI-C).

These considerations are not limited to eukaryotic organisms. In prokaryotes, protein translocation has also been shown to be independent of elongation $[13,28-30]$. It is now widely agreed that cotranslational and posttranslational translocation merely reflect kinetic differences and not principle mechanistic differences. The folding state of a precursor protein, however, is important for its translocation competence. Membrane translocation requires the precursor to be in an unfolded conformation. This seems to be very difficult or impossible for completely translated secretory proteins. The state of folding of precursor proteins may therefore differ when imported cotranslationally compared to posttranslationally and require special events, particularly in the latter case, to ensure import competence. These aspects will be discussed in detail in Sections III-C and VII-C.

The first exidence showing that mitochondrial proteins can be imported posttranslatior.ally came from in vivo experiments with intact cells [31-36]. At various times after a pulse with radioactive amino acids, cells were fractionated and labeled precursor proteins were immunoprecipitated. The following observations were made: (i) labeled proteins first appeared in a cytosolic pool in soluble form and were detected in mitochondria only after a certain lag period; (ii) the kinetics of appearance in mitochondria varied for different precursors; and (iii) translocation into mitochondria continued Juring chase periods after the inhibition of protein synthesis with cycloheximide.

These findings were substartiated by establishing in vitro assays for the import of mitochondrial proteins. Precursors were synthesized in a cell-free translation system derived from postmitochondrial supernatants of Neurospora crassa or fron rabbit reticulocytes. After translation, precursors were released to the postribosomal supernatani. Isolated inilochondria, added to such a supernatant, were able to import these precursor proteins [37-41]. This demonstrated that proteins could be imported into mitochondria after synthesis of the polypeptide had been completed.

In a number of cases, translocation may follow a cotranslational mechanism in vivo. It has been shown that cytoplasmic $80 \mathrm{~S}$ ribosomes were tightly attached to yeast mitochondria after inhibition of elongation with cycloheximide [42-44]. Two-thirds of the ribosomes remained bound after washing at high ionic strength but could be subsequently released with puromycin, indicating that they were coupled to the nascent polypeptide chain and probably in state of translocation across the mitochondrial membranes. (In these experiments it was not demonstrated whether the incomplete precursors were actually spanning the 
mitochondrial membranes. Using a different approach, however, it was recently shown that the amino-terminal parts of precursor proteins could be translocated into the mitochondrial matrix (where processing occurred) while the major domain of the polypeptide was still in the cytosol [45] (also see Section VI-C.).) In vitro trans-

TABLE II

Nuclear coded mitochend . 'precursor proteins

Cytoplasmic precursor proteins whose import has been studied in vitro o. in some detail in vivo are listed according to their submituchondrial localization. For the intermembrane space, only soluble or loosely attached memtrane proteins are listed. Inner membrane proteins largely exposed to the intermembrane space $(-\mathrm{g}$, cytorhrome $r$ and the Rieske Fe/S protein) are found with their respective respiratory chain complexes. The apparent molecular mass as well as the number of amino acids for precursors and processed forms are given. Where determined. certain characteristics of the import pathway are spucified. Abbreviations: n.d., not determined; NTPs, nucleoside triphosphates.

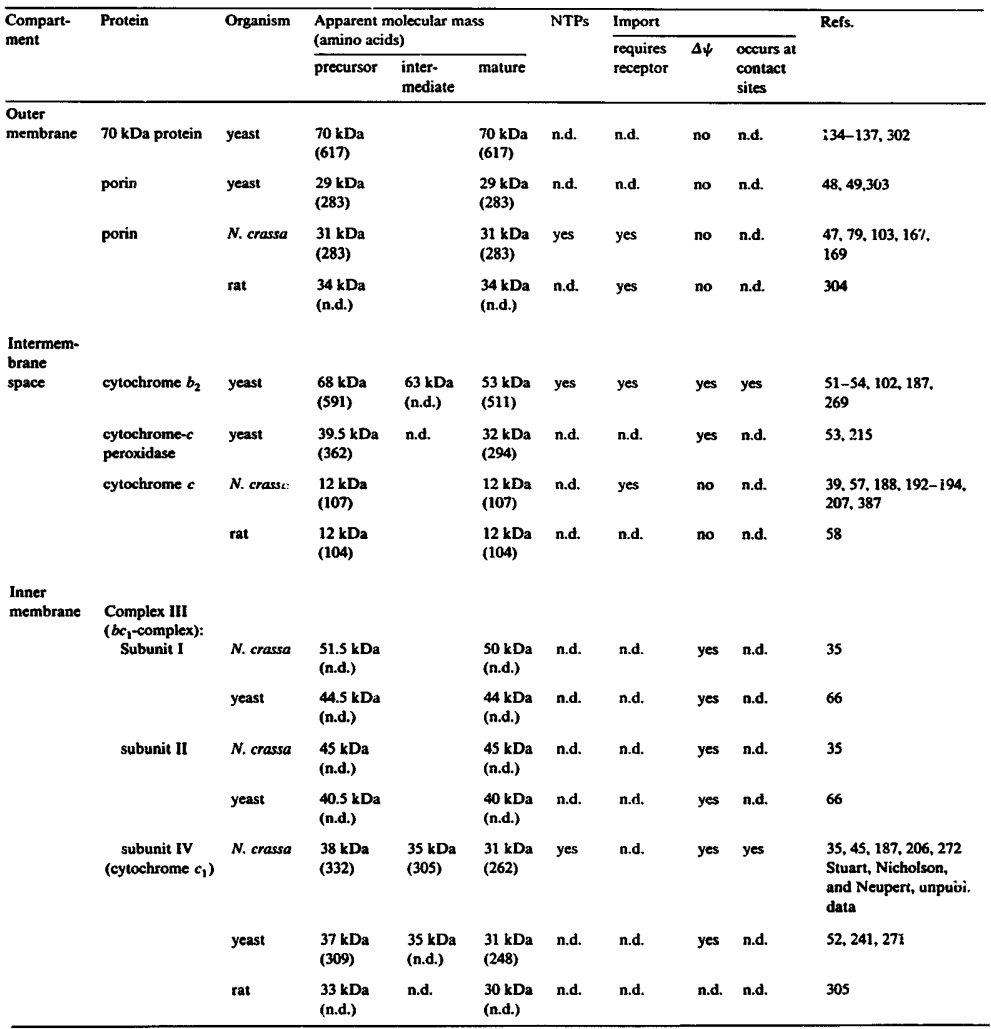

Table II continued overleaf. 
TABLE II (continued)

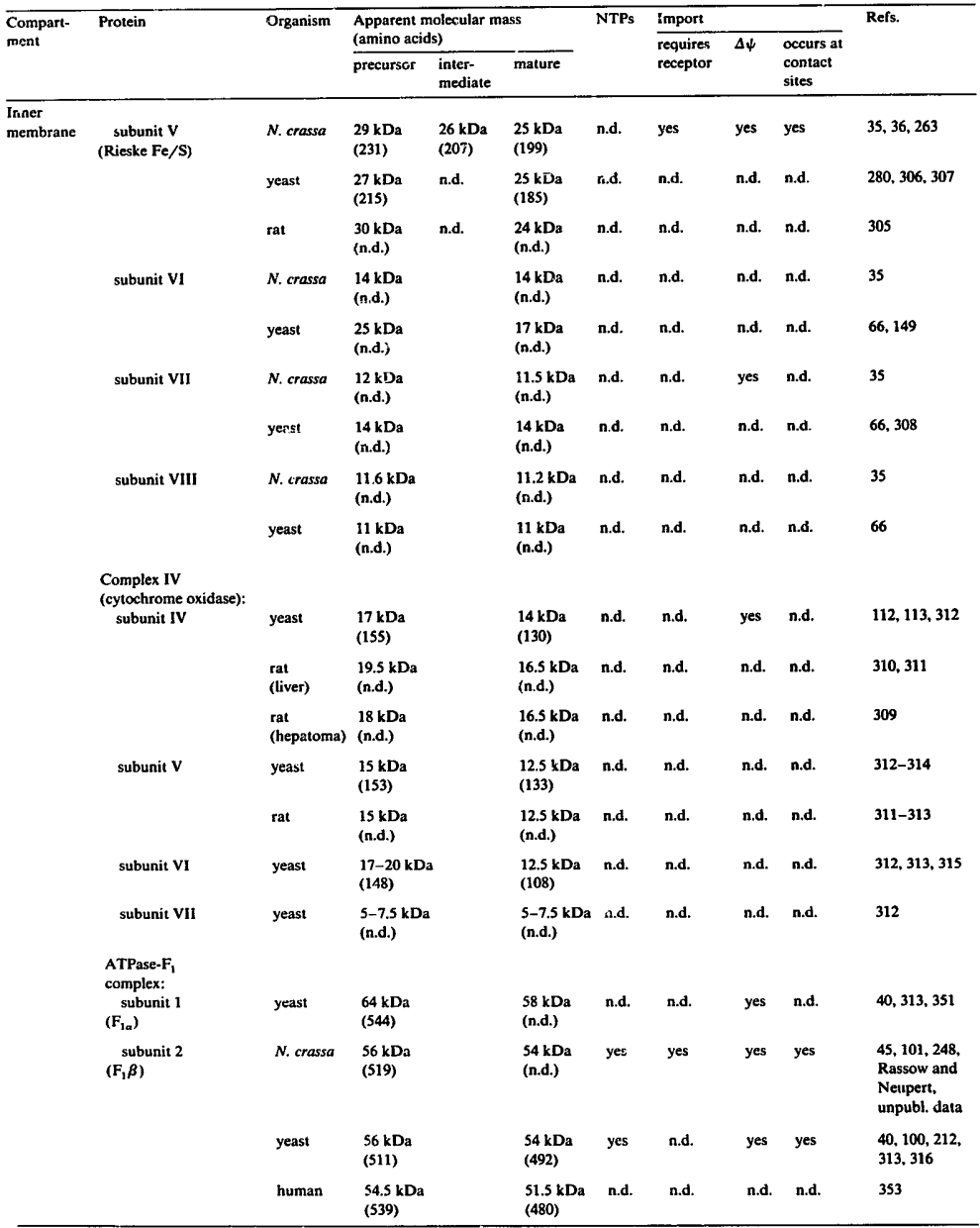


TABLE II (continued)

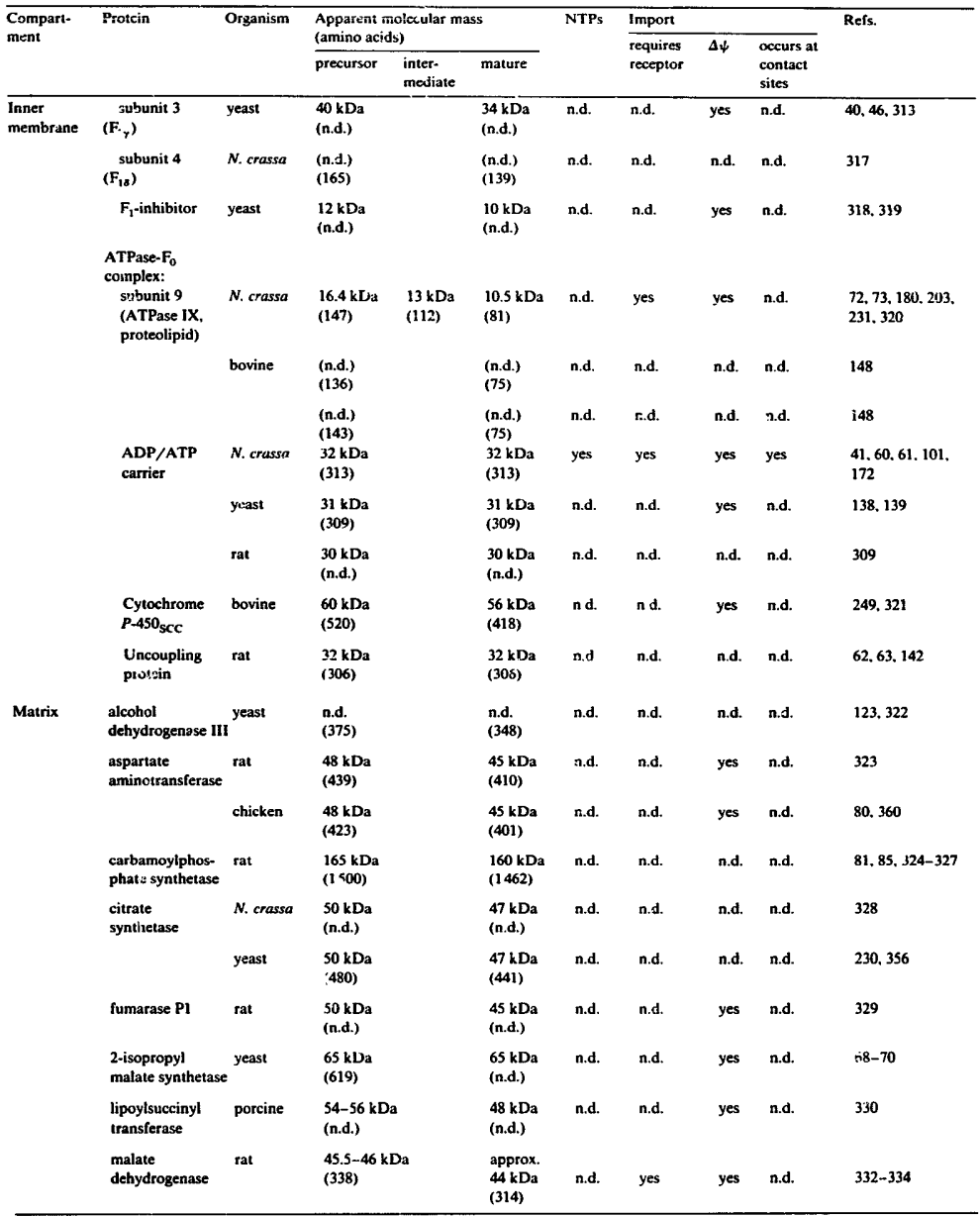

Table II continued overleaf. 
TABLE II (continued)

\begin{tabular}{|c|c|c|c|c|c|c|c|c|c|c|}
\hline \multirow{3}{*}{$\begin{array}{l}\text { Compart- } \\
\text { meint }\end{array}$} & \multirow[t]{3}{*}{ Protein } & \multirow[t]{3}{*}{ Organism } & \multirow{2}{*}{\multicolumn{3}{|c|}{$\begin{array}{l}\text { Apparent molecular mass } \\
\text { (amino acids) }\end{array}$}} & \multirow[t]{3}{*}{ NTPs } & \multicolumn{3}{|l|}{ Import } & \multirow[t]{3}{*}{ Refs. } \\
\hline & & & & & & & requires & $\Delta \psi$ & $\overline{\text { occurs at }}$ & \\
\hline & & & precursor & $\begin{array}{l}\text { inter- } \\
\text { mediate }\end{array}$ & mature & & receptor & & $\begin{array}{l}\text { contact } \\
\text { sites }\end{array}$ & \\
\hline \multirow[t]{6}{*}{$\overline{\text { Matrix }}$} & Mas I protein & yeast & $\begin{array}{l}50-51 \mathrm{kDa} \\
(462)\end{array}$ & & $\begin{array}{l}48 \mathrm{kDa} \\
\text { (n.d.) }\end{array}$ & n.d. & n.d. & yes & n.d. & 236 \\
\hline & $\begin{array}{l}\text { ornithine } \\
\text { aminotrans- } \\
\text { ferase }\end{array}$ & rat & $\begin{array}{l}49 \mathrm{kDa} \\
(439)\end{array}$ & & $\begin{array}{l}43 \mathrm{kDa} \\
(414)\end{array}$ & n.d. & n.d. & n.d. & n.d. & 335.336 \\
\hline & $\begin{array}{l}\text { withithine } \\
\text { transcarb- } \\
\text { amylase }\end{array}$ & rat & $\begin{array}{l}39 \mathrm{kDa} \\
(354)\end{array}$ & $\begin{array}{l}\text { approx. } \\
36 \mathrm{kDa} \\
(330)\end{array}$ & $\begin{array}{l}35 \mathrm{kDa} \\
(322)\end{array}$ & n.d. & n.d. & yes & n.d. & $\begin{array}{l}83,213,227.240 \\
325,337-339\end{array}$ \\
\hline & & human & $\begin{array}{l}40 \mathrm{kDa} \\
(354)\end{array}$ & & $\begin{array}{l}36 \mathrm{kDa} \\
(322)\end{array}$ & n.d. & n.d. & n.d. & n.d. & 173,343 \\
\hline & $\begin{array}{l}\text { 2-oxoglutarate } \\
\text { dehydrogenase }\end{array}$ & porcine & $\begin{array}{l}98 \mathrm{kDa} \\
\text { (n.d.) }\end{array}$ & & $\begin{array}{l}96 \mathrm{kDa} \\
\text { (n.d.) }\end{array}$ & n.d. & n.d. & yes & n.d. & 330 \\
\hline & $\begin{array}{l}\text { serine-pyruvate } \\
\text { aminotrans- } \\
\text { ferase }\end{array}$ & rat & $\begin{array}{l}45.8 \mathrm{kDa} \\
(414)\end{array}$ & & $\begin{array}{l}43.2 \mathrm{kDa} \\
(390)\end{array}$ & n.d. & n.d. & yes & n.d. & 331,362 \\
\hline
\end{tabular}

lation of the mRNA extracted from ribosomes bound to mitochondria showed that they were enriched in mRNAs encoding mitochondrial proteins [46], but that only part of the tota' mRNA for any given mitochondrial precursor was recovered from the bound polysomes, the rest being associated with free cytoplastric polysomes. Thus, cotranslational protein translocation into mitochondria appears possible, at least under suitable experimental conditions (e.g., after inhibition of elongation with cycloheximide), but it is clearly not obligatory for protein import. In vivo, the majority of mitochondrial protein import might even occur cotranslationally at contact sites between outer and inner membranes, since $\mathrm{N}$-terminal targeting sequences svould emerge from the ribosome before the completion of polypeptide synthesis.

In retrospect, the demonstration of posttranslational :mport has been most useful in proving the mechanistic independence of translation and translocation. Therefore, instead of the definition of cotranslational transport as being the strict coupling between translation and translocation, it is more appropriate to consider it as transport occurring during translation.

\section{III-B. Properties of cytoplasmic precursor proteins}

What is so unique about precursor proteins that they can be translocated across membranes in sharp contrast to their mature counterparts, and what are their functional, structurai and physical requirements? In general, features of precursors which must be different from their respective mature proteins fall into three cate- gories: (i) precursors must be soluble in the cytosol; (ii) they have to be specifically recognized by mitochondria; and (iii) they have to assume a conformation which is competent for translocation into or across membranes.

More than $\mathbf{4 0}$ different precursor proteins destined for import into either the matrix compartment or into the inner membrane have been analyzed to date (Table II). Most of them carry cleavable amino-terminal peptide extensions, so-called presequences, whose structure and function will be discussed in detail below (see Section IV-B). Several precursur proteins, however, are synthesized without a cleavable peptide extension. For example, none of the known outer membrane proteins contains a cleavable presequence. Besides the channel-forming protein porin [47-49], three functionally uncharacterized proteins of the outer membrane, having a molecular mass of 70,45 and $14 \mathrm{kDa}$, have been analyzed [49]. A $35 \mathrm{kDa}$ protein of rat liver mitochondria [50] might represent an exception. On SDS-polyacrylamide gels, the newly synthesized protein appears as a precursor having a slightly higher molecular weight. Sequencing data, however, will be required to confirm whether proteolytic processing of this outer membrane protein occurs or not.

Most proteins imported into the intermembrane space, such as cytochrome $b_{2}$ [51-54], cytochrome $c$ peroxidase [53,55] and sulfite oxidase [56], contain cleavable presequences. On the other hand, cytochrome $c[39,57,58]$ and also possibly adenylate kinase [59] do not. It seems noteworthy that the imrort pathway for cytochrome $c$ is very different from that of the rest of the intermembrane space proteins analyzed so far (see 
Sections VI-B and IX-B). It might be possible that other intermembrane space proteins without cleavable preseauences follow a cytochrome $c$-like import route.

Quite a number of inner membrane proteins do not contain N-terminal extensions, including the ADP/ATP carrier $[60,61]$, the closely related uncoupling protein of brown adipose tissue [62-65], subunits VI (14 kDa) ard VIII (11 kDa) of Neurospora [35] and yeast [56] complex III, and subunit VI of bovine complex III (ubiquinone-binding protein) [67]. Of the matrix proteins, 2-isopropylmalate synthetase and 3-oxoacyl-CoA thiolase are the only twe known examples of precursors not containing a cleavable presequence [68-71] (also see Section (V-A)

Many imported mitochondrial proteins are integral membrane polypeptides. The question that arises then is which features confer solubility is the cytoplasm to their precursors? Amino-terminal presequences which are important for the targeting of proteins certainly play a role also in this regard. Subunit 9 (ATPase IX, proteolipid or 'dicyclohexylcarbodiimide (DCCD) binding' protein) of the $F_{0} F_{1}$ ATPase from $N$. crassa is an excellent example of how this occurs; the mature part of the protein, consisting of 81 amino acids, is very hydrophobic. The precursor, however, carries a highly hydrophilic 66 amino-acid residue presequence [72] (Table III, Fig. 1). Transport of subunit 9 through the cytoplasm is accomplished in the form of high molecular weight aggregates [73]. In these aggregates, the presequences probably face the aqueous surroundings thus rendering solubility to the whole complex. In fact, most precursor proteins seem to form such aggregates. Other examples include subunit $V$ of cytochrome oxidase [74] and rat mitochondrial fumarase [75], although in the latter case solubility in an aqueous environment is not likely to pose a problem. It is unknown whether the cytosolic high molecular weight aggregates are homooligomers of the precursor proteins or whether further components are involved in the formation of these complexes. An interaction between different mitochondrial precursor proteins does not appear to be required for the formation of the aggregates, since synthesis of a single precursor species (derived from CDNA clones) in rabbit reticulocyte lysates also leads to the formation of soluble and import-competent aggregates (Pfanner and Neupert, unpublished data). Experiments in which distinct internal regions of the precursor of the $F_{1}$ AT'Pase subunit $\beta$ were deleted suggest that a sequence necessary for the formation of tetramer aggregates lies between residues 122 and $144[76,77]$. It is unknown, however, whether this segment is a specific tetramer-forming sequence or a domain which is highly important for the overall folding of the precursor.

In the case of precursors without cleavable presequences, solubility is aiso most probabiy conierred by a conformational arrangement different from that of the respective mature forms. For the ADP/ATP carrier, these conformational differences can be clearly demonstrated by the binding of the specific inhibitor carboxyatractyloside. While the precursor does not bind carboxyatractyloside the mature form does. Both forms can be distinguished by their different behavior on hydroxyapatite columns in the presence of carboxyatractyloside. The precursor binds to hydroxyapatite, whereas the correctly assembled and functionally active carrier passes through the column. This is true foi both the ADP/ATP carrier imported in vivo and in vitro [78]. The binding properties to hydroxyapatite are therefore useful as critericn to test for import and correct assembly in reconstituted import systems. The precursor to the ADP/ATr carrier also occurs in the cytoplasm in higher molecular weight complexes of 120 and 500 $\mathrm{kDa}$ [41].

Similar to the ADP-ATP carrier. the precursor to porin has to go through a conformational change to become the functionally active mature protein, which is embedded in the phospholipid bilayer of the outer membrane as a dimer. Interestingly, this conformational change can be reversed by acid-base treatment of the detergent-solubilized assembled porin whereby chemical amounts of import-competent soluble precursor can be produced [79].

Under physiological conditions newly synthesized precursor proteins have to stay in the cytoplasm $\mathrm{A.s}$ only a very short time before they are taken up by mitochondria. Accumulation of precursors in the cytosol of growing cells, however, can be achieved if import is blocked by inhibition of the membrane potentiai across the inner mitochondrial membrane with uncouplers of oxidative phosphorylation such as carbonylcyanide- $m$-chlorophenylhydrazone (CCCP) [34]. Probably due to their unfolded structure, cytosol c precursors are rapidly degraded compared to their nature mitochondrial counterparts. For example, the h. If-life of precursors to yeast cytochrome $c_{1}$ [34], chick : :spartate aminotransferase [80] and rat liser carbamoyinhosphate synthetase [81] was found to be in the range of 2 to $10 \mathrm{~min}$. The precursor to yeast $F_{1}$ ATPasc subunit $\beta$ seems to be more stable with a half-life of 50 min [14]. This has allowed the preparation of radiochemica:ly pure $F_{1} \beta$ precursor [82]. It seems possible that the different half-lives of precursor proteins are influenced by their ability to interact with cytosolic cofactors which have been found to be required for protein import into mitochondria [76,82-89] (see Section III-D).

\section{III-C. Cyiosolic unfolding of precursors}

In addition to features which enable the solubility of precursor's in the cytosol, conformation is a so of great importance for precursor molecules to be corapetent for import into mitochondria. For example the import of a 
fusion protein between the presequence of subunit IV of cytochiome oxidase (Cox IV) and dihydrofolate reductase (DHFR, a cytosolic protein) could be blocked by methothrexate, a strong competitive inhibitor of dihydrofolate reductase [90]. It was demonstrated by this approach that a protein having a stably folded structure cannot be translocated across the mitochondrial membranes. Essentially the same conclusions can be drawn from recent experiments on the import of a fusion protein beiween the 382 amino-terminal residues of ATPase $F_{1} \beta$ and 61 residues of yeast copper metallothionein [91]. Addition of copper to import reactions blocked translocation of the construct due to the tertiary conformation of the metallothionein portion induced by binding of the metal ligand.

The importance of conformation for protein translocation may also be emphasized by the following findings: the presequence of mitochondrial manganese superoxide dismutase was able to direct DHFR as a 'passenger' protein to mitochondria but not cytosolic invertase [92]. Destabilization of the tertiary structure of the DHFR moiety in a similar construct (presequence of Cox IV fused to DHFR) by selected point mutations led to an increased rate and efficiency of import into mitocho:siria [931. Carboxy-terminally truncated forms of carbamoylphosphate synthetase were imported less efficiently than the full-length protein in vivo [94].

Lack of tertiary structure seems to be a prerequisite for import competence. For example, precursor proteins could be trapped in translocation contact sites such that the amino-terminus protruded into the matrix space, while other portions of the precursor molecules were still outside the outer membrane $[36,45,95,96]$. A portion of the precursor protein was thus spanning the two mitochondrial membranes. Since the transmembrane distance was larger than the diameter of the assembled polypeptide chain, the precursor polypeptide was at least partially unfolded. This demonstrated that precursor proteins were indeed unfolded during translocation into mitochondria. It has been proposed that ATP-dependent defolding enzymes ('unfoldases') are required to keep precursor proteins destined to different organelles in a translocation-competent conformation [97]. It was recently shown that mitochondrial p-otein import also required nucleoside triphosphates (NTPs) [98-103] and that NTPs are very likely necessary for unfolding of precursor proteins (see Section VII-C).

A number of reports described the dependence of mitochondrial protein import on proteinaceous cytosolic factors (see below). It is not known, however, whether these cofactors are related to the requirement of NTPs and of the proposed unfoldase. Recent evidence points to the possibility that members of the 70 $\mathrm{kDa}$ heat-shock protein (hsp) family (for review see Refs. 104-106) are involved in AT ${ }^{\mathrm{P}}$-dependent unfolding of precursor proteins destined for import into differ- ent organelles. A yeast strain which was depleted in three genes of the SSA subgroup of hsp 70-related loci accumulated in vivo the precursor of prepro- $\alpha$-factor (a secretory protein) in the cytosol as well as unprocessed $\beta$ subunit of $F_{1}$ ATPase. Purified yeast hsp 70-like proteins stimulated translocation in vitro of prepro-atfactor into microsomes $[107,108]$. In addition to proteins of the hsp 70 family, yeast cytosolic fractions contained a different translocation-stimulating activity which was inactivated upon treatment with $N$-ethylmaleimide [108]. Posttranslational import of proteins contained in rabbit reticulocyte lysates into dog pancreas microsomes was found to be enhanced by a similar system consisting of hsp 70-related proteins and at least one additional component [109].

\section{III-D. Cytosolic cofactors}

Several studies have suggested a requirement of cytosolic cofactors for mitochondrial protein import [76,82-89]. The cofactors were partially characterized and determined to be of proteinaceous structure $[76,82-84,86]$ and to possibly contain RNA [85]. Argan and Shore proposed that a protein of $50 \mathrm{kDa}$ formed a complex with the precursor of ornithine transcarbamoylase [86]. Recently Ono and Tuboi [89] reported the partial purification of a cytosolic factor which was active in forming a complex with the chemically synthesized presequence of ornithin aminotransferase. Binding of the prepeptide to mitochondria was dependent on the presence of this factor. In another study, the specific binding of the ADP/ATP carrier precursor to the mitochondrial surface required a cytosolic component which was present in rabbit reticulocyte lysate and which interacted with isolated mitochondria [88]. The exact nature and function of these cytosolic cofactors remains elusive so far. It is possible that they play a role in conferring solubility to cytosolic precursors, in the formation of higher molecular-weight precursor aggregates or in keeping precursor proteins in an import competent conformation.

\section{Mitochondrial targeting signals}

\section{$I V-A$. Cleavable and non-cleavable targeting signals}

Many different proteins of various final destinations are synthesized on the same cytosolic polysomes. This then implies that the information for the correct intracellular location must reside within the protein itself (Fig. 1). Our functional understanding of the role of amino-terminal presequences in mitochondrial protein import is mainiy based on a number of experiments with fusion proteins during recent years. Hurt et ai. [110] and Horwich et al. [111] were the first to demon- 
strate that the presequence of a mitochondrial protein could direct a cytosolic protein, mouse dihydrofolate reductase (DHFR), into mitochondria. The coding region for the 25 amino acid presequence of cytechrome oxidase IV (Cox IV) [112], an inner membrane protein. was fused to DHFR, and the restilting fusion protein was successfully imported into the $\mathrm{r}$-atrix and processed by the processing peptidase [113]. If increasing numbers of amino acid residues were deleted rom the carboxyterminal side of the presequence, the 2 imino-terminal residues of the presequence were found to contain sufficient targeting information. On the othe hand, deletion of the first seven amino acid recidues abolished import, and the mature Cox IV was atither imported in vivo nor in vitro $[110,114]$. For alf if tile above-mentioned constructs, the imported protein was found in the matrix compartment but not the inner membrane. This was also the case when the entire presequence plus the first 28 amino acids of native Cox IV were fused to DHFR, indicating that information for intramitochondrial sorting to or assembly into the inner membrane must reside in the remaining amino acids of the mature protein [113].
Similar experiments were performed with the presequences of a number of other mitochondrial precursors. Horwich et al. [111] have shown both in vivo and in vitro that the 32 amino-acid residue presequence of the matrix enzyme ornithine transcarbamoylase (OTC) can direct DHFR into mitochondria. On the other hand, import experiments with a construct of human OTC precursor containing only the first 12-16 amino acid residues of the presequence demonstrated that the amino-terminal portion of the presequence was not absolutely required for targeting to mitochondria, while the middle portion of the prepeptide (amino acid residues 8 through 25) was required and sufficient [115]. The presence of the amino-terminal portion of the presequence, which by itself was not sufficient for targeting, seemed to increase the import efficiency of the construct. On the other hand, for the precursor of rat OTC it was suggested that an amino-terminal $\alpha$-helix in the prepeptide is important for targeting of the precursor to mitochondria $[116,117]$. The amino-terminal region is the most conserved one in the signal sequences of rat and human OTCs (also see Section IV-B).

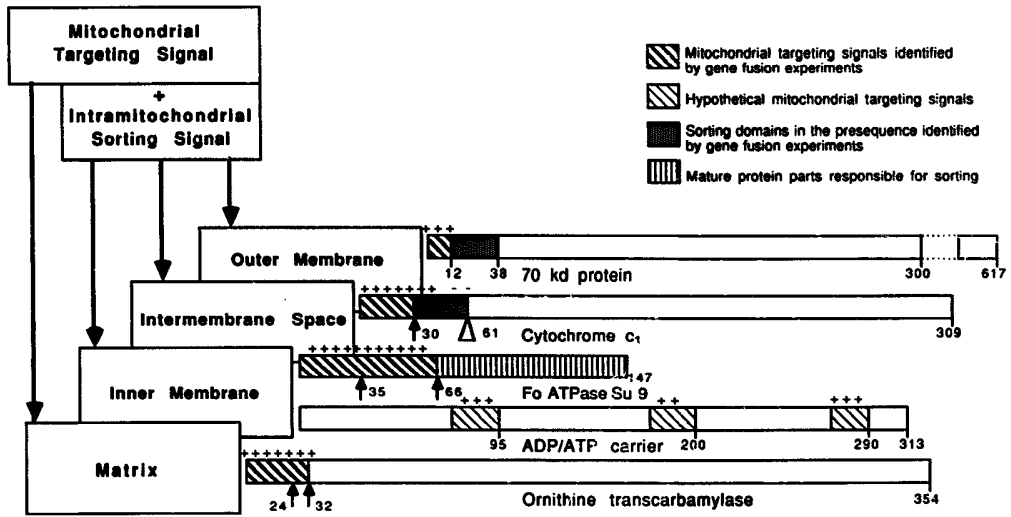

Fig. 1. Examples of structural domains in mitochondrial precursor proteins important for targeting and intramitochondrial sorting. For a number of mitochondrial precursor proteins having different submitochondrial locations, a functional role in targeting to mitochondria and intramitochondrial sorting has been assigned to specific structural segments. Mitochondrial targeting signals are typically hydrophilic and positively charged sequences contained in amino-terminal prepeptides. In most cases they are cleaved off during import. Targeting signals can also reside in internal parts of the protein (e.g. ADP/ATP carrier). In addition to targeting signals, sorting signals are found in amino-terminal sequences (e.g. 70 xDa outer membrane protein, cytochrome $c_{1}$ ). They often contain a stretch of hydrophobic amino acids of variable length. In the case of proteins which are soluble in the intermembrane space or which have a large domain exposed to the intermembrane space, complex presequences are proteolytically cleaved in two steps (e.g. cytochrome $c_{1}$ ). Information for intramitochondrial sorting can also reside in the mature protein part (e.g. F $_{0}$ ATPase subunit 9) (for details see Section IX). The respective cleavage site of the matrix processing peptidase is indicated by an arrow, the cleavage site for the second proteolytic processing step of cytochrome $c_{1}$ (occurring at the outer surface of the inner membrane) by an open arrowhead. Charged amino acid residues in functionally relevant domains are indicated. 
Gene-fusion studies with $E$. coli $\beta$-galactosidase or yeast invertase as 'passenger' proteins demonstrated the targeting function of the 9 amino-terminal residues of the presequence of $\hat{s}$-aminolevulinate synthase [118] and the 27 amino-terminal residues of $F_{1}$ ATPase subunit $\beta$ [119-121]. Interestingly, the precursor of $F_{1} \beta$ seems to contain redundant targeting information in the amino-terminal region of the precursor protein [122].

Sequence comparison and gene fusion experiments with the three isoenzymes of alcohol dehydrogenase (ADH I-III) confirmed the conclusions from these experiments on the importance of the presequence for targeting [123]. While ADH I and II are located in the cytosol, ADH $1 \mathrm{ll} 3$ is located in the mitochondrial matrix. Only newly synthesized ADH III carries an aminoterminal presequence of 27 amino acid residues. The sequence similarity between the mature parts of the three forms is between 80 and $90 \%$. If the ADH III presequence was flsed to ADH II, the resulting construct was importes into mitochondria, thus demonstrating that the presence or absence of an amino-terminal targeting sequen:e can determine whether a protein is located in the cytosol or within mitochondria.

This has also bisen shown most convincingly for isoenzymes, having different locations within the cell, which are encoded by the same gene (for review see Ref. 124). In the case of yeast histidinc-tRNA syntheiase, two transcription starts of the nuclear gene were identified, both of which were physiologically expressed [125]. Transcription starting at the first initiation site produced a longer mRNA coding for the mitochondrial isoenzyme precursor that carries an amino-terminal presequence. If the first start codon of the longer mRNA was deleted by a mutation, the mitochondrial isoenzyme was not synthesized, resulting in respiratory deficiency. Initiation of translation at the second in-frame start codon, however, still occurred and the cytosolic isoenzyme was produced. The same observations were made for the gene encoding valine-tRNA synthetase [126]. On the other hand, for methionine-, tryptophan- and threonine-tRNA synthetases the existence of distinct genes coding for the cytoplasmic and mitochondrial forms has been demonstrated [127-130]. Other examples where the subcellular location of a protein is determined by initiation of transcription at either one of two start sites include the genes for 2-isopropylmalate synthase [69,70] and for yeast fumarase [131]. In all of these cases two proteins are synthesized but only the larger one is imported into mitochondria. The same principle is followed in the intracellular sorting of cyclophilin (the cyclosporin A-binding protein) of $N$. crassa recently studied in our laboratory [132]. Two mRNAs are transcribed from the same gene. The longer mRNA codes for a precursor protein of $24 \mathrm{kDa}$ which was imported into mitochondria and proteolytically processed in two steps. The shorter mRNA directs the synthesis of the cytoplasmic form. Only about $20 \%$ of total cyclophilin was found in mitochondria, the remaining $80 \%$ being located in the cytoplasm, corresponding to the relative amounts of the twc mRNAs synthesized. It is unknown so far how initiation of transcription at either the first or second transcription start site is regulated.

Precursor proteins without cleavable presequences obviously contain the targeting signals within the mature part of the protein. In principle, targeting signals can either reside in a certain stretch of amino acids (terminal or internal) or result from a specific tertiary structure of the molecule as it has been hypothesized for proteins imported into glycosomes of Trypanosoma brucei [133]. For mitochondrial proteins there is no evidence for non-contiguous targeting signals so far.

In the case of the yeast $70 \mathrm{kDa}$ outer membrane protein, which contains no cleavable presequence, sufficient information for targeting and sorting was found in the first 41 amino-terminal amino acid residues [134-137] (Fig. 1). Amino acid residues 1 through 12 contain the mitochondrial targeting signal. The following hydrophobic segment (amino acid residues 10 through 37) was proposed to anchor the protein in the outer membrane ('stop-transfer' hypothesis, see Section IX-D).

Studies with yeast ADP/ATP carrier showed that the first 111-115 amino acid residues were sufficient for directing a $\beta$-galactosidase or DHFR passenger into mitochondria [138,139]. Within this region, the targeting signal was found to be contained in the segment residues 72 through 97 [139]. The constructs were, however, arrested at an intermediate stage oi the importpathway. Interestingly, the ADP/ATP carrier consists of three domains of about one hundred amino acid residues each which are homologous to each other $[6], 138,140]$. This structure was suggested to have evolved by triplication of an ancestral gene [141]. It therefore seems possible that each of the three domains contains a potential signal sequence [3] (Fig. 1). Indeed, a stretch of 20 amino acid residues is present in the carboxy-terminal half of each domain, which carries positive but no negative charges and is predicted to form an $\alpha$-helical structure [142] and therefore possesses features of mitochondrial presequences $[143,144]$ (see Section IV-B). A truncated ADP/ATP carrier lacking the N-terminal third of the precursor polypeptide was found to be competent for import into mitochondria [145]. The import of truncated ADP/ATP carrici showed all characteristics of the import of the authentic protein, demonstrating that the carboxy-terminal twothirds contain specific and sufficient targeting information.

In the case of mitochondrial 3-oxoacyl-CoA thiolase, which is made without a cleavable presequence, sufficient information for targeting to mitochondria was 


\section{TABLE III}

\section{Sequentes of amino-rerminal prepieces of imported mitochondrial proteins}

The amino acid sequences of the prepieces of imported mitochondrial proteins are listed by the single-letter amino acid code (beginning from the $\mathrm{N}$-terminus). Basic $(+)$, acidic $(-)$ and hydroxylated $(\cdot)$ amino acids are indicated. Proteolytic processing sites which are known with reasonable certainty are indicated by a solid arrowhead, while those which are only predicted cleavage sites (usually by alignment with known sequences of mature proteins) are marked by open arrowheads. In cases where the cleavage cites are unknown, or where processing does not occur, the first S0 amino acids are listed. The proteins are first grouped according to their intramitochondrial location. and then according to the respiratory complex to which they belong or by metabolic function. Most of the proteins presented in this table are synthesized as higher molecular-weight precursors; their sequences have been determined from cDNA clones; import and processing have been studied in vitro and in some cases in vivo as well (see Table II); and, processing sites have been ascertained by comparison with mature protein sequences. Some. however. are not proteolytically processed (i.e., sequences $1-3,75-81$ ) but are presented where they might be of interest with regard to import (in these cases, only proteins where the absence of a prepiece has been confirmed by the DNA sequence are shown). In a number of instances, aminorterminal sequenc's are taken from the nuclear gene sequences encoding mitochondrial proteins or putative mitcohondrial proteins. (For footnotes d-dd see page 15)

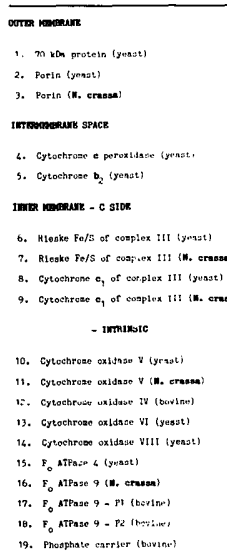

4. Cytochrowe e poristiace byent,

5. Cytochrobe $b_{2}$ (yenat)

\begin{tabular}{|c|c|}
\hline wots & Alsterbics \\
\hline $\mathrm{n}$ & $t_{2}$ \\
\hline$t$ & $\therefore$ \\
\hline 4 & U \\
\hline
\end{tabular}

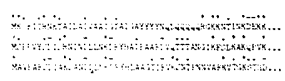

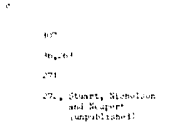

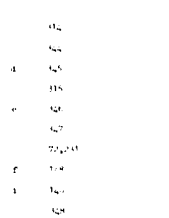

- 1 sios

20. Suburit 1 or eaaplex III (yesat)

21. Subunit 11 of ecsipiex :11 (ycuat)

22. Cytochruae axidase in (yesse)

23. F, atpane $\alpha$ (yos:t)

24. F, htPaes o (yrutt)

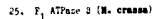

26. F, ATPase o (II. plubbaglalfolla)

27. F, hTPave is (nuean)

28. F, ATPage b (In. Crmaka)

29. Cycuehrote Pe-450(11a) (buvise)

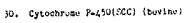

31. Cytushruese P-450(sce) (nuenn)

32. Prosusalag onhandiog proteln (W. erassa)

39. Mas 1 (yedat)

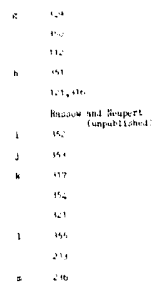
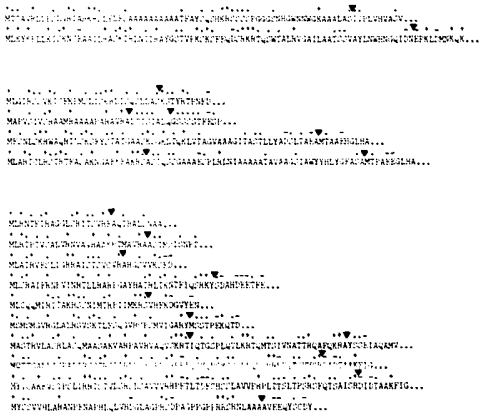

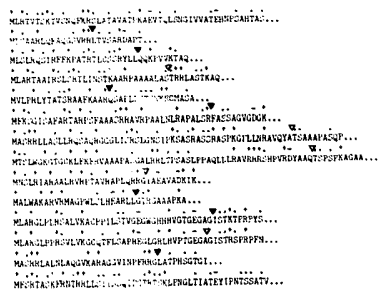

continued

The amino-terminus of the $70 \mathrm{kDa}$ protein is not removed during import. It is proposed to carry targeting information since it can specifically direct $\beta$-galactosidase to mitochondria $[135,136]$ (Section IV-A).

b Porin is not synthesized with an N-terminal extension; the first 50 amino acids of yeast porin have structural features resenbling the $70 \mathrm{kDa}$ outer membrane protein (aligning $70 \mathrm{kDa}$ amino acid 1 with porin amino deid 5) and have been implicated in mitochondrial targeting [298]. Similarly, the first 18 amino acids of $N$. crassu porin are able to form an amphiphilic $\alpha$-helix (as does the yeast porin amino terminus) which may support import [103].

c Precursors of sequences 4-9 are processed in two steps. With the exception of cylochrome $c_{1}$ and the Rieske Fe/S Frotein of the $N$. crassa complex III, only the second processing site is known. The precursor of $N$. crassa $F_{0}$ ATPase 9 (sequence 16) is also processed in two steps, both by the chelator-sensitive matrix peptidase. 
shown to be contained in the first 61 amino-ierminal residues (Ref. 71 and Mori, M., personal communication). The highly homologous peroxisomal 3-oxoacylCoA thiolase is made as a larger precursor with an amino-terminal extension that might mask a potential mitochondrial targeting signal contained in the amino terminus of the mature protein (corresponding to the amino-terminal residues of the mitochondrial enzyme).

\section{TABLE III (continued)}

uxthit

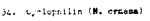

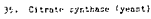

36. Fusarnis: |yeasel

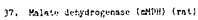

34. Pyournte detydroponase a suburit (huets)

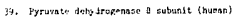

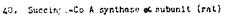

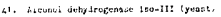

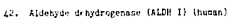

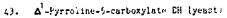

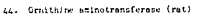

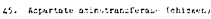

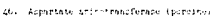

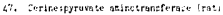

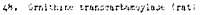

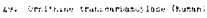

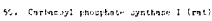

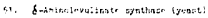

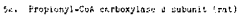

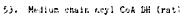

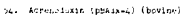

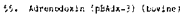

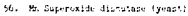

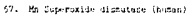

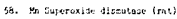

54. Ma suproxide distutape facuse?

b. eft -Ta tyuest

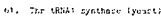

6. irp tketh aynthace (yetat)

6. 7is then ayntas: [yentst?

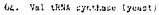

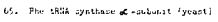

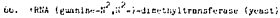

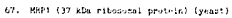

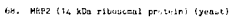

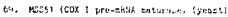

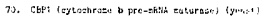

71. Chis: (cyluchroat b pre-shtih eoturoie) (yeact)

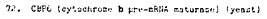

33. PIF : repatr/retegelisutteril (jeast)

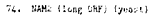

Miscenthutions

73. ;-0xageyt-Grih thatase irat!

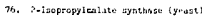

77. Suluntt y1 (17 kinj of tooplex III (yeaca)

7B. Subunit YIt (16 kDs) of eceplex 311 (jeazt)

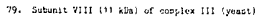

Fo. Cylochroge oxidade vo (1, halatad

81. Cytochtate bxthage itls (rat)

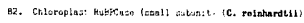

83. 5 gn $\$ 1$

Bi,. Sym $k_{2}$

B5. Sync n

356

n 131

$3 x$.

$357,357 n$

$\therefore$ r.

$357 \mathrm{~b}$

- 322

- 358

$9 \quad 359$

$329,3 \%$

$8 \mathrm{~s}, \mathrm{xi}$

为

it:

$943,949+4 i$

$3 x ?$

327

118,36 ?

r 366

36 ,

36

$\mathrm{t} \quad 367$

112

?us

to

370

L $\quad 3$

in

$12 \%$

n 125

n 1 ie

at

$\checkmark$ 32)

374

374

242

\%)

794

295

mis

$\times \quad 376$

$y \quad 71$

n $\quad$ as, n:

$\pm \quad 164$

308

in

ise 374

bb 37

te 165,340

Ja 100

us $1 \mathrm{wo}$

dd 160

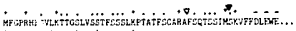

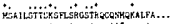

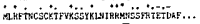

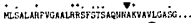

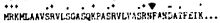

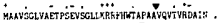

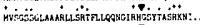

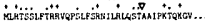

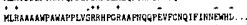

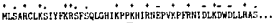

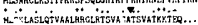

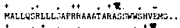

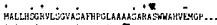

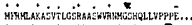

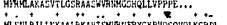

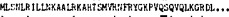

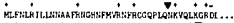

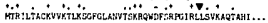

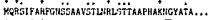

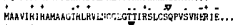

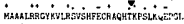

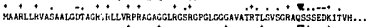

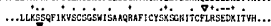

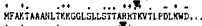

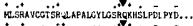

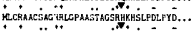

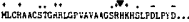

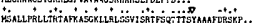

t+

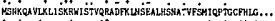

i.t. $\ldots+\ldots$....

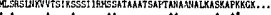

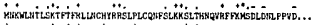

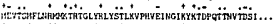

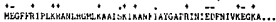

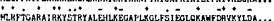

MOEFPT

ค̈.

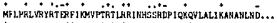

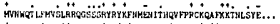

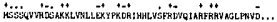

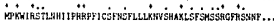

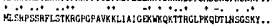

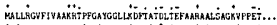

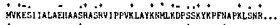

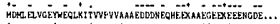

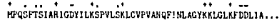

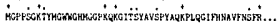

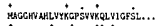

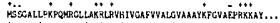

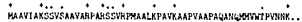

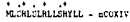

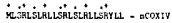

… … * * ** 
The importance of carboxy-terminal precursor regions for the import of some precursor proteins is emphasized by analysis of an altered apocytochrome $c$ [146]. Owing to an unspliced intron, the carboxyterminus of apocytochrome $c$ is altered, whereas the remaining part of the precuror is not affected. This mutated apocytochrome $c$ shows strongly reduced binding to mitochondria and cannot be imported.

For $F_{0}$ ATPase subunit 9, the mature protein part is involved in specific steps of the import pathway as well. The presequence of subunit 9 was sufficient to direct DHFR into mitochondria. When the (hydrophobic) mature protein part was present, the affinity to binding sites on the mitochondrial surface and the rates of import were increased. Precursors lacking such hydrophobic stretches, e.g. $F_{1}$ ATPase subunit $\beta$ and altered subunit 9 precursors, exhibited slow import and only weak interaction with binding sites [147]. We propose that hydrophobic 'assistant' sequences can increase the efficiency of import (see Section V-B).
In summary, amino-terminal regions of precursors (presequences or amino-terminal parts of non-cleavable precursors) carry essential information for targeting to mitochondria. There is increasing evidence, on the other hand, that non-amino-terminal precursor regions are also specifically involved in targeting and import.

\section{IV-B. Structural properties of targeting sequences}

The amino acid sequences of the amino-terminal extensions of a number of precursors have been analyzed (Table III). Most notably, no significant sequence homologies have been detected. For bovine $F_{0}$ ATPase subunit 9 there even exist two isoforms which differ considerably in their prepeptides but have exactly the same mature protein part [148]. The primary structures of mitochondrial presequences, however, exhibit several common features: (i) presequences are rich in positiveiy charged residues (mainly arginines); (ii) they generally lack acidic amino acid residues; (iii) in most cases they

d Bovine Cox IV is equivalent to yeast and $N$. crassa Cox V.

- Synthesis may actually start at the second Met produci.ng a 22 amino-acid extension instead of 27 amino-acid extension shown. Precursor also contains a C-terminal 'trailer peptide' (...Ser-Gly-Ala-Pl.e) not present in the mature form. A C-terminal peptide extension has also been identified in the cytochrome oxidase subunit VIla of yeast (...Lys-Gln-Glu-Asn; $\left[38_{4}\right]$ ).

1 Comparison of bovine $F_{0}$ ATPase 9 sequences with that from $N$. crassa suggest that they may also be processed in two steps, thou:a this had not been examined.

B Cleavaye site not identified, but difference between precursor and mature form is estimated to be 2-4 kDa.

h Possible cleavage site based on molecular weight difference between precursor and maturs forms, and un very high homoing with cytochrome $c$ peroxidase precursor cleavage site (which is, however, the second processing site and not expected to be cleaved by the matrix peptidase).

i Possible cleavage site based on homology with the $N$-torminus of mature $F_{1}$ ATPase $\beta$ from $I$ batatas.

j Possible cleavage site based on homology with the N-tern:inus of bovine mature $F_{1}$ ATPase $\beta$.

* Possible cleavage site based on homology with procesuing sits- of ATPase IX from $N$. crassa.

1 Possible cleavage site based on alignment with bovine cleavagi ite.

$m$ MAS I gene product is equivalent to $N$. crassa PEP (preceding sequince). Lituvage site is uniknuwn. Ajsuciation with inner membrane assumed by comparison to PEP localization.

n A single nuclear gene encodes both the cytosolic and mitochondrial forms. Starting Met of cytosolic form is denoted by an asterisk.

- Possible cleavage site based on alignment with N-terminus of cytosolic ADH II.

- First 35 amino acids are suggested to constitute mitochondrial targeting sequenct.

q Import experiments not published, but a 2 kDa difference between precursor and mature forms are reported (382). First 14 amino acids of precursor were not sufficient to direct fusions (with $\beta$-galactodidase) to mitochondria, bu: first 124 amino acids were (intermediate lengths were not tested).

- Prepiece is esimated to be 40-42 amino acids long. but sequence analysis of mature protein suggests cleavage occurs after amino acid 32.

3 Precursor also appears to be extended at C-terminus by 14 amino acids compared to mature protein [383].

- Adrenodoxin (pBAdx-3) is a second precursor form with a different prepiece sequence than adrenodoxin (pBAdx-4), but a common mature sequence. The complete N-terminal sequen, of pBAdx-3 has not Lic: identified. Clezvage site ic based on comparison to pBAdx-4 sitc.

- Possible cleavage site based on alignment with bacterial $(E$. coli $)$ mature sequence.

v Import not examined in vitro, but translation products beginning at either Met 1 or Met 17 are both transported into mitochondria in vivo. Amino-terminus beginning from second ATG (Met-17) has more typical prepiece characteristics.

w Amino acids 8-39 have homology with areas of high hydrophobic moment identifted in other mitochondrial prepiece sequences.

* Putative mitochondrial protein involved in RNA maturation; presumably active in matrix.

y Not synthesized with a transient presequence, but amino-terminal 14 amino acids have prepiece characteristics and are proposed to mediate targeting.

2 Unlike other prepiece sequences, amino terminus contains an unusually high content of acidic amino acids. Import. however, tas not been examined.

aw Apparently not synthesized with cleavable $\mathrm{N}$-terminal prepiece. Absence of prepiece not confirmed by nucleotide sequence, but $\mathrm{N}$-terminal 25 amino acids are suggested to have properties resembling most mitochondrial presequences.

bb Not synthesized with a transient presequence, but $\mathrm{N}$-terminal 20 amino acids are stizgested to have properties similar to other mirochondrial targeting sequences.

cc Not a mitochondrial protein, but the $35 \mathrm{~N}$-terminal amino acids are reported to direct fusions to mitochondria [165].

ut Artificial presequences which can direct the mature part of cytochrome oxidase subunit IV to mitochondria in vivo and ristore a Cox IV-deficient mutant. 
have a high content of hydroxylated residues; and (iv) many show the tendency to fold in an amphiphilic $\alpha$-helix. One striking exception is the amino-terminal sequence of the $17 \mathrm{kDa}$ subunit IV of yeast $b c_{1}$-complex which has a high content of acidic amino acid residues [149]. The pathway of $i$.ort of this protein into mitochondria, however, has .ot been studied; it may differ considerably from it.uat cî precursors with positivcly charged presequences.

How do presequences direct precursors to mitochondria and what is their role in mediating transport across the mitochondrial membranes? The answers to these questions are still mostly hypothetical. Presequences may interact with receptors on the surface of mitochondria. Due to their amphiphilic nature they may then spontaneously penetrate into the lipid bilayer. Because of their positive nel sharge their translocation across the inner membrane might follow an electrophoretic mechanism whose driving force is derived from the mitochondrial membrane potential (positive outside). Most likely a complex combination of these possibilities is involved.

The critical role of the positive charges contained in prepieces has been demonstrated [150-152,154]. When three arginine residues were substituted with glycines in the presequence of human ornithin transcarbamoylase (OTC), the modified precursor was no longer imported into mitochondria. Notably, however, not just the overall positive charge was important, but positive charges at defined positions of the presequence were necessary. For example, substitution of the arginine at position 23 of the OTC precursor with glycine resulted in a complete loss of targeting function [152] (also see Section VIIl-C); however, when arginine 23 was substituted with an amino acid residue supporting the formation of $\alpha$-helical structure, the modified precursor was imported into mitochondria. From these results it was concluded that local regions in the midportion of the presequence exhibiting a defined secondary structure (most likely $\alpha$-helical) are functionally essential. Experiments with precursors of rat OTC carrying mutations in the $\mathrm{N}$ terminal part of the presequence have stressed the importance of an $\alpha$-helical domain at the extreme aminoterminus (residues 1 through 15 ) of the prepeptide $[116,117]$. It was proposed that the OTC presequence can be divided into two separate $\alpha$-helices (residues $1-15$ and $20-26$ ) connected by a $\beta$-turn (residues $16-19$ ) [117] (also see Section IV-A). The functional importance of $\alpha$-helical regions in the presequence is also supported by results of Vasarotti et al. [154] who used a complementation assay to select for spontaneous mutations which restored the import of ATPase $F_{1} \beta$ whose amino-terminal targeting signal had been deleted. Different surrogate taigeting signals were found in the amino-terminus of the truncated $F_{1} \beta$ precursor. The observed modifications resulted in replacement of acidic residues by neutral or basic amino acids generating a less acidic amphipatic helix.

Theoretical structure analysis suggested that a number of mitochondrial presequences have the ability to form amphiphilic helices, i.e., an $\alpha$-helix with a hydrophobic face and a highly positively-charged face $[144,144 a]$. The segments of highest hydrophobic moment largely coincided with critical targeting regions in the presequences of cytochrome oxidass subunit IV [114], the $70 \mathrm{kDa}$ outer membrane proiein [135] and human ornithine transcarbamoylase [152], as defined by deletions and point mutations.

The physical properties of presequences were studied with synthetic prepiece peptides [155-158]. Roise et al. [156] chemically synthesized three peptides representing the first 15, 25 or 33 amino-terminal residues of the Cox IV precursor. These peptides were water-soluble and inserted spontaneously into lipid monolayers. In addition, the two longer peptides caused disruption of lipid vesicles which had a diffusion potential with the same orientation as the mitochondrial membrane potential (i.e., negative inside). If the vesicles had a potential with opposite polarity, the effect was decreased. Fot the 25 residue prepiece peptide, circular dichroism spectroscopy revealed induction of $\alpha$-helical structure with amphiphilic character in the presence of anionic detergents. In a similar study a prepiece peptide corresponding to the first 27 amino acid residues of the presequence of OTC assumed an (amphiphilic) $\alpha$-helical structure induced by anionic phospholipids and was able to lyse membranes into disc-shaped micelles if applied at high peptide/lipid ratios [155]. (It is interesting that anionic phospholipids also induce the expression of $\alpha$-helical structures within apocytochrome $c$ [159].) Recently, the interaction with liposomes of several authentic precursor proteins synthesized with cleavable presequences was investigated [159a]. In this study, binding of the precursors was only observed if the phospholipid vesicles contained cardiolipin.

It was concluded that the potential to form a sided $\alpha$-helix is an essential feature for the function of the presequence $[144,144 a]$. As an initial interaction, its non-polar face was suggested to be buried in the outer leaflet of the membrane. At the same time, the basic residues on the polar face would interact with negatively charged phospholipid headgroups. The membrane potential across the inner membrane would then make translocation of the prepiece energetically favorable.

This working hypothesis for the function of presequences is probably oversimplifying the physiological situation. On the one hand, in a study with artificial prepiece peptides consisting almost exclusively of leucine, arginine and serine, Allison and Schatz [160] found that an amphiphilic $\alpha$-helix was not essential for targeting to and import into mitochondria [160] (also see Table III). Presequences with amphipatic structure 
ther than $\alpha$-helices were also found to be sufficient for argeting [161]. Studies with the prepeptide of rat OTC howed that the peptide bound reversibly to lipid vesicles ontaining physiological mole ratios of anionic lipids 157]. The affinity of the peptide for lipid vesicles, Iowever, was unaffected by a transbilayer potential negative inside). There was no evidence that the OTC repeptide could undergo spontaneous transfer across he lipid bilayer.

On the other hand, there is abundant evidence that roteinaceous components are essential parts of the nitochondrial import machinery (see Sections $V$ and VI). Mitochondrial protein import appears to mainly xccur through a hydrophilic membrane environment 95]. In a study by Gillespie et al. [162] a synthetic peptide consisting of the $27 \mathrm{~N}$-terminal amino acid residues of the rat OTC precursor was able to block the import of authentic pre-OTC while a peptide consisting of amino acids 16-27 did not [162]. The peptide 1-27 also blocked import of two other mitochondrial precursors; namely the matrix protein malate dehydrogenase and the inner membrane component thermogenin (uncoupling protein). Ono and Tuboi [89] reported that the chemically synthesized prepeptide of ornithine aminotransferase (34 amino acid residues) competitively inhibited the import of several mitochondrial precursor proteins, including authentic ornithine aminotransferase, a large subunit of succinate dehydrogenase, sulfite oxidase and porin. These results suggest that common receptors or later components of the import machinery are involved which are shared by these proteins. It has to be noted that synthetic prepiece peptides dissipate the membrane potential of isolated mitochondria [143,156,162]. This, however, was not the case in the presence of reticulocyte lysate, conditions which were used in the study mentioned above [162].

\section{IV.C. Cryptic and artificial targeting signals}

Several recent studies have shown that sequences which are not specific for mitochondrial protein import could also target 'passenger' proteins to mitochondria. Banroques et al. [163] showed that b14 maturase of yeast (which is normally encoded for by a mitochondrial gene and synthesized within the mitochondrion) if cytoplasmically translated could complement mutants deficient in this maturase without any mitochondrial targeting sequence being added. One explanation could be that a small number of maturase molecules could get into mitochondria using a non-physiological bypass of the specific import pathway. Another explanation could be that the maturase contains an internal sequence(s) which exhibits features of a mitochondrial targeting sequence. Hurt and Schatz [164] have recently demonstrated the existence of so called 'cryptic mitochondrial targeting signals' within the cytosolic protein mouse dihydrofolate reductase (DHFR). When the first 85 amino acids of DHFR were fused to the authentic DHFR, the construct was imported into mitochondria in vitro and in vivo, albeit with much lower efficiency than DHFR directed by the presequence of Cox IV. Authentic DHFR was not imported. It was suggested that in the authentic DHFR protein the potential signal sequence is not exposed to the surface of the molecule. In the construct, however, the targeting signal (like in true mitochondrial precursor proteins) would fold independently of the authentic DHFR (or the mature part of the mitochondrial protein, respectively) and therefore enable it to direct import into mitochondria. These results make it very likely that potential mitochondrial targeting sequences are hidden in many noinmitochondrial proteins [164] and perhaps also in the mature part of mitochondrial proteins. Indeed, targeting of passenger proteins to mitochondria he.i also been reported for a chloroplast 'transit' sequence [165] (also see Section IV-D), sequences selected from the $E$. coli genome [166], and artificial presequences [160]. Furthermore, changes of individual amino acid residues at the amino-terminus of the mature protein part of ATPase $F_{1} \beta$ allowed import of a precursor protein from which the presequence had been removed [154].

These results are surprising, since mitochondrial piotein import has been assumed to be highly selective. With regard to the question of how mitochondria maintain their specific protein composition, it should be noted that the import of proteins targeted by nonmitochondria-specific targeting signals in vivo and in vitro seems to occur at low rates $[160,163-165]$. In the following chapters (Sections $\mathrm{V}$ and VI) we will discuss how mitochondrial protein import can be dissected into several distinct steps, each of which can contribute to the specificity and efficiency of the import process. Some of these steps, like the interaction of precursors with cytosolic cofactors, can be bypassed $[90,167]$. Pretreatment of mitochondria with low concentrations of proteinases causes a marked decrease of the overall import efficiency. Residual import (approx. 10\% of the control value) with slower kinetics, however, is independent of proteinase-sensitive components on the surface of mitochondria [168]. The inefficient mitochondrial import of the chloroplast protein ribulose-bisphosphate carboxylase (small subunit) did not require a proteinase-sensitive receptor site on the mitochondrial surface [169] (also see Section IV-D). Apparently, a precursor protein does not have to interact with all components of the mitochondrial import machinery, but can bypass certain steps. The remaining import, however, is of low efficiency and is less specific, thus allowing precursor proteins with non-mitochondrial targeting sequences to be imported [170]. This bypassimport still reflects several obligatory mechanistic features for translocation of proteins into mitochondria; 
precursors must have the ability to insert into the outer mitochondrial membrane which may be facilitated by an amphiphilic structure of the signal peptide; and precursors enter the inner membrane in a manner that is dependent on the mitochondrial membrane potential, which probably exerts an electrophoretic effect on the positively charged signal sequence $[45,171]$. This could explain why a positive net charge is a common structural characteristic of physiological and artificial mitochondrial targeting sequences.

The importance of a bypass-import may be overestimated when the test system does not measure rates of import but only distinguishes between growth or non-growth of cells. In vivo complementation of mutants which are deficient in a certain mitochondrial protein by expressing this protein in the cytoplasm and importing it has been shown to be a very sensitive test system (Ref. 163 and Grivell, L.A., personal communication). Cytoplasmic expression is often done using high-copynumber plasmids, whereas restoration of the mutant may require only very low import rates. To determine whether a precursor is imported using a bypass route or by the highly specific and efficient physiological import pathway, rates of import should be assessed in vivo and in vitro in comparison to those of authentic mitochondrial precursors. In addition, it should be asked whether defined steps in the import pathway, like the interaction with receptors on the surface of mitochondria, can be demonstrated.

\section{IV-D. Heterologous import}

The targeting of proteins to mitochondria and their translocation across the mitochondrial membranes is a complex multistep process which has apparently been highly conserved during evolution. This has been demonstrated by heterologous import studies where transport of precursor proteins from one organism into mitochondria of a different organism was tested. For example, the precursor proteins of the Rieske $\mathrm{Fe} / \mathrm{S}$ protein, subunit $\beta$ of $F_{1}$ ATPase and cytochrome $c$ of $N$. crassa were all imported into yeast mitochondria (Refs. 35 and 207, and Hartl and Neupert, unpublished data). Precursors of ADP/ATP carrier and subunit 9 of $F_{0}$ ATPase, also from $N$. crassa, were successfully imported into rat liver mitochondria [172]. Human OTC was recently shown to be imported into yeast mitochondria in vivo [173].

Suburit 9 of $F_{0}$ ATPase from $N$. crassa [72] (and from mammals [148]) is synthesized in the cytosol with an amino-terminal extension. The subunit 9 of yeast [174-177] and of plants [178,i79], however, is synthesized within mitochondria and without a presequence. Surprisingly, subunit 9 from Neurospora is imported into yeast mitochondria and correctly processed to the rnature protein [180] (also see Section IX-C).
Heterologous import into mitochondria has also been demonstrated for a precursor destined for a different organelle. The amino-terminal prepeptide of ribulose1,5-bisphosphate carboxylase (small subunit) was fused to either dihydrofolate reductase or to the mature part of subunit IV of yeast cytochrome oxidase. The first construct was imported into yeast mitochondria in vivo and in vitro [165], and the latter construct was able to complement a Cox IV-deficient yeast mutant. As discussed above, the efficiency of import was lower than that for constructs containing the authentic mitochondrial prepiece. A study with transgenic plant cells did not reveal any apparent mistargeting between mitochondria and chloroplasts [181]. Thus, the low mitochondrial targeting efficiency of a chloroplast prepeptide is not necessarily important in vivo (also see Section IV-C). On the other hand, mitochondrial and chloroplast prepeptides share common features such as the high content of basic and hydroxylated amino acid residues (Table III). This may explain the still surprising fact that a chloroplast transit sequence can direct a protein into mitochondria at all.

\section{Import receptors}

An early step on the import pathway of mitochondrial precursor proteins is the specific recognition of precursors by mitochondria. Several lines of evidence suggest that proteinaceous receptors on the mitochondrial surface perform the key functions of recognition.

\section{$V$-A. Proteinase-sensitive components on the mitochondrial surface for the import of precursor proteins}

In a number of studies, isolated mitochondria were pre-treated with low concentrations of proteinases such as trypsin or proteinase $K$. This inhibited the subsequent import of mitochondrial precursor proteins, including the precursors of porin, cytochrome $b_{2}$, ADP/ATP carrier, subunit 9 of the $F_{0} F_{1}$ ATPase, the Rieske $\mathrm{Fe} / \mathrm{S}$ protein of the $b c_{1}$-complex, subunit $\beta$ of $F_{1}$ ATPase, citrate synthase, and ornithine transcarbamoylase $[36,79,83,88,96,167-169,182-184,186]$. Mild proteinase treatment did not degrade the outer membrane barrier $[36,88,96,187]$ and only a few proteins of the outer membrane were degraded [168].

An exception to this ready inhibition of import by mild proteinase treatment is the import of apocytochrome $c$, the precursor of cytochrome $c$. Stronger proteinase treatment, which partially degrades the outer membrane barrier, was required to inhibit the binding and import of this precursor [188]. Apparently, the binding protein for apocytochrome $c$ does not expose proteinase-sensitive sites to the outer surface of the outer membrane.

Pre-treatment of mitochondria with elastase inhibited the import of porin, Fe/S protein, the ADP/ATP sar- 
ir and $F_{0}$ ATPase subunit 9, but not of $F_{1}$ ATPase bunit $\beta$, whereas pretreatment with trypsin inhibited e import of all these proteins $[168,169]$. Thus, the uport receptor for $F_{1} \beta$ seems to be different from ose of the other four precursors.

When polyclonal antibodies which had been preared against $45 \mathrm{kDa}$ proteins of the yeast mitochondrial ster membrane were added to trypsin-treated mito1ondria, the inhibition of protein import was enhanced 89. Thus, antigenic sites of the $45 \mathrm{kDa}$ proteins seem , be related to mitochondrial import sites. An as-yetnresolved problem is that isolated $y$ zast mitochondria ppear to contain additional import sites on the inner lembrane which allow protein import into trypsineated mitochondria when the outer membrane was sbsequently opened [190]. In contrast, this does not sem to be the case for Neurospora mitochondria [96]. It smains to be determined whether this is due to technial or species-specific differences.

\section{'-B. Binding of precursors to mitochondria and import om the bound state}

The precursors of ADP/ATP carrier $[88,168,171,191]$, ytochrome $b_{2}$ [184] and $F_{0}$ ATPase subunit 9 [147] can e bound to the mitochondrial surface in the abser.ce of membrane potential $(\Delta \psi)$. Binding requires a proeinase-sensitive component on the mitochondrial urface. By re-establishing $\Delta \psi$, the precursors can be mported from the bound state. For ADP/ATP carrier nd subunit 9 it has been shown that the import from he bound state occurs without release from the nitochondrial membranes. The efficiency of specific inding in the absence of $\Delta \psi$ (i.e., the ratio between mport of precursor from the bound state and import of ree precursor) is up to 1 in the case of ADP/ATP arrier, about 0.5 in the case of subunit 9 , but poor $<0.1$ ) in the case of cytochrome $b_{2}$.

On the other hand, the precursors of $F_{1} \beta$ and $F e / S$ rotein only bind very weakly to mitochondria in the lbsence of $\Delta \psi$ (Refs. 45 and 168; Pfaller, Pfanner and Neupert, unpublished data). The affinity constants for nteraction of these precursors with their binding sites on the mitochondrial surface appear to be rather low. Furthermore, binding sites for these precursors might only be present in very limited amounts; but since the zfficiency of their import is very high this seems rather unlikely.

A fusion protein between the complete precursor of $F_{0}$ ATPase subunit 9 and the cytosolic protein dihycirofolate reductase (DHFR) showed the same properties as authentic subunit 9, i.e., efficient specific binding to the mitochondrial surface. Fusion proteins between the presequence of subunit 9 (or part of it) and DHFR were imported into mitochondria in the presence of $\Delta \psi$, but they bound only weakly to the mitochondrial surface in the absence of $\Delta \psi$ [147]. This suggests that the mature (hydrophobic) part of the subunit 9 precursor is involved in the speciric binding of the precursor to the mitochondrial surface. All in:- precursors mentioned above, which are specifically accumulated on the mitochondrial surface in the absence of $\Delta \psi$ (ADP/ATP carrier, cytochrome $b_{2}$, subunit 9 , and the fusion protein between complete subuizit 9 and DHFR), contain one o' more hydrophobic stretches in their sequences (class I precursors). On the other hand, the four precursors which are not able to specifically bind in the absence of a membrane potential $\left(F_{1} \beta, F e / S\right.$ protein, and the fusion proteins between the presequence of subunit 9 and DHFR) do not contain a hydrophobic stretc: (class II precursors). Furthermore, class I precursors are more rapidly imported than class II precursors. This suggests that (hydirophobic) 'assistant' sequences present in class I prfcursors support a strong interaction of precursors with binding sites and thereby facilitate rapid import [147]. The predicted hydrophobic stretch in the sequence of the cytochrome $b_{2}$ precursor contains a single positive charge [54]. This might explain the low efficiency of specific binding of cytochrome $b_{2}$.

The precursor of porin can bind to the mitochondrial surface at low temperature and then be completely imported into the outer membrane and assembled by subsequently raising the temperature $[79,167,168]$. The binding is also inhibited by mild pre-treatment of the mitochondria with proteinases [168].

Apocytochrome $c$ can be bound to mitochondria in the presence of deuterohemin, a competitive inhibitor of cytochrome $c$ heme lyase. The binding is rapid and reversible. The bound apocytoch $c$ is accessible to externally added proteinases (Fig. 5). By addition of heme, apocytochrome $c$ is converted to holocytochrome $c$ and imported into the intermembrane space [192-198].

\section{$V$.C. Distinct steps in the binding of ADP / ATP carrier and of porin}

Recent studies have shown that two distinct steps of specific binding of the ADP/ATP carrier to mitochondria can be defined: (i) binding to proteinase-accessible receptor sites and (ii) the interaction with the proteinase-protected 'general insertion protein' (GIP) in the outer membrane $[88,101,169,186$, 199] (see Ssction V-D). The precurscr of ADP/ATP carrier could be bound to mitochondria having a dissipated membrane potential, at low temperature or at decreased levels of nucleoside triphosphates (NTPs) (see Section VII-C). The specifically bound precursor remained sensitive to treatment of the mitochondria with low concentrations of proteinases and was accessible to externally added antibodies (receptor binding; Fig. 2, stage 2). Binding at higher temperature or at higher 


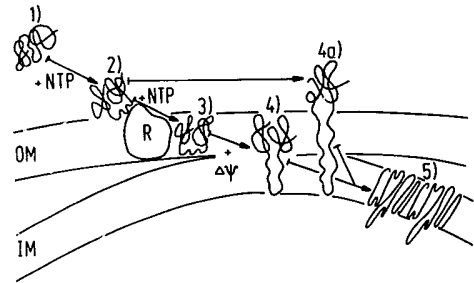

Fig. 2. W stking hypothesis for the translocation of the ADP/ATP carrier frim the cytosol into the innes mitochondrial membrane. The precurse $r$ of the ADP/ATP carrier is synthesized on cytosolic polysomes without an amino-terminal peptide extension (stage 1). The precur sor binds to a receptor protein (R) (stage 2) on the mitochondrial surface in a sucleoside triphosphate (NTP)-dependent step. It is then inserted into a proteinaceous site in the outer membrane. named the 'general insertion protein' (GIP) (stage 3) (Section V-D). This step requires higher levels of NTPs than the initial binding event (Section VII-C). The interaction of precursor with the inner membrane (stage 4) occurs at contact sites between outer and inner membranes (Section VI-C) and requires the membrane potential $\Delta \psi$, but not NTPs. Completion of translocation into the inner membrane and assembly into the functional dimer (stage 5 ) do not require $\Delta \psi$ or NTPs. When the precursor is incubated with mitochondria at low temperature in the presence of $\Delta \psi$, it accumulates at contact sites (stage $4 a$ ): the precursor is still accessible to externally added proteinases, but the completion of translocation into the inner membrane can occur in the absence of $\Delta \psi$. OM, outer mitochondrial membrane; IM. inner mitochondrial membrane.

levels of NTPs led to insertion of the precursor into the outer membrane where it was not accessible to proteinases or antibodies (interaction with GIP; Fig. 2, stage 3). The GIP-associated intermediate was beyond the initial proteinase-sensitive receptor, since it could be completely imported after proteinase treatment which inhibited the inport of the free precursor. Saturability and resistance to extraction by salt, but extractability at alkaline $\mathrm{pH}[200,201]$, suggested iti the GIP-associated intermediate wa: embedded into proceinaceous sites in the outer membi ane (named GIP) [88,i86].

The specifically bound precursor of porin was also resistant to mild proteinase treatment which inhibited the import of the free precursor. After this proteinase treatment, the bound porin could be completely imported into the outer membrane and assembled into the functional form. Our current understanding (Fig. 3) suggests that there are two forms of binding sites for the import of porin; the proteinase-sensitive receptor site and the proteinase-resistant GIP site.

$V$-D. Titration of binding sites and competition of different precursors for specific binding sites

By Scatchard analysis, the binding sites for precursors of porin, cytochrome $c$, and ADP/ATP carrier have been titrated. For these studies the precursors of porin and cytochrome $c$ were repared from their respective mature forms. The mitochondrial porin was solubilized from the membranes with Genapol X-100, purified over hydroxyapatite/celite and precipitated with trichloroacetic acid. By solubilization with $\mathrm{NaOH}$ and neutralization with $\mathrm{NaH}_{2} \mathrm{PO}_{4}$ it was converted to a water-solıble form which could be specifically imported into mitochondria $\{79,167]$. Apocytochrome $c$ was prepared by removal of heme from purified holocytochrome $c$ by cleavage of the thioether bonds with $\mathrm{Ag}_{2} \mathrm{SO}_{4}$ or $\mathrm{HgCl}_{2}$ at low $\mathrm{pH}$ and the subsequent removal of $\mathrm{Ag}$ (or $\mathrm{Hg}$ ) by treatment with dithiothreitol. An import-competent conformation was restored by dialysis from $8 \mathrm{M}$ urea $[39,202,202 \mathrm{a}]$. Both precursors were radiolabeled with ${ }^{14} \mathrm{C}$ by reductive methylation $[79,193]$. The precursor of the ADP/ATP carrier, the most abundant protein of mitochondria, was synthesized in vitro in sufficient amounts to perform Scatchard analysis [169].

The number of binding sites, the affinity constants, and the methods used to block import at the level of binding are given in Table IV. For the ADP/ATP carrier, the binding to receptor sites and the binding to GIP could be titrated separately. The number of GIP sites appears to be about 10 -fold higher than the number of specific receptor sites (Ref. 169; Steger and Neupert, unpublished data). For porin, the proteinaseprotected binding sites (i.e., GIP sites) were titrated.

For apocytochrome $c$ the calculated number of high-affinity binding sites is significantly higher than those for porin or for the ADP/ATP carrier. The affinity constant for the high-affinity binding of apocytochrome $c$ is lower than those for the other two precursors. Thus, the binding sites for apocytochrome $c$ seem to be different from those for porin and ADP/ATP carrier.

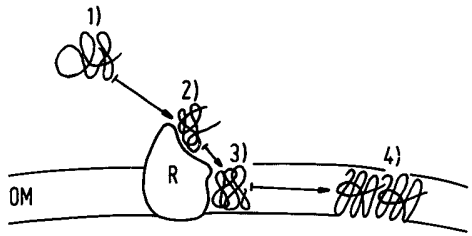

Fig. 3. Working hypothesis for the translocation of porin from the cytosol into the outer mitochondrial membrane. The precursor of porin is synthesized on cytosolic polysomes and does not contain an amino-terminal peptide extension (stage 1). The precursor binds to a receptor protein ( $R$ ) on the mitochondrial surface (stage 2 ) and is then inserted into the outer mitochondrial membrane (interaction with GIP, stage 3). Finally, it is assembled into the functional dimer in the outer membrane (stage 4). The import of porin is independent of the mitochondrial membrane potential. $O M$, outer mitochondrial membrane. 
TABLE IV

Titration of binding sites for mitochondrial precursor proteins

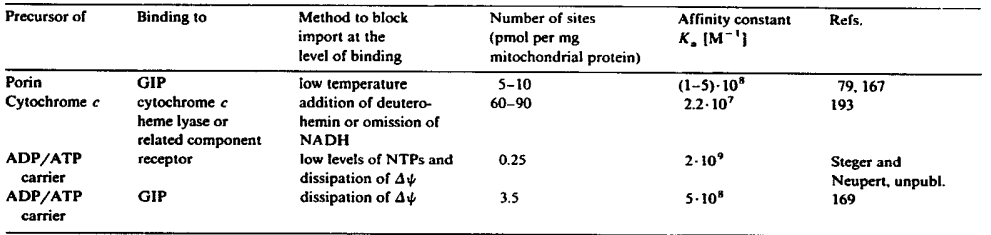

In support of this, unlabeled apocytochrome $c$, which can compete for binding and import of labeled apocytochrome $c$, did not compete for the binding or import of any other mitochondrial precursor protein tested so far $[35,203]$.

The precursor of porin, however, competes for the import of proteins destined for all other mitochondrial compartments, including the $\mathrm{Fe} / \mathrm{S}$ protein of the $b c_{1}$ complex (intermembrane space), the ADP/ATP carrier, subunit 9 of $F_{0}$ ATPase (inner membrane), and $F_{1}$ ATPase subunit $\beta$ (matrix), but not for the import of cytochrome $c$. Unspecific effects of porin, such as complexing of precursors in the cytosol or perturbation of the mitochondrial membrane potential, have been excluded [169]. In the case of the ADP/ATP carrier, the generation of the GIP-associated intermediate was competed for by porin. The formation of the receptor-bound intermediate and the transport from the GIP sites into the inner membrane were not competed for by porin $[167,169]$. The competition of import between porin and $\mathrm{Fe} / \mathrm{S}$ protein, $F_{0} 9$ or $F_{1} \beta$ again seems to occur for the interaction with GIP. We conclude that a component of the outer membrane (GIP) is common for the import pathway of several mitochondrial precursor proteins. These sites appear to be involved in the insertion of precursors into the outer membrane. This site was therefore named the 'general insertion protein' (Fig. 4).

\section{$V-E$. Role of specific binding sites}

The binding of precursor proteins to receptor proteins of the mitochondrial outer membrane is an essential step in the specific recognition of precursor proteins by mitochondria. At least four different import sites were proposed to exist for mitochondrial precursor proteins: for porin, for the ADP/ATP carrier, for $F_{1} \beta$, and for cytochrome $c$. The receptor sites for porin, ADP/ATP carrier and $F_{1} \beta$ are accessible to proteinases added to the outside of the outer membrane (see Section V-C). The import pathways of ADP/ATP carrier, porin, $F_{1} \beta$ and of other proteins, such as $F e / S$ protein of the $b c_{1}$-complex and subunit 9 of $F_{0}$ ATPase, converge at a common membrane insertion site (GIP) [169]. Beyond GIP the import pathways diverge to direct proteins to the outer membrane (as is the case for porin) or to contact sites and thus to other mitochondrial compartments (Fig. 4). Authentic mitochondrial precursor proteins can also bypass the initial proteinasesensitive receptor sites (but not GIP), resulting in a low efficiency/decelerated import ('bypass-import'). This bypass-import seems to be the only import pathway used by non-mitochondria-specific precursors such as chloroplast proteins $[170,186]$ (see Section IV-C). GIP might be among the proteins which are recognized by antibodies prepared against $45 \mathrm{kDa}$ proteins of yeast outer mitochondrial membrane. These antibodies were reported to inhitit protein import into trypsin-pretreated mitochondria by binding to a component of the outer membrane [189].

It may be possible that precursor proteins initially interact with low affinity with lipids of the outer menbrane. By subsequently binding to receptor proteins in the outer membrane, the ratio between free and mitochondria-associated precursors would be strongly shifted to the bound state. Studies of the interaction of chemically synthesized presequences with artificial lipid membranes [155-158] suggest such a pathway might occur. With this model, the probability that a free precursor protein interacts with mitochondria, and therefore with specific import sites, would be increased since the lipids of the outer membrane are a much larger initial target than the receptor sites alone. On the other hand, in this model the precursors could also interact with lipids of other cellular membranes. Thus, the physiological significance of a precursor/lipid interaction for mitochondrial protein import remains to be elucidated.

\section{Membrane translocation of precursor proteins}

After specific interaction with the recognition apparatus of the outer mitochondrial membrane, the pre- 


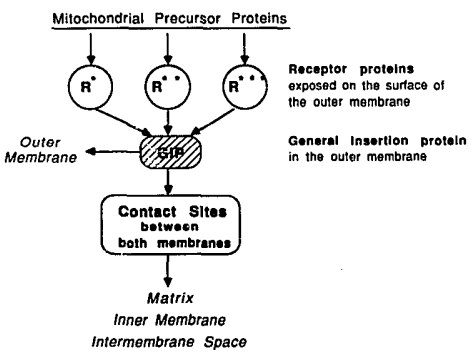

Fig. 4. Working hypothesis for the binding and membrane translocation of mitochondrial precursor proteins. The import pathway of cytochrome $c$ is not covered by this model since it does not seem to involve GIP (adapted from Ref. 169). $R^{*}, R^{* *}, R^{* * *}$, different classes of surface receptors; GIP, general insertion protein.

cursors are translocated into or across the mitochondrial membranes.

\section{$V I-A$. Import of outer membrane proteins}

Precursors destined for the outer membrane, such as porin or the mitochondrial $70 \mathrm{kDa}$ protein of yeast $[134,135]$, apparently use the 'simplest' import pathway. They are inserted into the outer membrane from their specific binding sites and are assembled to their functional forms (Fig. 3). This import is independent of the mitochondrial membrane potential and does not involve proteolytic processing of the precursors [47-49].

\section{VI-B. Import of apocytochrome c}

During its import, cytochrome $c$ must only be translocated across the outer mitochondrial membrane (Fig. 5 ). The way in which this occurs, however, appears to be unique to cytochrome $c$ and differs markedly from the translocation mechanisms used by other proteins destined for the intermembrane space (see Section IX-B). The import of cytochrome $c$, like that of outer membrane proteins, is independent oi the mitochondrial membrane potential and is not accompanied by prolsolytic processing $[57,203]$. The precursor, apocytochrome $c$, has no detectable secondary structure and lacks covalently attached heme compared to its mature counterpart holocytochrome $c[159,202]$. The covalently bound heme moiety itself is responsible for mediating or stabilizing the compact structure of holocytochrome : $[202,204]$. These circumstances have apparently favored the evolution of an import mechanism in which the coniformational change accompanying the covalent attachment of heme to apocytochrome $c$ has been linked to the process by which the protein is transported across the outer membrane. For example, evjdence indicates that apocytochrome $c$ can spontaneously insert part way through the lipid bilayer of the outer membrane [205] where it is bound with high affinity to a specific receptor $[192,193]$. The enzyme cytochrome $c$ heme lyase, which faces the intermembrane space $[188,194-$ 198], attaches heme to the partially inserted precursor in a process which is tightly coupled to its translocation completely through the outer membrane to a proteinase-resistant location [206]. This process is dependent on NADH plus FMN (ci FAD), which appear to be required to reduce the heme iron prior to coupling to apocytochrome $c$ [207] and can be reversibly inhibited by the analogue deuterohemin $[192,194]$.

The folding of cytochrome $c$ which accompanies the binding of heme - occurring at the intermembrane space side of the outer membrane - is therefore probably responsible for driving the translocation of cytochrome $c$ across the outer membrane. This model accounts for the independence of cytochrome $c$ import of the mitochondrial membrane potential and its very tight coupling to covalent heme linkage. Because of the absence of covalently bound heme in other proteins of the intermembrane space (with the exception of cytochrome $c_{1}$; see Section VIII-D), this import pathway is understandably exclusive to cytochrome $c$. It will be interesting to see what role the heme attaching step during cytochrome $c_{1}$ import may play in membrane translocation events.

\section{$V I$-C. Import via translocation contact sites}

The maiority of imported mitochondrial precursor proteins have to be translocated (at least partially) into

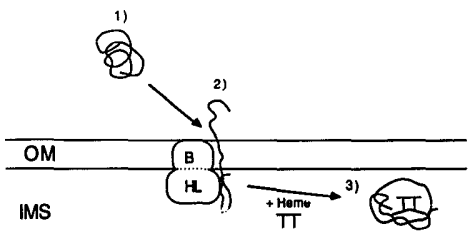

\section{IM}

Fig. 5. Working hypothesis for the translocation of apocytochrome $c$ from the cytosol into the mitochondrial intermembrane space. Apocytochrome $c$, the precursor of cytochrome $c$, is synthesized on cytosolic polysomes and does not contain an amino-terminal peptide extension, 1. Apocytochrome $c$ is bound by a membrane-associated protein (B) into a complex at the outer mitochondrial membrane which includes the intermembrane-space facing cytochrome $c$ heme lyase (HL), 2. By attachment of heme, holocytochrome $c$ is iol isted. Cytochrome $c$ is then transported to its functional destination on the outer surface of the inner membrane, 3 (Section V1-B). OM, outer mitochondrial membrane; IM, inner mitochondrial membrane; IMS, intermembrane space. 
or across the inner membrane. The transport of precursors from the cytosol to the inner mitochondrial membrane could occur in two functionally and structurally different ways: (i) precursor proteins are completely translocated across the out:: membrane, pass through the intermembrane space and then reach the inner membrane; or, (ii) precursor proteins are translocated across both mitochondrial membranes in one step at sites of close contact between outer and inner membranes.

From electrcr-microscopic studies, contact sites between outer and inner mitochondrial membranes have been known about for many years [208]. The function of these contact regions was first suggested by Butow and co-workers $[42,43,209]$ who found that ribosomes were frequently associated with the outer mitochondrial membrane, especially at sites of close contact between outer and inner membranes. They proposed that mitochondrial precursor proteins were synthesized by these membrane-bound ribosomes and were cotranslationally imported into mitochondria through contact sites $[44,209,210]$. This was supported by later studies which showed that mRNAs in mitochondria-associated ribosomes were enriched in mRNAs for mitochondrial precursor proteins (also see Section III-A). On the other hand, it was shown that the majority of translatable mRNAs for imported mitochondrial proteins were still found in free cytosolic polysomes [46,73]. Furthermore. it could not be demonstrated that imported mitochondrial precursor proteins indeed originated from these membrane-associated mRNAs and ribosomes. It was thus obvious that ribosomes containing nascent chains with exposed presequences could bind to mitochondrial import receptors via the presequences, but the importance of this process for mitohcusial protein import was unclear. On the other 'and, there was abundant evidence that mitochondrial protein import could occur posttranslationally in vivo and in vitro. Since at that time principle mechanistic differences were assigned to post- and cotranslational protein translocation, the possibility of a posttranslational mode of import appeared to be incompatible with the involvement of ribosomes associated with the outer membrane. Thus, the importance of the cotranslational transport might have been underestimated for the last 10 years.

By reversible accumulation of precursor proteins in sites of close contact between outer and inner membranes, it was demonstrated that mitochondrial protein import did indeed take place at these contact sites [45]. Protein import was performed at low temperatures ( 2 to $12^{\circ} \mathrm{C}$ ) in vivo and in vitro. The precursor proteins were specifically processed by the matrix-located processing peptidase, and thus the amino-terminus of the precursors had entered the matrix space. The processed precursor proteins were, however, still accessible to externally added proteinases which did not degrade the

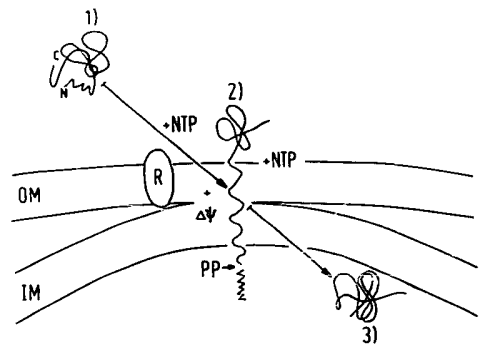

Fig. 6. Working hypothesis for the translocation of $F_{1} \beta$ from the cytosol to the miner tace si the mitochondrial inner membrane. The precursor of ATPase $F_{1} \beta$ is synthesized on cytosolic polysomes and contains an amino-terminal presequence. 1 . In a resopin (1) and GIP-dependent step it is transported into contact sites between outer and inner membranes, 2 (Sections V-E and VI-C). Insertion into or (ranslocation of the presequence across the inner membrane requires $\Delta \psi$. The completion of translocation to the inner side of the inner membrane, 3. is independent of $\Delta \psi$ (Section VII-B). Both import steps require nucleoside triphosphates (NTPs). Higher levels of NTPs are required for the completion of Iranslocation than for the initial interaction (Section VII-C). The presequence is cleaved ofi by the processing peptidase (PP) in the mitochondrial matrix. OM. oliser mitochondrial membrane; IM, inner mitochondrial membrane; $N$, amino-terminus: $C$, carboxy-terminus.

outer membrane barrier. Furthermore, the precursors were recognized by antibodies added to the mitochondrial suspension after generation of the intermediate [199]. The precursor proteins thus stretched from outside the outer membrane into the matrix space thereby spanring both mitochondrial membranes simultaneously.

In conclusion, the mitochondrial membranes must be close enough together to be spanned simultaneously by a single polypeptide chain (translocation contact sites) (Fig. 6). Only the transport of precursors from the cytosol into translocation contact sites requires the membrane potential $(\Delta \psi)$. The completion of transport into the inner membrane or matrix is independent of $\Delta \psi$ (also see Section VII-B). Import via translocation contact sites has now been demonstrated for the precursors of $F_{1}$ ATPase subunit $\beta$, cytochrome $c_{1}$ [45], the $\mathrm{Fe} / \mathrm{S}$ protein of the $b c_{1}$-complex [36], the ADP/ATP carrier [88], and cytochrome $b_{2}[95,102]$. For the precursor of the ADP/ATP carrier, which is synthesized without a cleavable presequence, the differential requirement for $\Delta \psi$ was taken as criterion to show import via contact sites [88]: the precursor was incubated with mitochondria at low temperature in the presence of $\Delta \psi$, precursor associated with mitochondria was still accessible to externally added proteinases, but completion of translocation into the inner membrane could take place 
in the absence of a membrane potential (Fig. 2). Thus, the $\Delta \psi$-dependent interaction of the precursor with the inner membrane had already taken place for the precursor associated with mitochondria at low temperature. The precursor was therefore spanning translocation contact sites (Fig. 2, intermediate 4a).

In addition to lowering the temperature during import, two other methods for accumulating precursor proteins in translocation contact sites have been developed. (i) Polyclonal antibodies were prebound to carboxy-terminal parts of precursor proteins. After addition of mitochondria, amino-terminal parts of the precursors were transported into the matrix space and the presequences were cleaved off by the processing peptidase. A carboxy-terminal part of the precursor was kept outside the outer membrane by the bound antibody $[45,96]$. (ii) The discovery that the completion of translocation requires higher levels of nucleoside triphosphates (NTPs) than the initial transport into contact sites was used to generate contact-site intermediates (see Section VII-C). By moderately lowering the level of NTPs, precursor proteins were trapped in translocation contact sites (Fig. 6) [100-102]. Increasing the level of NTPs led to complete import of the precursor proteins.

A crucial question is how the biochemically defined translocation contact sites are related to the morphologically described contact sites between the outer and inner membranes. To study this question, the precursor of $F_{1} \beta$ was prebound to polyclonal antibodies and then trapped in translocation contact sites. After then decorating the antibodies with protein-A-gold particles, electron-microscopic evaluations were performed. They showed that the biochemically defined translocation contact sites were identical with the morphologically described sites of contact between outer and inner membranes [96j. For chloroplasts, Pain et al.[211] recently identified an outer membrane protein using antiidiotypic antibodies raised against antibodies specifically recognizing the presequence of the small subunit of ribulose-bisphosphate carboxylase. These antibodies were able to inhibit import of the precursor, suggesting a role of the outer membrane polypeptide in recognition of the presequence. Interestingly, immonogold electron microscopy demonstrated that the outer membrane component(s) recognized by the antiidiotypic antibodies was clustered around regions where outer and inner envelope membranes were closely apposed, thus stressing the importance of translocation contact sites for the import of precursors into chloroplasts as well.

Translocation contact sites appear to be stable structures. Their existence seems to be independent of the energy state of mitochondria $[88,96]$ and they can be enriched by subfractionation of mitochondria into vesicles by sonication [96]. The precursor proteins trapped in contact sites could be extracted from the membranes by hydrophilic perturbants (protein de- naturants) such as alkaline $\mathrm{pH}$ or urea [95]. Thus, translocation contact site intermediates are not firmly integrated into the hydrophobic lipid phase of the membranes. It cannot be excluded yet if this is caused by a local rearrangement of the polar lipid headgroups. It is much more likely, however, that proteins are essential components of translocation contact sites.

This latter possibility might be supported by new findings of Grivell and colleagues (Grivell, L.A., personal communication). They have shown that the 10 amino-terminal residues of the presequence of core II subunit (complex III) could target the passenger protein manganese superoxide dismutase to the inner membrane but failed to direct complete translocation of the construct inte the matrix. The full presequence plus 20 residues of the mature core II subunit, however, transported superoxide dismutase into the matrix. A possible explanation of these results was that the 10-residue amino-terminal segment of the presequence did not translocate proteins across the inner membrane due to its inability to interact with a (protein) component of the translocation machinery.

\section{Energy requirement of protein import}

\section{$V I I-A$. General remarks}

It is now widely accepted that nucleoside triphosphates (NTPs) are necessary to keep mitochondrial precursor proteins in an import-competent conformation, and that the membrane potential across the inner membrane is necessary for the initial interaction of precursor proteins with the inner membrane.

Very early studies on mitochondrial protein import showed that energy was required [31]: addition of protonophores, which dissipated the electrochemical potential across the inner membrane and subsequently lowered the level of ATP, prevented the uptake of precursor proteins by mitochondria $[34,203,212]$. This was examined in $r o^{-}$mutants of yeast, which lack a functional respiratory chain and $F_{0} F_{1}$ ATPase (the two main possible contributors to an electrochemical potential across the inner mitochondrial membrane). Mitochondrial protein import, however, still occurred in $r h o^{-}$mutants. It was concluded that the electrochemical potential was not the direct driving force for mitochondrial protein import, and ATP was suggested as the primary energy source [212]. Later studies (see below), however, demonstrated that it was an energized inner membrane which was essential for transport of precursors into the inner membrane. It is likely that mitochondria from rho- mutants can still create a (low) electrochemical potential, e.g., by importing ATP via the ADP/ATP carrier. Low potentials (20-40 mV) have been shown to be sufficient to drive protein import [171]. 
VII-B. Requirement for the mitochondrial membrane potential

Schleyer et al. used specific inhibitors of the respiratory chain (rotenone, antimycin $A$ and potassium cyanide) and of the $F_{0} F_{1}$ ATPase (oligomycin), protonophores (CCCP and FCCP), a $\mathrm{K}^{+}$ionophore (valinomycin) and an inhibitor of the ADP/ATP carrier (carboxyatractyloside) to study the energy requirement of protein import in vitro [172]. These studies demonstrated that the electrochemical potential was essential for transport of proteins into or across the inner membrane. Similar results were obtained by Gasser et al. [182] and Kolanski et al. [213]. Since at this time research focused on the question of whether either the electrochemical potential or ATP was required, it was mistakenly roncluded that the electrochemical potential alone was the energy source for import. (In Section VII-C the evidence will be summarized that both an energized inner membrane and ATP are required independently for mitochondrial protein import.)

The electrochemical potential (total protonmotive force) consists of two components: the membrane potential $\Delta \psi$ (electrical component) and the proton gradient $\Delta \mathrm{pH}$ (chemical component). It has been shown that the transport of the precursor of the ADP/ATP carrier from the outer membrane into the inner membrane required only the electrical component $\Delta \psi[171]$ : this transport could be driven by a valinomycin-mediated $\mathrm{K}^{+}$diffusion potential; addition of protonophores did not abolish this import; imposing a $\Delta \mathrm{pH}$ alone did not support import. Therefore, mitochondrial protein import does not seem to be mediated by proton movement (which is driven by the total protonmotive force), in contrast to several other processes depending on an energized inner membrane such as synthesis of ATP by the $F_{0} F_{1}$ ATPase. On the other hand, it has been shown that only the initial interaction of precursor proteins with the inner membrane, involving the positively charged presequence in the case of cleavable precursors, requires $\Delta \psi$ (Figs. 2 and 6). The completion of translocation into the inner membrane or matrix can take place in the absence of $\Delta \psi[45,88]$ (see Section VI-C). A current working hypothesis is that the role of the membrane potential includes an electrophoretic effect on the positively charged presequences or on positively charged domains in precursors that do not contain cleavable presequences $[171,214]$.

Precursor proteins which do not interact with the inner mitochondrial membrane, like the outer membrane protein porin [47-49] and the intermembrane space protein cytochrome $c$ [203], do not require the membrane potential for import. The majority of mitochondrial proteins, however, are translocated into or across the inner membrane and therefore do require space proteins like cytochrome $b_{2}[52]$ and cytochrome-c peroxidase [53.215] which transiently interact with the inner membrane during distinct phases of their import pathways (also see Section IX-B).

\section{VII-C. Role of nucleosicie triphosphates}

By manipuicting the levels of NTPs and $\Delta \psi$ independently of each other, we have shown that protein import requires NTPs in addition to a membrane potential [98]. The in vitro import system (reticulocyte lysate and isolated mitochondria) was depleted of ATP and ADP by incubation with apyrase (an adenosine-5'-(di)triphosphatase from potato). A membrane potential was then established (by addition of substrates of the electron transport chain) and oligomycin was included to prevent dissipation of $\Delta \psi$ and synthesis of ATP by the $F_{0} F_{1}$ ATPase. Under these conditions, protein import was inhibited. Re-addition of ATP or GTP restored import, whereas non-hydrolyzable ATP analogues were not able to fulfill this requirement. In the presence of ATP, but absence of $\Delta \psi$, protein import was also inhibited $[98,172]$. This demonstrated that the requirement for NTPs was independent of the requirement for $\Delta \psi$. Since nucleoside-phosphate kinases are present in the system used, it cannot be determined yet which NTP (e.g., ATP or GTP) is the direct energy source. Similar results were obtained by studies with a largely purified precursor protein [99] and in studies using iesalted reticulocyte lysate [100]. A requirement for NTPs has now been shown for the import of $F_{1}$ ATPase subunit $\beta[98,100]$, the ADP/ATP carrier [101], cytochrome $c_{2}$, cytochrome $b_{2}$ [102], $\mathrm{Fe} / \mathrm{S}$ protein of the $b c_{1}$-complex (Pfanner and Neupert, unpublished data), porin [103], fusion proteins between $\bar{F}_{0}$ iTPase subunit 9 and DHFR [101], and a fusion protein between the presequence of cytochrome oxidase subunit IV and DHFR [99].

Thus, even protein import which does not require a membrane potential, as is the case for porin, is dependent on NTPs. A notable exception to this general requirement for NTPs appears to be that of cytochrome $c$ whose import does not require NTPs (Nicholson and Neupert, unpublished data).

NTPs are necessary for both the initial interaction of precursor proteins with the mitochondrial surface and for the completion of translocation from the surface into mitochondria (Figs. 2 and 6). For completion of translocation, higher levels of NTPs are necessary than for the initial binding interaction. Precursors which have identical presequences, but different mature protein parts, require different levels of NTPs for import. The sensitivity of in vitro synthesized precursor proteins towards digestion by proteinase $\mathrm{K}$ is increased by the presence of NTPs. We concluded that NTPs are re- 
import-competent ('unfolded') conformation [101]. We propose that a factor, which might be an unfoldase as recently proposed [97], acts together with NTPs to keep precursor proteins in an import-competent conformation. This is supported by two observations: (i) Whereas the import of in vitio synthesized porin needs NTPs [103], the import of the water-soluble porin prepared by acid-base treatment of the purified membrane form (see Section V-D) is independent of NTPs. Other impori properties - such as specific binding to receptor sites, two-step insertion into he outer membrane, and formation of specific membrane pores - are identical for both precursors. Subjection of the biosynthetic porin precursor to a similar acid-base treatment rendered its import into mitochondria also independent of NTPs. This converted precursor exhibited a higher sensitivity towards Jigestion by low concentrations of proteinase $K$ than the authentic precursor, indicating that the converted precursor is in a more unfolded conformation. This suggests that the acid-base treatment, which destabilizes the conformation of proteins, can replace the NTP-dependent step of mitochondrial protein import $[167,216]$. (ii) The import of incompletely synthesized (nascent) polypeptide chains into mitochondria requires lower tevels of NTPs than the import of the corresponding completed precursor [217]. The likely explanation seems to be that nascent polypeptide chains are only ioosely folded and thus require less NTPs for unfolding than completed chains.

In addition to the folded-stat: of precursor polypeptides, the levels of NTPs required for import might also depend on the aggregational state of precursors. For example, the precursor of ATPase $F_{1} \beta$ appears to contain a domain that is necessary for the formation of cytosolic tetrameric aggregates $[76,77]$. Deletion of this region is accompanied by a loss of the ability to form tetramers and the loss of an ATP. requirement for import. It is possible that ATP-dependent unfolding is also involved in dissociating cytosolic precursor aggregates prior to import. Several reports described the dependence of mitochondrial protein import on proteinaceous cytosolic cofactors $[76,82-84,86]$. Further functional characterization is needed, however, to answer the question of whether these cofactors are related to the proposed unfolding activity (also see Sections III-C and III-D).

At present it can not be excluded that besides their role in the unfolding of precursors, NTPs are required for further import steps; e.g., for phosphorylation of components of the import machinery. Eilers et al. [218] reported that the unfolding of an artificial precursor protein (presequence of Cox IV fused to DHFR) occurred at the surface of mitochondria in an ATP-independent manner. Complete translocation into mitochondria, however, required ATP. These results may be explained by differences in the folding and unfolding behavior between cytosolic proteins (DHFR) and authentic mitochondrial precursors. On the other hand, a multifunctional role of NTPs in mitochondrial protein import is possible.

\section{$V I I-D$. Energy' requirement for protein transport across other biological membranes}

Similarly to protein import into mitochondria, it had originally been assumed that an electrochemical potential was the only energy source for protein export in $E$. coli. Recently, however, it was also shown that both the electrochemical potential and ATP are necessary [219-221]. A requirement for ATP only, but not for an electrochemical potential, has been reported for protein import into chloroplasts $[181,222,223]$ and for protein translocation across the membranes of the endoplasmic reticulum [19,21-23,25,27,224] and of peroxisomes [225]. In the latter cases, an additional requirement for a (low) electrochemical potential cannot be excluded [225a].

In summary, the energy requirements for translocation of proteins across biological membranes seem to be more similar to each other than has been assumed for many years.

\section{Processing of precursor proteins}

\section{VIII-A. The processing peptidase in the mitochondrial matrix}

Amino-terminal presequences of imported proteins are proteolytically removed during or after translocation across the mitochondrial membranes. The proteolytic activity is found in the matrix, and was first detected in hypotonic extracts of yeast mitochondria [226]. It was also described for mitochondria from rat liver and Neurospora. The processing peptidases (or matrix proteinases) from different sources show similar properties $\{227-231\}$ including: (i) solubility in the absence of detergents; (ii) neutral pH-optimum; (iii) inhibition by divalent cation chelators such as EDTA, ortho-phenanthroline and batho-phenanthroline; (iv) insensitivity towards a number of known protcinase inhibitors, including those of serine proteinases such as phenylmethylsulfonyl fluoride (PMSF); and (v) stimulation by divalent cations such as $\mathrm{Co}^{2+}, \mathrm{Mn}^{2+}$ and $\mathrm{Zn}^{2+}$ which can reverse the inhibition by chelators.

Processing activity was determined to be localized in the matrix via the following investigations. Upon subfractionation of mitochondria, processing activity cofractionated with matrix marker proteins. In intact mitochondria the processing activity could not be inhibited by EDTA or batho-phenanthroline, which do not cross the inner membrane barrier, but it was blocked by ortho-phenanthroline which can permeate the inner membrane $[230,231]$. The processing peptidase is coded 
for by nuclear genes and hence must itself be imported into mitochondria.

Purification of the processing peptidase from a number of sources has bcen attempted. The enzyme from yeast mitochondria was enriched about 200-fold [228]. According to gel-filtration analysis, the activity was found in a fraction corresponding to an apparent molecular mass of $115 \mathrm{kDa}$. On SDS-polyacrylamide gels a prominent protein band with an apparent molecular mass of $59 \mathrm{kDa}$ and several minor bands in the molecular mass range of 39 to $35 \mathrm{kDa}$ were detected. In another study the processing activity of yeast mitochondria was purified about 100-fold [230]. As estimated by gel filtration, the active enzyme fraction again had a molecular mass of $115 \mathrm{kDa}$. SDS-polyacrylamide electrophoresis separated about 10 protein bands, none of which, however, exhibited an apparent molecular mass in the range of $59 \mathrm{kDa}$. The partially purified enzyme preparation was able to process the precursors of subunit $\mathrm{V}$ of cytochrome oxidase and yielded the correct amino-terminus of the mature protein [232].

Using a series of purification steps the processing enzyme from $\boldsymbol{N}$. crassa mitochondria has been purified from a whole-cell homogenate [233]. The activity was enriched about $\mathbf{2 0 0 0}$-fold over mitochondria. On silverstained SDS-polyacrylamide gels, two protein bands with apparent molecular weights of 57000 and 52060 were visible. Monospecific antibodies were raised against these proteins. By immunoblotting against iotai mitochondrial extracts,both the 57 and $52 \mathrm{kDa}$ polypeptides were detected in mitochondria; the $52 \mathrm{kDa}$ component being about 15 -fold more abundant. Soth polypeptides were required for processing activity, but apparently did not form a (tight) complex. When the two components were separated by gel filtration,elution of activity coincided with neither protein peak but assumed an intermediate distribution where the two peaks overlapped. The $57 \mathrm{kDa}$ component alone exhibited low but detectable processing activity. Addition of purified $\$ 2 \mathrm{kDa}$ component, which did not have any processing activity by itself, to the $57 \mathrm{kDa}$ component resulted in a several-fold stimulation of processing activity. Likewise, antibodies directed against the $57 \mathrm{kDa}$ polypeptide were able to deplete mitochondrial extracts of the processing activity. Only 5-10\% of the total activity, however, was recovered in the immunoprecipitate. Recombination of supernatant and immunoprecipitate reconstituted processing activity as did addition of purified $52 \mathrm{kDa}$ component to the immunoprecipitate. In summary, the $57 \mathrm{kDa}$ component bears the catalytic center and is therefore the 'matrix processing peptidase' (MPP) proper. The $52 \mathrm{kDa}$ component is a 'processing enhancing protein' (PEP) which might contribute to the specificity of the cleavage reaction (see Section VIII-C).
MPP and PEP have somewhat different locations in Neurospora mitochondria [233]: MPP is completely soluble in the mairix while PEP is largely attached to the inner (matrix) surface of the inner membrane. It is possible that PEP has an aciditional role in protein translocation by inieracting with the presequences of precursor proteins as soon as they enter the matrix. For such a function an approx. 20 amino acid long $\alpha$-helical segment having a high negative net charge identified within the sequence of PEP (from the cDNA-denimed amino acid sequence) might be important.

Temperature-sensitive mutants in yeast have contributed considerably to our knowledge of the processing enzyme [234-236a]. In order to identify essential components in the mitochondrial import pathway, Schat: and colleagues $[234,235]$ have isolated yeast mutants which were characterized by strongly reduced protein import into mitochondria (e.g., import of $\beta$ subunit of $F_{1}$ ATPase). Two complementation groups were identified (mas 1 and mas 2; mas for mitochondrial assem bly). In both cases the phenotype is caused by a single nuclear mutation. The mas $I$ mutant was shown to be defective in the matrix-localized processing activity in vitro [235]. The corresponding nuclear gene has been cloned and on SDS-polyacrylamide gels the mas I gene product exhibits an apparent molecular mass of $48 \mathrm{kDa}$. Interestingly, an antiserum directed against the $48 \mathrm{kDa}$ polypeptide crossreacts with the $N$. crassa $52 \mathrm{kDa}$ component PEP [236]. Sequence similarity between the polypeptides is about 70\% [233]. PEP (and its counterpart in yeast [236]) is made with an amino-terminal extension that can be cleaved by the purified processing peptidase (Hawlitschek and Neupert, unpublished data).

Recently, in a new effort, Horwich and colleagues [236a] selected a set of temperature-sensitive yeast mutants defective in mitochondrial protein import. So far, four complementation groups of socalled mifmutants (mif for mitochondrial import function) were identified, which are characterized by the accumulation of mitochondrial precursor proteins at the non-permissive temperature. Mif 1 and mif 2 were found to be identical with the formerly described mas 1 and mas 2 mutations. Biochemical analysis of the phenotype of the mif 2 mutation revealed that MPP, the catalytic component of the processing enzyme, was defective [236a]. The MPP gene codes for a protein with an apparent molecular mass of $53 \mathrm{kDa}$. A structural comparison between MPP and PEP showed 24\% identity and about 50\% similarity if isofunctional residues were considered suggesting a common origin for MPP and.PEP.

The mitochondrial matrix processing enzyme differs in many respects from other peptidases involved in protein translocation. Both the bacterial leader peptidase [237] as well as the eukaryotic signal peptidase of the endoplasmic reticulum [14] are metal-independent membrane-integrated enzymes which share processing 


\section{TABLE V}

Proteolytic processing siles of imported mitochondrial precursor proteins

Ihe sites of proteolytic processing of imported mitochondrial precursor proteins are presented beginning six amino acids (from the amino-terminal side) preceding the cleavage site. Basic $(+)$, acidic $(-)$ and hydroxylated $\left({ }^{\circ}\right)$ amino acids are indicated. Oniy sequences where the cleavage site has seen identified by direct evidence (i.e., from the known amino terminus of the mature protein, or from radiosequence analysis) are given. Proteins are grouned by respiratory complex or by metabolic function.

\section{MATRIX PROCESSING PEPTIDASE}

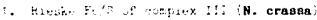

$\therefore$ Suburit It of conplex III (yedest)

5. Cyerengume: c. in. crassa!

4. Cytuchrome oxidua IV (N. crassa?

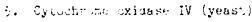

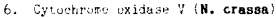

7. cytuchrore uxidust $V$ (yeust)

8. Cy,uchrome oxidase IV fbovine?

7. Cytochrume oxidaze VI (yeast)

19. Cytortirrme uxidase VIII (yeast)

11. F, RTPase \& (yeasu

72. E, ATfase 9 (N. Crasar) , th site $2^{\text {tid }}$ site

13. $\mathrm{F}_{4 \mathrm{q}}$ मtrise 9 - P1 (hovine!

14. Fo ATPast 9 - PE (buvine)

15. F ATPase 9 - 1 (human)

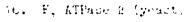

\%. F, RTPase B (N. crassa)

18. Phusphty carrjer (bovine)

19. Processing enhaneing frotein (H. crassa)

20. Mr Superoxide di srutase (yeast)

21. Mn Superoxide dismutase (human)

22. Wh Superoxide dismutase (rat)

2). Mn Superoxidt dismulase (mouse)

24. Aspartate amjutrunsferase ichicken]

2t. Aspertate arifotransferase (porcinu)

2t. Serine:pyruvate amolnotransferase (rat)

27. Drnithine uminotransferase (rat)

38. Malate dehydrogenase (rat)

29. Fymuate dehydrogenase $\alpha$ (human)

30. Pyruvato dehydrofenase a (human)

31. Eucoiny1-Co A synthase $\alpha$ (rat)

32. Ornithicre transcurbanuylase (ret)

3). Crnithine transoarbamoylaze (human)

34. Carbantoyl phosphate synthuse i (rat)

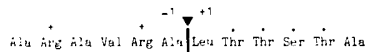
a]n iy Ger val Arg Are tes Thr val Ser Ala Arg

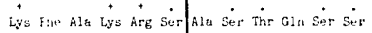
Thr Thr Val Val Are Cys Asn Als Giu Thr Lys Pro Thr Thr val Val ATE Cys Asen Ala Giu thr Lys pro Ser Ser Arg Tyr Leu Leu Gln Gln bys Pro Vo: Val Thr Met ala Val Arg Ale Ala Ser Thr Met Pro nle Ile Thr Sar val arg Phe Ala rilr Thr His Ala Leu Thr Ser Val Cys Val Arg Ala His Gly Ser Val Val il: Gln Ser Arg Lys Tyr Ser Asp Ale His Asp Giu Ile Ile Met Lys Arg Ser Val His Phe Lys Asp Gly Val Ile Gly Ala Are Tyr Met Ser Ser Thr Pro Giu Gln Val Ser Lys Arg Thr Ile Gln Thr Gly Ser Pro Ala Phe Gla Lys arg Ala Tyr Ser Ser Giu tle Ala Tir Ser Val Val sér Arg Asp Ile Asp Thr Ala Ala Thr Ser Ala tle Ser Arg Ásp 11 e Asp Thr Als Ala Thr sir Vul Val Ser Arg Asp ile Asp Thr ala Ala

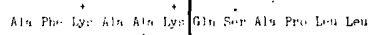
Pro hla Leu Ser Arg Phe Ala Ser Ser Ala Gly Val Arg Asn Leu Ala Ala Ala Ala Val Gíu Gíu Gln Tyr Asn Pro Phe Arg Arg Gly Leu A? Thr Pro tis Ser Thr Thr Ala Arg Arg Thr Lys Val Thr Leu Pro Asp Tyr leu Gly Ser Arg Gln Lys His Ser Leu Pro Asp Tyr latu Gly Ser Arg Cln Lys His Ser Leu Pro Asp Thr Alu Gly Ser Arg His Lys His Ser Leu Pro Asp Ala Ala Gly Ser Arg His Lys His Ser Leu Pro Asp Ala Ala Thr Ala Arg Ala Ser Ser Trp Trp Ser His Ala Ala Ser Ala Arg Ala Ser Trp Trp Ala His Val Trp Val Arg Asn Met Gly Ser His Gin Leu Leu Val Thr Ser Val ala Sèr Ala Thr Ser Val Ala Thr Lys Thr Ser Ala Gln Asn Asn Ala Lys Val Ala Val Leu Leu Val Ala Ser Arg Asn Phe Ala Asn Asp Ala Thr Trp Thr Ala Pro Ala Ala Val Gln Ved Thr Val Are Gln Asn Gly the Arg His Gly Sirr Tyr Thr Ala Ser Tyr Gly Lys Pro Val Gln Sor Glr Val Gln Leu Lys Cys Gly Gln Pro Leu GIn Asn Lys $y_{a l}$ GIn Leu Lys

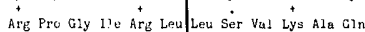

\section{ROTE REFEREACE}

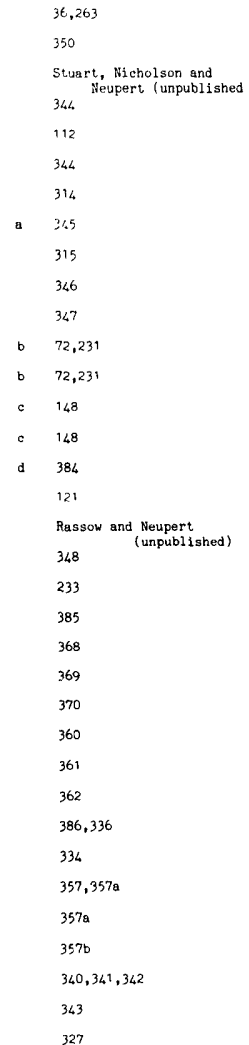




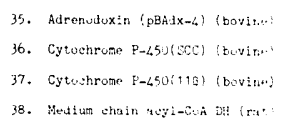

OTHER PROTBOLITIC ACTIVITIES (Second Processing)
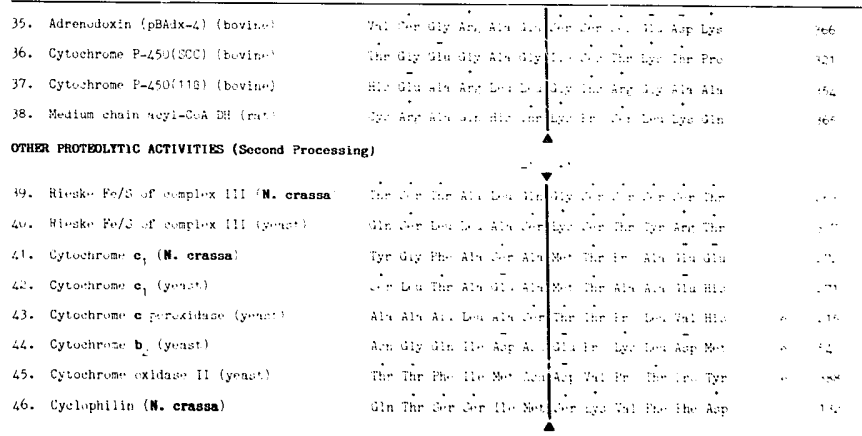

\footnotetext{
- Bovine cytochrome oxidase subunit IV is equivalent to subunit $V$ of $N$. crassa and yeast.

- Unlike other precursor proteins which are processed in two steps, the chelator-sensitive matrix peptidase cleaves both sites of the $F_{0}$ ATPase 9 precursor.

- Alignment of the prepiece sequences indicate that the cleavage sites of the two bovine $F_{0}$ ATPase 9 iso-forms occur in the region of the second site of the $\boldsymbol{N}$. crassa prepiece. Whether the bovine precursors are processed in two steps has not been investigated.

d Two human $F_{0}$ ATPase 9 iso-forms, homologous to the two bovine types. have been identified. It is also unknown whether they are processed in onc or two steps.

- A temperature-sensitive yeast mutant, believed to have an alteratic $t$ in the gene encoding a processing proteinase, is deficient in the second processing step of cytochrome $b_{2}$ (a nuclear gene product) and removal the prepiece from cytochrome oxidase subunit II (a mitochondrial gene product). The second processing step of cytochrome-c peroxidase .owever, is not affected [243].
}

specificity [238]. The mitochondrial processing peptidase, and probably the corresponding enzyme of the chloroplast stroma [239], appear to belong to a new class of pricessing peptidases.

\section{VIII-B. Additional proteolytic processing enzymes}

A number of imported mitochondrial proteins are proteolytically processed in two steps. Except the Neurospora subunit 9 of the $F_{0} F_{1}$ ATPase [231] and rat ornithine transcarbamoylase (OTC) $[227,240]$, all of these proteins are either soluble in the intermembrane space or are anchored to the inner membrane but piotrude into the intermembrane space. Such proteins include cytochrome $b_{2}[51-53,187]$, cytochrome-c peroxidase [53], cytochrome $c_{1}[35,52,187.241]$ and the Rieske $\mathrm{Fe} / \mathrm{S}$ protein of the $b c_{1}$-complex [36]. The role of two-step processing in the intramitochondrial sorting of these proteins will be discussed in Section IX-B.

In all cases where prepiece removal occurs in two steps, the first proteolytic processing event is performed by the processing peptidase in the matrix. Only in the case of Neurospora subunit 9 of $F_{0}$ ATPase and perhaps rat OTC is the matrix peptidase responsible for both proteolytic events $[231,240]$. For subunit 9, radiose- quence analysis proved the existence of a true intermediate and generation of the correct amino-terminus of the mature protein [231].

The second processing step of the precursors to cytochrone $b_{2}$, cytochrome-c peroxidase and cytochrome- $c_{1}$ is catalyzed by a different activity which is located at the outer surface of the inner membrane and which is insensitive to metal chelators $[51,53,187,241]$. The second processing step of the Rieske $\mathrm{Fe} / \mathrm{S}$ protein occurs within the boundaries of the inner membrane and is possibly catalyzed by a peptidase other than the matrix-processing enzyme. Iron-sulfur cluster formation seems is ba tight!y cuupled to the processing event (Hartl and Neupert, unpublished data).

There is also evidence that at least two different proteinases exist at the intermembrane-space surface of the inner membrane to perform second processing steps. A temperature-sensitive pet mutant (harboring a single nuclear mutation) was identified which was defective in the second processing step of cytochrome $b_{2}$ but not of cytochrome-c peroxidase $[242,243]$. In addition, the mutant was unable to process the precursor of subunit II of cytochrome oxidase (Cox II), a mitochondrially synthesized protein. If the structural gene coding for a proteinase itself was mutated, the existence of two 
different proteinases for the second processing of cytochrome $b_{2}$ and cytochrome $c$ peroxidase must be expected. On the other hand, it is possible that a component involved in membrane translocation of cytochrome $b_{2}$ and Cox II is affected by the mutation (see Section IX-B).

Assuming an endosymbiotic origin of mitochondria, the processing peptidase(s) residing at the outer surface of the inner membrane could be the evolutionary equivalent to the bacterial leader peptidase. This idea is particularly appealing in light of the finding that proteins destined for the intermembrane space follow a 'conservative sorting' pathway involving export of intermediate-sized forms from the matrix (see Section IX-B). In chloroplasts the corresponding enzyme(s) is located in the thylakoid membrane [244].

\section{VIII-C. The specificity of proteolytic processing}

How do the processing enzymes recognize the correct cleavage site within mitochondrial precursor proteins? Table $\mathrm{V}$ shows the amino acid sequences around the cleavage sites for $\mathbf{3 8}$ different precursors from yeast (8 examples), $N$. crassa ( 7 examples) and higher eukaryotes (23 examples). Although there is apparently no strict consensus sequence, comparison of the 39 cleavage sites reveals in 22 'typical' cases the preferential occurrence of the following motive of amino acids around the cleavage site: Position -2 is most conserved. A basic residue is alwaj's found (arginine in $\mathbf{2 1}$ cases and lysine in one case). Position $-\mathbf{3}$ in seven cases is also a positively charged residue. Otherwise valine or serine are often found. Alanine is most frequent in position -1 while position +1 seems to be less specific having alanine, leucine or serine residues in several cases. Serine occurs most frequently in position +2 , and serine or threonine in position +3 . The remaining 17 'atypical' cleavage sites are mainly from higher eukaryotes (only two being from yeast). This may be the case for a number of reasons. Cleavage specificity could vary between the mitochondria of different organisms, although heterologous import and processing show a high degree of conservation. On the other hand, it cannot be completely excluded that more than one chelator-sensitive proteinase having different specificities might exist within the same organelle. The partially purified proteinase from yeast, however, was able to process precursors to $\beta$ subunit and subunit 9 of the $F_{0} F_{1}$ ATPase, to citrate synthase, and cytochrome oxidase subunits IV [230] and V [232]. The isolated processing peptidase of $N$. crassa catalyzed the processing of all available precursors tested so far, including precursors to subunits $\beta$, 3 and 9 of the $F_{0} F_{1}$ ATPase, precursors to cytochrome $c_{1}$, core proteins I, II and the $\mathrm{Fe} / \mathrm{S}$ protein of complex III, to cytochrome $b_{2}$, and to isocitrate dehydrogenase [233]. Another possibility for this variability of clea- vage-site sequences is that there is sorne uncertainty as to whether cleavage sites have always been determined correctly. Incorrect determination of cleavage sites may be a frequent danger, since it is well known that artificial cleavage of amino-terminal amino acid residues can occur during the procedures involved in the isolation and sequencing of proteins.

In addition to the specific amino acids encompassing the cleavage site itself, it might be possible that the specificity of the peptidase is also dependent on regions either in the presequence or in the mature part of the precursor that are at some distance from the actual cleavage site. Indeed this possibility is supported by a number of findings. When the normal cleavage site of the Cox IV precursor (between amino acids 25 and 26) was removed by fusing just the first 22 amino acids of the prepiece to DHFR, the construct was still processed; the new processing site being between amino acids 17 and 18 of the presequence [114]. The flanking regions of this site show no homology to the authentic cleavage site. Removal of as few as four amino-terminal residues from the presequence of Cox IV abolished processing by a mitochondrial extract containing processing peptidase activity [245]. That the mature sequence as well is somehow required for specific processing was reported by Nguyen et al. [246]. A hybrid protein bearing the presequence ( 32 amino acids) plus five amino acids of mature rat ornithine transcarbamoylase followed by 250 amino acids of the cytosolic enzyme asparagine synthetase of $E$. coli was transported into heart mitochondria but was incorrectly processed. When the hybrid contained 28 amino-terminal residues of mature OTC in addition to the presequence, however, processing occurred at the correct site. Recently, the same laboratory demonstrated the requirement for correct processing of certain elements within the presequence of OTC. When amino acids 22 to 30 of the $\mathbf{N}$-terminal prepiece were deleted, the mutated precursor was still imported but remained largely unprocessed [247]. The authors concluded that residues 22-30 may contribute to a specific conformation within the signal sequence that is required for recognition by the processing peptidase. On the other hand, results with the precursor of OTC which was mutated in the amino-terminal region of the presequence demoristrated that this part of the prepeptide was also important for correct processing [117].

For human pre-OTC it was shown that the positive charges in positions 23 and 26 of the presequence are not absolutely required for processing [152]. Position 23, however, proved to be very critical, since substitution of this arginine with glycine completely abolished both import into mitochondria as well as piocessing by mitochondrial matrix extracts. Substitution of the glycine with asparagine,alanine or lysine successively restored import and conversion to the mature form. For 
rat OTC it was reported that the precursor was proteolytically processed in two steps by the matrix processing peptidase $[227,240]$. The first cleavage occurs between amino acid residues 24 and 25 . The cleavage site is thus located adjacent to the critical arginine 23 residue. Substitution of arginine 23 with an aspartic acid or glycine residue inhibited both processing steps. In this case, however, membrane translocation was not affected by the mutations. Interestingly, the mutated precursors were processed at a 'new' cleavage site between residues 16 and 17 of the presequence; again only two residues away from an arginine in this case at position 15.

In summary, despite the great effort of several groups it is still unclear how the processing site is recognized by the matrix-located processing peptidase (MPP). The available data suggest that at least certain structures in the vicinity of the cleavage site are essential, which might be important in orienting the precursor towards the active site of the peptidase. Besides the importance of a positively charged residue in position -2 , there is apparently no requirement for a strict consensus sequence at the cleavage site itself. It is possible that the key to understanding the sleavage specificity lies in the functional role of the regulating $52 \mathrm{kDa}$ component (PEP) of the processing enzyme. We speculate that PEP first interacts with certain conformational structures within the prepeptide, thereby presenting the processing site to MPP. It seems doubtful, however, whether experiments with mutated precursor proteins (as described above) can shed iight onto exactly what kind of conformational structure is required.

It has to be noted that proteolytic processing is not a prerequisite for translocation of proteins across the mitochondrial membranes. After inhibition of the processing peptidase with chelators, precursor molecules were still imported (e.g., subunit $\beta$ and subunit 9 of $F_{0} F_{1}$ ATPase, the Rieske $\mathrm{Fe} / \mathrm{S}$ protein of the $b c_{1}$-complex and cytochrome $\left.P-450_{\mathrm{SCC}}\right)[36,248,249]$. Upon release of the block of the matrix peptidase by $\mathrm{Mn}^{2+}$, the presequence was cleaved off without further requirement for the membrane potential. If protein constructions were used which have a presequence but no cleavage site, import still occurred [114,137,240,246,247]. Finally, there are several precursor proteins which are made without cleavable presequences and are, of course, imported without proteolytic processing (see Section IV-A, and Tabies ii and III).

\section{VIII-D. Attachment of prosthetic groups}

In addition to proteolytic processing, the maturation of imported precursor proteins often includes a number of other covalent and non-covalent modifications. For many mitochondrial proteins, the attachment of prosthetic groups is a requisite step which enables them to function as electron carriers. This includes the covalent attachment of heme $c$ to cytochromes $c$ and $c_{1}$, and the construction of iron-sulfur centers on several subunits of respiratory complexes I, II and III. Other modifications include the non-covalent yet tight binding of coenzymes and cofactors such as NAD, FAD (FMN), hemes (having various side-chain substitutions) and metal ions.

For most imported proteins it is not known at what stage of import the attachment of prosthetic groups, particularly non-covalently associated ones, occurs. Events such as transiocation and prepiece removal do nu? appear to be affected by their absence. On the other hand, assembly of subunits into functional complexes has been shown to require the prior attachment of prosthetic groups or cofactors in several cases. For example, the assembly of cytochrome oxidase subunit I with a preassembled complex of subunits II and III was shown to be dependent on heme in rat mitochondria [250]. Similarly, mitochondria from copper-depleted $N$. crassa were unable to assemble cytochrome oxidase, although the synthesis of both nuclear and mitochondrial gene products was unaffected [251]. In yeast, the assembly of cytochrome oxidase subunits I and II with subunits VI and VII did not occur under anaerobic conditions, but happened immediately upon shifting to an oxygen ervironment [252].

The covalent attachment of heme to cytochrome $c$ and $c_{1}$ has been studied more extensively. In contrast to coenzyınes and cofactors that are non-covalently associated with mitochondrial proteins and which appear to only be required at the stage of assembly of multisubunit complexes, the covalent attachment of heme to c-type cytochromes is an integral part of the import process itself. In the case of cytochrome $c$, thioether linkages are formed between the heme vinyl groups and the thiols of cysteines 14 and 17 . This reaction is catalyzed by cytochrome $c$ heme lyase, a membranebound enzyme which faces the intermembrane space [188,194-198,253]. The precursor protein (apocytochrome $c$ ) is bound to the outer membrane and transported across it concomitant with covalent heme attachment [194] (Fig. 5). A likely mechanism is that the newly attached heme group forms the nucleus around which the remainder of the protein is folded, drawing it across the outer membrane as it does so $[192,194]$. It appears that the heme iron must be in the ferrous state prior to this process, accounting for the NADH requirement observed in vitro [207]. In the case of cytochrome $c_{1}$, heme attachment occurs at a later stage of import. The precursor is first imported and processed to an intermediate-sized form by the processing peptidase in the matrix (for details see Section IX-B). Heme is then added to this intermediate in a step which is tightly coupled to the second proteolytic processing event that generates the mature-sized cytochrome $c_{1}$. This has been demonstrated in vivo with heme-deficient mutants 
of yeast whose mitochondria accumulate the intermediate-sized form $[52,241]$, and by import experiments in vitro employing inhibitors of heme attachment [206]. In the absence of the heme-attaching step, the import of cytochrome $c_{1}$ appears to be stalled at a stage shortly following the first processing step (Nicholson and Neupert, unpublished data).

For the Rieske $\mathrm{Fe} / \mathrm{S}$ protein iron-sulfur cluster formation appears to be a prerequisite for the second proteolytic processing step of the precursor (Hartl and Neupert, unpublished data) (for details see Section IXB).

It is clear that the aquisition of prosthetic groups is important for the function of several mitochondrial proteins. In the cases that have been studied to date, these steps occur at both the early stages of import (e.g., cytochrome $c$ ) and at the later stages as well (e.g., cytochrome oxidase subunits). Subsequent steps of the import pathway can be blocked if prosthetic group attachment is inhibited.

\section{VIII-E. Modification of amino acids}

In principle, posttranslational modifications affecting proteins in the cytosol can also occiir with mitochondrial precursor proteins - particularly those whose import in vivo might occur with slow kinetics exposing them to longer periods to cytosolic enzymes catalyzing such reactions (for review see Ref. 254). Cytochrome $c$ is a good example of the type and extent to which such modifications may occur, since a large number of sequences have been determined [255]. For example, many proteins, particularly in higher eukaryotes, are acetylated at the amino-terminus. Cytochrome $c$ reflects this general pattern, always being $N$ - $\alpha$-acetylated in vertebrates and higher plants, but never in yeast or bacteria. There are no known instances in eukaryotic cytochromes $c$ in which the amino-terminal methionine has not been removed posttranslationally. Several cytochromes $c$ have extensive amino acid amidation and some have been reported to contain an unusual $\epsilon-N$-trimethyllysine $[256,257]$. In the latter case, it has been suggested that the methylation of the cytochrome $c$ precursor enhances its import into yeast mitochondria [258]. The purpose of amino acid modifications, however, is for the most part presumed to contribute to protein function or stability, although their effects on import have received little attention.

Once imported and fully assembled, some mitochondrial protein functions are regulated by reversible covalent modifications such as phosphorylation-dephosphorylation and ADP-ribosylation. For example, specific kinases and phosphatases modulate the activity of pyruvate dehydrogenase in response to ATP levels [259]. A $30 \mathrm{kDa}$ protein of the inner membrane of rat mitochondria is specifically mono-ADP-ribosylated, an event which has been suggested to be involved in the regulation of calcium release [260]. Poly-ADP-ribose has been reported to be specifically associated with a $100 \mathrm{kDa}$ protein (comprised of two $50 \mathrm{kDa}$ subunits) in the inner membrane of rat liver mitochondria and was part of an inner membrane protein-DNA-RNA complex involved in mitochondrial DNA replication $[261,262]$. Whether reversible covalent modifications of proteins is involved in regulating import processes is unknown.

\section{Intramitochondrial protein sorting and assembly}

\section{IX-A. General remarks}

Mitochondria can be structurally and functionally subdivided into four distinct subcompartments: namely the outer membrane, intermembrane space,inner membrane and matrix. The general reactions for the targeting of precursors to mitochondria, their insertion, and their translocation into and across the mitochondrial membranes (described in the preceding chapters) cannot sufficiently explain the intramitochondrial sorting of precursors to these different locations. Several precursors destined for different mitochondrial subcompartments even use a common insertion protein (GIP) in the outer membrane and must therefore be distributed to their final locations after this point. Hence, in addition to mitochondrial targeting information, sorting signals also have to be present in precursor molecules (Fig. 1) to direct them to their correct mitochondrial subcompartment. A summary of the pathways of intramitochondrial sorting identified so far is given in Fig. 7.

Proteins of the outer membrane and matrix seem to follow a relatively simple sorting mechanism. Outer membrane proteins are made without a cleavable presequence. They are apparently inserted directly from the cytosol into their target membrane. This process has been studied in most detail for porin of $N$. crassa $[47,79,103,167]$ (see Section VI-A) and the yeast $70 \mathrm{kDa}$ protein $[135,137]$. To date, the latter protein is the only outer membrane protein where the mitochondrial targeting sequence has been resolved (see Section IX-D).

Precursors of matrix proteins are transported across outer and inner membranes at translocation contact sites, thereby reaching their target compartment. Further sorting step is not required. Entry into mitochondria via translocation contact sites is also used by proteins of the inner membrane and probably by most proteins of the intermembrane space as well, although their sorting and assembly pathways are apparently more complicated. As outlined above (see Section VIII-B), twostep proteolytic processing has been found to be a common feature for a number of proteins of the intermembrane space and of inner membrane proteins which 


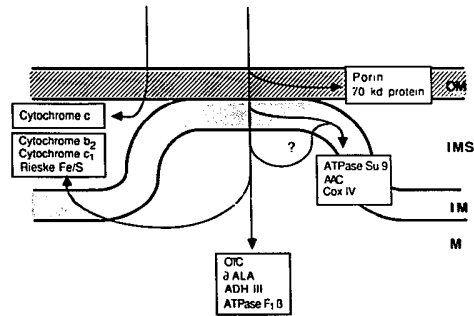

Fig. 7. Intramitochondrial sorting of precursor proteins. Sorting pathways are presented schematically for groups of proteins with the same submitochondrial location. Protcins destined for the matrix, inner membrane or intermembrane space enter mitochondria via translocation contact sites. The outer membrane protein porin and proteins of the inner membrane and matrix use common membrane components for recognition and insertion. Cytochromes $b_{2}$ and $c_{1}$, and the Rieske $\mathrm{Fe} / \mathrm{S}$ protein follow the 'conservative sorting' pathway via the matrix (Figs. 8 and 9). It is also possible that import into the matrix in the case of inner membrane proteins takes place prior to insertion into the membrane (Section IX-C). The import pathway of cytochrome $c$ is exceptional in that it does not require $\Delta \downarrow$ and that the precursor is translocated directly across the outer membrane to reach the intermembrane space (Section VI-B). OM, outer membrane; IMS, intermembrane space; IM, inner membranes; $M$. matrix; AAC, ADP/ATP carrier; Cox IV, cytochrome oxidase subunit IV; OTC, ornithine transcarbamoylase; ALA, \&-aminolaevulinate synthetase; ADH III, alcohol dehydrogenase III.

protrude into the intermembrane space with a hydrophilic portion of the molecule. In each case, the first proteolytic processing step is catalyzed by the chelator-sensitive processing peptidase in the matrix and therefore the precursors have to be translocated either completely or at ieast partially across the inner membrane.

$I X-B$. The 'conservative sorting' of intermembrane space proteins

The import pathway into mitochondria of the Rieske $\mathrm{Fe} / \mathrm{S}$ protein of the ubiquinol-cytochrome-c reductase (complex III or $b c_{1}$-complex) could be resolved into several distinct steps as depicted in Fig. 8 [36]. This protein is encoded for by a nuclear gene, synthesized in the cytoplasm as a precursor having a 32 residue amino-terminal extension [35,36,263], and transported to its functional location at the outer surface of the inner membrane. Both the amino-terminus and the large carboxy-terminal hydrophilic domain of the protein face the intermembrane space (Ref. 264; Hartl and Neupert, unpublished data). During import, the precursor is first completely translocated, via translocation contact sites, into the snatrix of mitochondria. There, cleavage by the processing peptidase to an intermediate containing an eight amino-acid residue extension occurs (see Tables III and V). This intermediate is then processed to the mature-sized protein, retranslocated in a $\Delta \psi$-independent manner back across the inner membrane and assembled in:o complex III. Thus, during import and sorting the $\mathrm{Fe} / \mathrm{S}$ protein has to cross the inner membrane twice. The role of the eight amino-acid residue extension for the sorting process is not yet clear. It probably does not contain targeting information for retranslocation since it is cleaved in the matrix space. Two lines of evidence suggest that iron-sulfur cluster formation might be a prerequisite for processing to the mature size: (i) The second processing step can be inhibited by the ferrous-iron chelator ortho-phenanthroline. This block can be released by low concentrations of $\mathrm{Fe}^{2+}$. As to the localization of $\mathrm{Fe} / \mathrm{S}$ cluster formation, it might be indicative that batho-phenanthroline, which cannot reretrate the inner membrane, does not exhibit this inhibiting effect. (ii) If the four cysteine residues of the imported precursor (three of which are believed to take part in cluster formation) are alkylated by $N$-ethylmaleimide, processing to the mature form is efficiently inhibited and the intermediate-sized form of

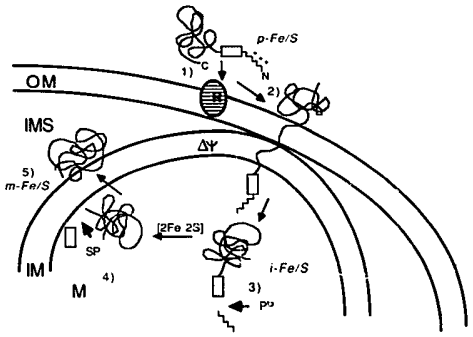

Fig. 8. Working hypothesis for the translocation of the Rieske $\mathrm{Fe} / \mathrm{S}$ protein to the outer surface of the inner mitochondrial membrane. The Rieske $\mathrm{Fe} / \mathrm{S}$ protein (subunit V of complex III or $b c_{1}$-complex) is synthesized in the cytoplasm as a precursor $(\mathrm{p}-\mathrm{Fe} / \mathrm{S})$ which carrics an amino-terminal prepeptide consisting of 32 amino-acid residues. After interaction with a receptor on the surface of mitochondria, 1. p-Fe/S is translocated through contact sites between outer and inner membranes into the matrix, 2. This process is dependent on the membrane potential $\Delta \psi$ across the inner membrane. In the matrix the aminoterminal 24 amino-acid residues of the presequence are cleaved off by the matrix-localized processing peptidase (PP) generating intermediate-sized $\mathrm{Fe} / \mathrm{S}$ protein (i-Fe/S), 3. As a prerequisite for the second proteolytic processing step, probably performed by a second processing proteinase (SP) in the matrix. 4 , the $\mathrm{Fe} / \mathrm{S}$-cluster is attached. The mature-sized protein $(\mathrm{m} \cdot \mathrm{Fe} / \mathrm{S})$ is finally re-translocated to the outer surface of the inner membrane, 5. OM, outer membrane; IMS. intermembrane space; IM, inner membrane: $M$. matrix: $N$, amino-terminus. 
the $\mathrm{Fe} / \mathrm{S}$ protein is accumulated (Hartl and Neupert, unpublished data).

Available data of bacterial and chloroplast Rieske proteins demonstrate a high homology in structure, topology and function with the mitochondrial counterpart. The $\mathrm{Fe} / \mathrm{S}$ protein of the photosynthetic bacterium Rhodopseudomonas sphaeroides, which is part of a $b c_{1}$ complex, is located (as in mitochondria) on the opposite side of the $F_{1}$ ATPase facing the thylakoid lumen (periplasmic space), which is functionally equivalent to the mitochondrial intermembrane space $[265,266]$. The structure and topology of the Rieske protein of chloroplast thylakoids is also directly homologous [265]. In $R$. sphaeroides, the $\mathrm{Fe} / \mathrm{S}$ protein is synthesized in the bacterial cytoplasm and has to be translocated across the photosynthetic membrane to its periplasmic face. It does not carry a presequence comparable to the mitochondrial protein [266]; however, a slight decrease in molecular mass has been observed upon assembly which could be equivalent to the transition from intermediate to mature $\mathrm{Fe} / \mathrm{S}$ protein in mitochondria [267].

Based on the hypothesis for the endosymbiotic origin of mitochondria, it was proposed that the mitochondrial $\mathrm{Fe} / \mathrm{S}$ protein is a component whose gene has been transferred from the endosymbiont to the nucleus of the host cell. Since the function and primary structure as well as the three-dimensions! folding and the topological arrangement of the protein have been conserved during evolution, it was assumed that the assembly pathway of the protein might also have been conserved. Hence, after transfer of the gene to the host cell nucleus, the $\mathrm{Fe} / \mathrm{S}$ protein had to be translocated across both mitochondrial membranes back into the matrix space in order to enter the conserved part of the assembly pathway. For this purpose, during evolution a positively charged presequence was added to the $\mathrm{Fe} / \mathrm{S}$ protein and translocation contact sites were introduced to accomplish direct transport of the precursor into the matrix. After cleavage by the processing peptidase, the protein then is assumed to enter the 'ancestral' assembly pathway which begins with translocation from the matrix (equivalent to the bacterial cytosol) across the inner membrane (equivalent to the bacterial plasma membrane) $[36,268]$.

For two other proteins of the intermembrane space, namely cytochrome $b_{2}$ and cytochrome $c_{1}$, it has also been investigated as to whether their sorting pathways follow this 'conservative' principle. Cytochrome $b_{2}$ is a soluble component of the intermembrane space of yeast mitochondria [269]. Its presequence of 80 amino acids [54] can be divided into two parts. The amino-terminal part exhibits the typical features of a mitochondrial targeting sequence (see Section IV-B); however, the carboxy-terminal part (in contrast to the precursor of the $\mathrm{Fe} / \mathrm{S}$ protein) contains a hydrophobic stretch of 21 amino acids (see Table III). Like the $\mathrm{Fe} / \mathrm{S}$ protein, it

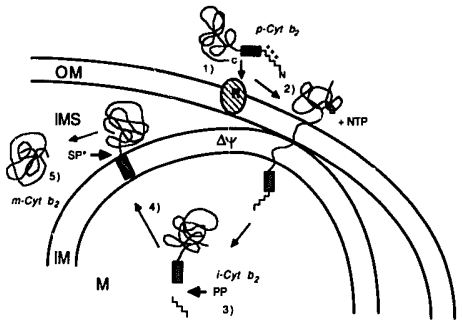

Fig. 9. Working hypothesis for the translocation of cytochrome $b_{2}$ to the intermembrane space. The precursor of cytochrome $b_{2}$ (p-Cyt $b_{2}$ ) carries an 80 amino-acid residue amino-terminal presequence with bipartite structure. $\mathrm{p}-\mathrm{Cyt} \boldsymbol{b}_{2}$ binds to a proteinaceous receptor on the surface of the outer membrane, 1 , and is subsequently tsanslocated into the matrix via translocation contact sites, 2. Membrane translocation is dependent on nucleoside triphosphates (NTP) and $\Delta \psi$, In the matrix the first proteolytic processing event occurs, performed by the chelator-sensitive processing peptidase (PP), resulting in the formation of intermediate-sized $b_{2}$ (i-Cyt $b_{2}$ ), 3. The prepeptide of i-Cyt $b_{2}$ (the carboxy-terminal part of the original presequence) directs the protein back across the inner membrane, 4. At the outer surface of the inner membrane $\mathrm{i}-\mathrm{Cyt} b_{2}$ is processed by a second processing protease (SP*) to mature-sized $b_{2}$ (m-Cyt $b_{2}$ ), a soluble component of the intermembrane space, 5. OM, outer membrane; IMS, intermembrane space; IM, inner membrane; $M$, matrix; $N$, amino-terminus.

was recently shown that the precursor to cytochrome $b_{2}$ is also first completely imported via translocation contact sites into the matrix of mitochondria where it exists as a soluble species $[95,102,187]$ (Fig. 9). In the matrix the amino-terminal part of the presequence is cleaved off by the processing peptidase resulting in the formation of an intermediate-sized form. This intermediate is then retranslocated back across the inner membrane and processed to the mature-sized protein which is subsequently soluble in the intermembrane space. In the case of cytochrome $b_{2}$ it could be shown that it is the intermediate-sized species which is retranslocated from the matrix back across the inner membrane and that the second processing step occurs at the outer surface of the inner membrane. Results with the pet mutant ts $\mathbf{2 8 5 8}$ $[242,243]$ (see Section VIII-B) suggest that the same peptidase also catalyzes the processing of the precursor to subunit II of cytochrome oxidase which, after synthesis on mitochondrial ribosomes, also has to be translocated across the inner membrane to the intermembrane space. It seems likely that the presequence of intermediate-sized cytochrome $b_{2}$ represents a second targeting (or sorting) signal for redirecting the protein across the inner membrane from the matrix side. At present the energy source for the retranslocation process is unknown. 
In principle, similar results were obtained for the import and sorting pathway of cytochrome $c_{1}$ [187] which with respect to function, structure and topology is homologous to cytochrome $c_{1}$ of $R$. sphaeroides $[265,266]$ and to cytochrome $f$ of chloroplast thylakoids $[265,270]$. In the carboxy-terminal part of the presequence of the cytochrome $c_{1}$ precursor a hydrophobic stretch of approx. 20 amino acids is also contained $[271,272]$ (see Fig. 1 and Table III). After import of the precursor into the matrix and the first processing event, intermediate-sized cytochrome $c_{1}$ is probably not completely retranslocated across the inner membrane but remains anchored to the inner membrane by the transmembrane segment in the carboxy-terminal part of the mature sequence. Interestingly, the second proteolytic processing step occurring at the outer face of the inner membrane is strongly dependent on NADH, which might be necessary for heme attachment $[187,206,241]$. The accumulation of intermediate cytochrome $c_{1}$ in a heme-deficient mutant has been demonstrated [52] (also see Section VIII-D).

Generally, intermembrane space proteins seem to first be completely translocated across both mitochondrial membranes. They are then redirected from the matrix back across the inner membrane to their target compartment. In the case of precursors having a bipartite presequence (cytochrome $b_{2}$, cytochrome $c$, and very likely cytochrome-c peroxidase too) the matrix targeting signal and the sorting signal for retranslocation of the intermediate-sized species are linearly arranged and act sequentially. The characteristics of transport from the matrix to the intermembrane space strongly resemble those of protein export from the cytoplasm across the plasma membrane in prokaryotes. Indeed, the prepieces of intermediate-sized cytochromes $b_{2}$ and $c_{1}$ show structural features similar to the signal peptides of bacterial proteins destined for export [273]. The sorting signal for retranslocation, however, can also reside in the mature part of the protein. This appears to be the case for the Rieske $\mathrm{Fe} / \mathrm{S}$ protein.

On the other hand, at least one exception for entry into the intermembrane space by this sorting principle is already known. Import of cytochrome $c$ circumvents transport into the matrix (see Section VI-B). Cytochrome $c$ has no cleavable presequence and its import is independent of the membrane potential across the inntr membrane. Accordingly, other proteins may also follow such a 'new' pathway and reach the intermembrane space by simply crossing the outer membrane.

\section{IX-C. The sorting of inner membrane proteins}

Are typical inner membrane proteins, i.e., proteins tightly embedded in the phospholipid bilayer and having only small portions exposed to the membrane surface, also first completely imported into the matrix space? For subunit 9 of $F_{0}$ ATPase ('proteolipid') pre- liminary ' 'ata suggest such an intramitochondrial sorting pathway does occur (Mahlke and Neupert, unpublished data). the precursor of subunit 9 from Neurospora can be acch nulated in a proteinase-resistant location in mitochondria in vitro if the processing peptidase in the matrix is blocker by chelators. This precursor is still protected against extes ally added proteinase after disruption of the outer mitochundrial membrane by low concentrations of digitonin. Undei these conditions it is not yet embedded into the phosphoisinid bilayer of the inner membrane (since it is extractable at aikaline $\mathrm{pH}$ ), but can be chased to the fully integrated nature-sized subunit when the processing peptidase is reaitivated by divalent metal ions. An artificial precursor carrying the presequence of Neurospora subunit 9 fused in DHFR ended up as soluble protein in the matrix. fusion protein between the complete subunit 9 precursor and DHFR was anchored to the inner membrane after import, suggesting that sorting information for the inner membrane is contained in the mature part of subunit 9 (Mahlke and Neupert, unpublished data).

Interestingly, in yeast [174-177] and plants $[178,179]$ subunit 9 is made without a cleavable presequence inside the mitochondrion. In Neurospora [72] and higher eukaryotes [148] it is synthesized in the cytoplasm containing a long presequence (66 amino acid residues in Neurospora). Upon import, the presequence is removed in two steps ( 35 and 31 amino acid residues) by the processing peptidase in the matrix $[73,231]$ (see Section VIII-B and Table V). Since subunit 9 in yeast mitochondria (and also in bacteria [274] and chloroplasts) is inserted into the membrane from the matrix side, it seems reasonable to assume that in Neurospora and higher eukaryotes the mature subunit also assembles from the matrix side. The precursor of Neurospora subunit 9 can be imported into yeast mitochondria and is correctly processed [180]. A fusion protein between the presequence of Neurospora subunit 9 and the mature part of yeast subunit 9 was imported into yeast mitochondria in vitro and processed [275]. Similarly, subunit 9 of $F_{0}$ ATPase, also a mitochondrially synthesized hydrophobic subunit, could be imported into yeast mitochondria in vitro if the presequence of Neurospora subunit 8 was fused to its amino-terminus and the construct was expressed in a cytosolic protein synthesizing system [276].

For the precursor of cytochrome $P-450_{\mathrm{ScC}}$ from adrenal cortex, an inner membrane protein facing the matrix, it has been demonstrated in vitro that complete translocation across both mitochondrial membranes takes place [249]. The imported precursor was salt-extractable and in the matrix, while the mature polypeptide was found to be integrated into the inner membrane.

Altogether, a number of inner membrane proteins also seem to be sorted via the matrix compartment. It 
cannot be excluded, howeyer, whether some integral membrazic polypeptides diffuse laterally from translocation coritact sites to their final destination in the inner membrane.

\section{IX-D. The 'stop-iransfer' hypothesis}

According to the so-cislled 'stop-transfer'-hypothesis, presequences of mitochondrial precursor proteins can be dissected into linearly arranged functional domains: (i) matrix targeting domains, (ii) 'stop-transport' domains, and (iii) proteolytic cleavage sites [277]. The presence or absence of these domains as well as their arrangement may determine which submitochondrial compartment a precursor is finaliy sorted to. Matrix targeting domains are situated at the amino-terminus of the presequence and show common features such as the occurrence of positively charged amino-acid residues (see Section IV-B). They direct a precursor to mitochondria and across the two mitochondrial membranes into the matrix. 'Stop-transport' domains are potential membrane spanning hydrophobic stretches of approx. 20 amino-acid residues. If present, they follow the matrix targeting domain at a variable distance and could thus prevent complete translocation of the precursor either at the level of the outer or the inner membrane.

The yeast $70 \mathrm{kDa}$ outer membrane protein is made without a cleavable presequence (Fig. 1). Its aminoterminal 41 residues contain the information for both targeting and sorting of the precursor [134-137]. Amino acids 1 through 12, if fused to mature subunit IV of cytochrome oxidase, could direct the fusion protein into the matrix of mitochondria in vivo and, if fused to DHFR, also to the matrix both in vivo and in vitro [137]. It is assumed that the overlapping sequence of amino-acid residues 10 through 37 (a hydrophobic stretch of 27 residues) is responsible for anchoring the precursor to the outer membrane thus preventing complete transport of the native $70 \mathrm{kDa}$ protein into the matrix. If the first 41 amino acids of the $70 \mathrm{kDa}$ precursor (containing the 'stop-transport' domain) were fused to $E$. coli $\beta$-galactosidase, the construct was directed to mitochondria and inserted into the outer membrane with the correct orientation compared to authentic $70 \mathrm{kDa}$ protein [135]. It is not yet possible to explain why the 'stop-transport' domain holds the protein in the outer membrane instead of in the inner membrane. The length and the relative strength of the hydrophobic segment, as well as its position relative to the matrix targeting sequence,might be critical [277].

For intermembrane space proteins such as cytochrome-c peroxidase [215], cytochrome $b_{2}$ [54] and cytochrome $c_{1} \quad[271,277-280]$ it was proposed that the hydrophobic segments in the carboxy-terminal parts of the presequences might prevent complete translocation of the precarsor across the inner mitochondrial mem- brane. The complete presequence of cytochrome $c_{1}$ when fused to DHFR directed the passenger protein to the intermembrane space. If only the amino-termisal part of the presequence excluding the hydrophobic segment was fused to DHFR, the construct was found in the matrix [278]. These experiments, however, did not exclude the possibility that transient import of the fusion protein carrying the authentic presequence of cytochrome $c_{1}$ into the matrix had occurred, since intermediates on the import pathway were not resolved. Recently, it was reported for the same fusion protein that the precursor was never found in a proteinase-resistant position in mitoplasts (i.e., mitochondria whose outer membrane had been disrupted by osmotic shock) when the matrix peptidase was blocked by metal chelators [280]. Import of authentic cytochrome $c_{1}$ was not tested in these studies.

The 'stop-transfer' model for the import of intermembrane-space proteins differs from the 'conservative sorting' pathway of authentic cytochromes $c_{3}$ and $b_{2}$ described above (and also as discussed in detail in Ref. 187). It has been shown for several different precursor proteins (including cytochrome $b_{2}$ ) that transport across both mitochondrial membranes at translocation contact sites occurs through a hydrophilic environment (possibly a proteinaceous channel) [95] (see Section V1-C). A potential hydrophobic 'stop-transport' sequence would be effective only through a strong protein-lipid interaction $[215,277]$ which does not seem to occur during translocation of proteins from the cytoplasm across the mitochondrial membranes. Similar results were recently reported for the translocation of proteins into chloroplasts [281]. Chimaeric precursor proteins containing putative 'stop-transfer' regions (made between mouse immunoglobulin $\mathbf{M}$ or vesicular stomatitis virus glycoprotein fused to the precursor of the small subunit of ribulose-1,5-bisphosphate carboxylasc) were found inside the chloroplast stroma upon import in vitro. They were not embedded in the envelope membranes.

On the other hand, Shore and colleagues $[282,283]$ stated that the membrane spanning segment of vesicular stomatitis virus G-protein was active in anchoring a fusion protein carrying the signal sequence of ornithine transcarbamoylase either to the mitochondrial inner membrane or to the outer membrane depending on its position with respect to the signal sequence. The authors concluded that this segment could act as a 'stop-transfer' sequence during translocation across the inner membrane. It was not excluded, however,that the construct had inserted into the inner membrane after having first been completely translocated into the matrix (see Section IX-C).

\section{IX-E. Assembly of imported mitochondrial proteins}

Many imported mitochondrial proteins are constituents of supramolecular complexes. Assembly of 
proteins into these functional complexes is therefore the final step in the import pathway. The processes involved in assembly are poorly understood. A number of important questions regarding the final stages of mitochondrial biogenesis, such as how the coordination between the cytoplasmic and the mitochondrial protein-synthesizing systems occurs, have been raised. The present knowledge in this area has recently been reviewed [3].

Mitochondrial respiratory complexes, with the possible exception of complex II, contain subunits coded for by exons of the mitochondrial genome as well as subunits coded for by nuclear genes. Strict coupling between both systems, however, cannot be detected. If mitochondrial protein synthesis was inhibited, synthesis of mitochondrial proteins in the cytoplasm continues and vice versa $[284,285]$. In the absence of mitochondrial protein synthesis, cytoplasmically made subunits of $F_{1}$ ATPase or $b c_{1}$-complex were still imported normally into mitochondria and were even partially assembled [286-289].

On the other hand, several studies describe the participation of nuclear gene products in regulating transcription/translation in mitochondria. In yeast cells, coupling between both protein-synthesizing systems at the level of transcription has been suggested. For example, control of nuclear transcription of the mitochondrial RNA polymerase (itself an imported protein) could be used to modulate the expression of the mitochondrial genome [290,291]. Furthermore, a number of mRNA-maturases, which are necessary for the processing of mitochondrial pre-mRNAs, are nuclear gene products [292-295]. These maturases appear to be specific for individual mitochondrial transcripts.

Another interesting principle of coordination between cytoplasmic and mitochondrial protein-synthesizing systems acts on the level of mitochondrial translation. Nuclear gene products have been described which are imported into mitochondria and regulate the translation of certain mitochondrial mRNAs, probably by interacting with the $5^{\prime}$-untranslated leader region [296-299].

What are the principles underlying the assembly of individual subunits? These processes have mainly been studied in yeast mutants defective in single subunits of respiratory protein complexes. For the $F_{0} F_{1}$ ATPase and the cytochrome oxidase complex, assembly of subunits seems to occur in a sequential order (for review see Ref. 3); however, many aspects are still unclear. It also has to be noted that the use of mutants in these studies raises the question as to whether the residual assembly reflects the physiological processes occurring in the wild-type cell.

For only a few mitochondrial precursor proteins whose import pathways have been studied has assembly been demonstrated in vitro. Lewin and Norman [300] investigated the import of subunits of $F_{1}$ ATPase into isolated yeast mitochondria. Assembly of the three largest subunits with each other could be demonstrated. Preincubation of mitochondria with unlabeled subunits reduced the incorporation of labeled subunits into the complex, suggesting that assembly occurred from an intramitochondrial pool of subunits. Subunit 9 of the $F_{0}$ ATPase of $N$. crassa imported in vitro could be precipitated from detergent-solubilized mitochondria vith an antibody directed against $F_{1}$ ATPase, indicating that it was functionally assembled [73]. Similar conclusions can be drawn from studies of import of the Riesis $\mathrm{Fe} / \mathrm{S}$ protein [36]. Following the import reaction, an antibody directed against cytochrome $c_{1}$ coprecipitated the mature-sized $\mathrm{Fe} / \mathrm{S}$ protein from detergent-solubilized mitochondria in exactly the same manner as observed with mitochondria that had been radiolabeled in vivo. Assembly into complex 111 did not occur if processing of imported $\mathrm{Fe} / \mathrm{S}$ protein was inhibited by metai chelators. For the ADP/ATP carrier was shown that the in vitro imported precursor acquired functional properties of the authentic mature protein [78]. Completely imported precursor, but not receptor-associated precursor, was able to bind the specific inhibitor carboxyatractyloside and to pass over hydroxyapatite in a manner that was indistinguishable from that of the in vivo imported carrier (also see Section III-B).

These studies, however, provide only a first insight into the complexity of the processes involved in mitochondrial protein assembly. Many questions, such as the exact sequence of events during the assembly of multisubunit protein complexes, cannot as yet be answered. One particularly interesting aspect is the possibility that imported assisting proteins. so-called chaperones, could play a role in protein assembly. Such a protein (the RUBISCO large subunit-binding protein) was shown to be involved in the assembly of ribulosebisphosphate carboxylase small and large subunits in the chloroplast stroma by non-covalently binding the chloroplast encoded large subunits of the enzyme (for review see Refs. 301 and 301a). The binding protein itself is an oligomer complex consisting of two different subunits which are cytoplasmically synthesized as precursors and imported into the chloroplast stroma. As generally defined, chaperones are not contained in the final assembled complex. So far, chaperones have not yet been identified in mitochondria.

\section{Present and future}

Despite the many advances made over recent years towards our understanding of how proteins are imported into mitochondria, a great deal more attention is required to get a detailed comprehension of the complexities of mitochondrial biogenesis. In this final sec- 
tion we address some of the questions which must be answered in future research.

Mitochondrial protein import can be a suitable model sysiem to study protein translocation across biomembra ies in general, one of the most intriguing aspects of pres:ent molecular cell biology. We have discussed that tit. transpo.t of proteins across a number of cellular me:nbrancs tollows similar principles. Future work will no doubt be directed towards defining and identifying the strictural components involved in these processes. In genersl, this search for components may proceed along two lines: On the one hand, biochemical and immunological characterization of distinct components will enable their isolation and reconstitution. On the other hand, selection and functional characterization of mutants defective in import will certanly contribute a useful approach, especially if such mutants can be characterized by in vitro analysis of the distinct steps of the import pathways.

Import of cytoplasmically synthesized proteins inte mirochondria can be organized into the following complexes of questions:

\section{$X-A$. Specific targeting and recognition}

In the case of precursors carrying amino-terminal extensions, sufficient information for targeting is contained within the presequences themselves. Emphasis should be placed ois the further analysis cf signals to characterize what their common structural features really are. Is it possible to dissect targeting signals into structural elements required for specific binding to mitochondrial surface receptors and into elements required for insertion into the translocation machinery? Studies with artificial presequences should be helpful in identifying such elements. Targeting signals within precursor proteins that do not contain cleavable presequences are currently much less understood. Do some of these precursor proteins contain multiple targeting signals (as proposed for the ADP/ATP carrier) and, if so, do they act in concert or independently? Do discontiguous targeting signals exist and how might they function?

For several precursor proteins, specific interactions with receptor structures on the mitochondrial surface have been described. So far no mitochondrial import receptor has been structurally characterized. How many different classes of receptors do exist? Are receptors evenly distributed over the mitochondrial surface or are they clustered at translocation contact sites? How do receptors 'hand over' the precursor proteins to further components of the import machinery? A general insertion protein (GIP) of the outer membrane has been proposed. Its nature and function has to be verified, and the initial insertion of precursors into the outer membrane must be studied in detail. In the future it may be possible to look at the mechanism of the interaction of precursors with isolated binding proteins in reconstituted liposome systems.

\section{$X-B$. Translocation across the mitochondrial membranes}

How proteins are translocated across biologica! membranes is still almost completely unknown. What is known, however, is that precursors must be unfolded to a certain extent in order to become competent for translocation. Where does this unfolding reaction take place: in the cytosol or at the mitochondria! surface? What is the nature of the postulated 'unfoldases"? What is the role of NTPs in this process and which NTP is actually required, ATP or GTP? With regard to the physiological significance of the unfolding reaction it must be asked whether precursor proteins really do fold under normal conditions in the intact cell. Is the 'unfolding' machinery only employed under conditions of 'stress' (e.g., heat shock or extreme growth rates) as a saluage pathway for (mis)folded precursors? For example, supposing that a cotranslational mode of translocation normally prevails, folding of precursors may not pose a problem.

It is a characteristic of mitochondrial protein import that precursors destined for the matrix or the inner membrane, and also most precursors of intermembrane space proteins, have to be transported (at least partially) across two membranes via translocation contact sites. Very little is known about the nature of these contact sites. What is their molecular composition and what forces keep the two membranes in close contact? One of the main questions is how do precursors actually move through contact sites. Translocation apparently occurs through a hydrophilic environment, implying that proteins probably play a role, but no proteinaceous component direcily involved in membrane translocation of precursors has yet been identified. Mitochondria might serve as a model system to answer a number of questions currently under debate, such as: Does the translocation of proteins across biomembranes really occur through a proteinaceous pore? Does it proceed in a threadlike or domain-wise manner? It might be speculated that translocation contact sites contain a 'translocase' which could work like a membrane-integrated 'unfoldase' drawing the polypeptide chain across the membranes. What is the driving force for membrane translocation? Is it merely the re-folding of a protein after translocation that ienders the whole process energetically favorable, and what is the function of $\Delta \psi$ in the translocation of precursor proteins into and across the inner membrane?

\section{$X$-C. Processing and intramitochondrial sorting}

Presequences of precursors are cleaved by the highly specific metal-dependent processing peptidase (MPP) in 
the matrix. The enzyme is dependent on PEP, the processing enhancing protein, for full activity. Questions to be solved are: What structural features of the presequence, and perhaps of the mature protein part. are recognized by the processing enzyme? What is the enzymatic mechanism of the proteolytic cleavage and how does PEP take part in this reaction? Does PEP interact with the precursor directly and does it have additional functions in membrane translocation of precursors?

Proteolytic processing also plays an important role in the sequence of steps involved in the intramitochondrial sorting of proteins. For example, precursors destined for the intermembrane space are first imported into the matrix. Sorting information for re-translocation across the inner membrane appears to be contained in the carboxy-terminal segments of the presequences and maybe in other sequences of the maiure protein parts. With regard to the export of proteins from the matrix, the inner mitochondrial membrane represents a separate, as yet almost completely neglected system of protein translocation. Its similarity to protein export in bacteria is evident on the basis of evolutionary considerations. For example, proteolytic cleavage (i.e., the second proteolytic processing step of intermembrane space precursor proteins) occurs, after translocation, at the outer suiface of the inner membrane by a membrane-iniegrated peptidase. Over the coming years, mitochondrial protein export will certainly be characterized in more detail. An important question is whether export is restricted to certain areas of the inner membrane (e.g., the outer boundry mernbrane). How does membrane insertion of proteins which are synthesized on mitochondrial ribosomes (such as cytochrome oxidase II) occur? Up to now a tight coupling between synthesis and insertion has been assumed. Efforts should be directed towards establishing a vesicle system derived from inner membranes that would be competent in protein translocation. With regard to the idea that mitochondrial protein export is evolutionarily related to prokaryotic protein export, it would be interesting to further characterize and isolate the peptidase(s) performing the (second site) cleavage at the outer surface of the inner membrane to compare them with their bacterial counterparts.

Further questions requiring attention include: What is the nature of sorting signals residing in the mature part of imported proteins, such as the inner membrane proteins subunit 9 of the $F_{0} F_{1}$ ATPase, the ADP/ATP carrier, the uncoupling protein, the phosphate carrier and the nuclear encoded subunits of cytochrome oxidase? What are the principles by which the ordered assembly of individual subunits into multi-subunit protein complexes occur? Are there helper proteins ('chaperones') which assist in the assembly of imported and mitochondrially made proteins? How are the cyto- plasmic and mitochondrial protein-synthesizing systems interconnected and coordinated? Furthermore, how does transport of RNA across the mitochondrial membranes occur, and does it function in such regulation?

These of course are only some of the many questions in mitochondrial protein import waiting to be answere: In our view, the most interesting avenue of futiure research in this area will be directed towards the complete understanding of the components involved in the two mitochondrial protein translocation systems and their active reconstitution into artificial membranes.

\section{References}

1 Hay, R., Böhni, P. and Gasser, S. (1984) Biochim. Biophys. Acta 779. 65-87.

2 Harmey. M.A. and Neupert. W. (1985) in The Enzymes of Biological Membranes (Martonosi. A.. ed.). Vol. 4. pp. 431-464. Plenum Press, New York.

3 Pfanner, N. and Neupert, W. (1987) Curr. Top. Bioenerg. 15. 177-219.

4 Blobel, G. and Dobberstein, B. (1975) J. Cell Biol. 67, 852-862.

5 Meyer, D.1. and Dobberstein, B. (1980) J. Cell Biol. 87, 498-502.

6 Walter, P., Ibrahimi. I. and Blobel. G. (1981) J. Cell Bid. 91. S45-550.

7 Walter, P. and Blobel, G. (1981) J. Cell Biol. 91, 551-556.

8 Walter, P. and Blobel, G. (1981) J. Cell Blol. 91. 557-561.

9 Gilmore. R., Blobel, G. and Walter, P. (1982) J. Cell Biol. 95, 463-469.

10 Meyer. D.I. Krause. E. and Dobberstein. B. (1982) Nature 297. 647-650.

11 Gilmore, R. and Blobel, G. (1985) Cell 42, 497-505.

12 Meyer. D.I. (1985) EMBO J. 4, 2031-2033.

13 Wickner, W.T. and Lodish, H.F. (1985) Science 230, 400-407.

14 Svans, F.A., Gilmore, R. and Blobel, G. (1986) Proc. Natl. Acad. Sci. USA 83, 581-585.

15 Lazarow, P.B. and Fujiki. Y. (1985) Ar.nu. Rev. Cell Biol. I. 489-530.

16 Borst, P. (1986) Biochim. Biophys. Acta 866, 179-203.

17 Just, W.W. and Harti, F.-U. (1987) in Peroxisomes in Biology and Medicine (Fahimi. H.D. and Sies. H., eds.). Pp. 402-416. Springer-Verlag, Berlin.

18 Sabatini, D.D., Kreibich, G., Morimoto, T. and Adesnik, M. (1982) J. Cell Biol. 92, 1-22.

19 Hansen, W., Garcia, P.D. and Walter, P. (1986) Cell 45. 397-406.

20 Maher, P.A. and Singer, S.J. (1986) Proc. Natl. Acad. Sci. USA 83, $9001-9005$.

21 Mueckler, M. and Lodish, H.F. (1986) Nature 322, 549-552.

22 Rothblatt, J.A. and Meyer, D.I. (1986) EMBO J. S, 1031-1036.

23 Waters, M.G. and Blobel, G. (1986) J. Cell Biol. 102, 1543-1550.

24 Zimmermann, R. and Mollay, C. (1986) J. Biol. Chem. 261, 12889-12895.

25 Schlenstedt, G. and Zimmermann, R. (1987) EMBO J. 6, 699-703.

26 Ainger, K.J. and Meyer, D.I. (1986) EMBO J. S, 951-955.

27 Perara, E., Rothman, R.E. and Lingappa, V.R. (1986) Science 232, 348-352.

28 Randall, L.L. (1983) Cell 33, 231-240.

29 Muller, M. and Blobel, G. (1984) Proc. Natl. Acad. Sci. USA 81, 7421-7425.

30 Randall, L.L., Hardy, S.J.S. and Thom, J.R. (1987) Annu. Rev. Microbiol. 41, 507-541.

31 Hallermayer, G. and Neupert, W. (1976) in Genetics and Biogenesis of Chloroplasts and Mitochondria (Bücher, T., Neupert, W., Sebald, W. and Werner, S., eds.), pp. 807-812, North-Holland, Amsterdam. 
32 Hallermayer, G., Zimmermann, R. and Neupert, W. (1977) Eur. J. Biochem. 81, 523-532.

33 Scltatz, G. (1979) FEBS Lett. 103, 203-211.

34 Reid, G.A. and Schatz, G. (1982) J. Biol. Chem. 257, 13056-13061.

35 Teintze, M., Slaughter, M., Weiss, H. and Neupert, W. (1982) J. Biol. Chem. 257, 10364-10371.

36 Hartl, F.U., Schmidt, B., Wachter, E. Weiss, H. and Neupert. W. (1986) Cell 47, 939-951.

37 Harmey, M.A., Hallermayer, G. and Neupert, W. (1976) in Genetics and Biogenesis of Chloroplasts and Mitochondria (Bücher, T., neupert, W., Sebald, W. and Werner, S., eds.), pp. 813-818, North-Holland, Amsterdam.

38 Harmey, M.A., Hallermayer, G., Kork, H. and Neupert, W. (19i7) Eur. J. Biochem. 81, 533-544.

39 Korb, H. and Neupert, W. (1978) Eur. J. Bixhem. St, 609-620.

40 Maccecchini, M.-L., Rudin, Y., Blobel, G. and Schatz, G. (1979) Proc. Natl. Acad. Sci, USA 76, 343-347.

41 Zimmermann, R. and Neupert, W. (1980) Eur. J. Biochem. 109. 217-229.

4? Kellems, R.E. and Butow, R.A. (1972) J. Biol. Chem. 247, 8043-8050.

43 Kellems, R.E., Allison, V.F. and Butow, R.A. (1974) J. Biol. Chem. 249, 3297-3303.

44 Ades, !.Z. and Butow, R.A. (1980) J. Biol. Chem. 255, 9918-9924.

45 Schleyer, M. and Neupert, W. (1985) Cell 43, 339-350.

46 Suissa, M. and Schatz, G. (1982) J. Biol. Chem. 257, 13048-13055.

47 Freitag. H., Janes, M. and Neupert, W, (1982) Eur. J. Biochem. 126, $197-202$.

48 Mihara, K., Blobel, G. and Sato, R. (1982) Proc. Natl. Acad. Sci. USA 79, 7102-7106.

49 Gasser, S.M. and Schatz, G. (1983) J. Biol. Chem. 258, 3427-3430.

so Shore, G.C., Power, F., Bendayan, M. and Carignan, P. (1981) J. Biol. Chem. 8761-8766.

51 Daum, G., Gasser, S.M. and Schav, G. (1982) J. Biol. Chem. 257, 13075-13080.

52 Gasser, S.M., Ohashi, A., Daum, G., Böhni, P.C., Gibson, J., Reid, G.A., Yonetani, T. and Schatz, G. (1982) Proc. Natl. Acad. Sci. USA 79, 267-271.

53 Reid, G.A., Yonetani, T. and Schatz, G. (1982) J. Biol. Chem. 257, 13068-13074.

54 Guiard, B. (1985) EMBO J. 4, 3265-3272.

S5 Maccecchini, M.-L., Rudin, Y. and Schatz, G. (1979) J. Biol. Chem. 254, 7468-7471.

56 Mihara, K., Omura, T., Harano, T., Brenner, S.. Fleischer, S. and Rajagopalan, K.V. (1982) J. Biol. Chem. 25்7, 3355-3358.

57 Zimmermann, R., Paluch. U. and Neupert, W. (1979) FEBS Lett. 108, 141-146.

58 Matstura, S., Arpin, M., Hannum, C., Margoliash, E., Sabatini, D.D. and Morimoto, T. (1981) Proc. Natl. Acad. Sci. USA 78, 4368-4372.

59 Watanabe, K. and Kubo, S. (1982) J. Biochem. 123, 587-592.

60 Zimmermann, R., Paluch, U., Sprinzl, M. and Neupert, W. (1979) Eur. J. Biochem. 99, 247-252.

61 Arends, H. and Sebald, W. (1984) EMBO J. 3, 377-382.

62 Freeman, K.B., Chien, S.-M., Lichtfield, D. and Patel, H.V. (1983) FEBS Lett. 158, 32S-330.

63 Ricquier, D., Thibault, J., Bouillaud, F. and Kuster, Y. (1983) J. Biol. Chem. 258, 6675-6677.

64 Bouillaud, F., Weissenbach, J, and Ricquier, D. (1986) J. Biol. Chem. 261, 1487-1490.

65 Ridley, R.G., Patel, H.V., Gerber, G.E., Morton, R.C. and Freeman, K.B. (1986) Nucl. Acids Res. 14, 4025-4035.

66 Van Loon, A.P.G.M., Kreike, J., De Ronde, A., Van der Horst, G.T.J., Gasser, S.M. and Grivell, L.A. (1983) Eur. J. Biochem. $135,457-463$.

67 Nishikimi, M., Shimomura, Y. and Ozawa, T. (1986) Biochem. Biophys. Res. Commun. 138, 1291-1297.
68 Hampsey, D.M. Lewin. A.S. and Kohlhaw, G.B. (1983) Proc. Nat. Acad. Sci. USA 80, 1270-1274.

69 Beltzer, J.P., Chang, L.-F.L., Hikkanen, A.E. and Kohlhaw, G.B. (1986) J. Biol. Chem. 261, 5160-5167.

70 Beltzer, J.P., Morris, S.R. and Kohlhaw, G.B. (1988) J. Biol. Chem. 263, 368-374.

71 Arakawa, H., Takiguchi, M., Amaya, Y., Nagata, S., Hayashi, H. and Mori, M. (1987) EMBO J. 6, 1361-1366.

72 Viebrock, A., Perz, A. and Sebald, W. (1982) EMBO J. 1, 565-571.

73 Schmidt, B., Hennig, B., Zimmermann, R. and Neupert, W. (1983) J. Ceil Biol. 96, 248-255.

74 Neupert, W. and Schatz, G. (1981) Trends Biochem. Sci. 6, 1-4.

75 Ono, B.-I., Fink, G. and Schatz, G. (1975) J. Biol. Chem. 250 , $775-782$.

76 Chen, W.-J. and Douglas, M.G. (1987) J. Biol. Chem. 262, 15598-15604.

77 Chen, W.-J. and Douglas, M.G. (1988) J. Biol. Chem. 263, 4997-5000.

78 Schleyer, M. and Neupert, W. (1984) J. Biol. Chem. 259, 3487-3491.

79 Pfaller, R., Freitag, H., Harmey, M.A., Benz, R. and Neupert, W. (1985) J. Biol. Chem. 260, 8188-8193.

80 Jaussi, R., Sonderegger, P., Flïckiger, J. and Christen, P. (1982) J. Biol. Chem. 257, 13334-13340.

81 Raymond, Y. and Shore, G.C. (1981) J. Biol. Chem. 256. 2087-2090.

82 Ohta, S. and Schatz, G. (1984) EMBO J. 3, 651-657.

83 Argan, C., Lusty, C.J. and Shore, G.C. (1983) J. Biol. Chem. 258, 6667-6670.

84 Miura, S., Mori, M. and Tatibana, M. (1983) J. Biol. Chem. 258, 6671-6674.

85 Firgaira, F.A., Hendrick, J.P., Kalousek, F., Kraus, J.P. and Rosenberg, L.E. (1984) Science 226, 1319-1322.

86 Argan, C. and Shore, G.C. (1985) Biochem. Biophys. Res. Commun. 131, 289-298.

87 Burns, D. and Lewin, A. (1986) J. Biol. Chem. 261, 6153-6155.

88 Pfanner, N. and Neupert, W. (1987) J. Biol. Chem. 262, 7528-7536.

89 Ono, H. and Tuboi, S. (1988) J. Biol. Chem. 263, 3188-3193.

90 Eilers, M. and Schatz, G. (1986) Nature 322, 228-232.

91 Chen, W.-J. and Douglas, M.G. (1987) J. Biol. Chem. 262, 15605-15609.

92 Van Steeg, H., Oudshoom, R., Van Hell, B., Polman, J.E.M. and Grivell, L.A. (1986) EMBO J. 5, 3643-3650.

93 Vestweber, D. and Schatz, G. (1988) EMBO 3. 7, 1147-1151.

94 Ness, S.A. and Weiss, R.L. (1987) Proc. Natl. Acad. Sci. USA 84, 6692-6696.

95 Pfanner, N., Hartl, F.-U., Guiard, B. and Neupert, W. (1987) Eur. J. Biochem. 169, 289-2/3.

96 Schwaiger, M., Herzog, V. and Neupert. W. (1987) J. Cell Biol. 105, 235-246.

97 Rothman, J.E. and Kornberg, R.D. (1986) Nature 322, 209-210.

98 Pfanner, N. and Neupert, W. (1986) FEBS Lett. 209, 152-156.

99 Eilers, M., Oppliger, W. and Schatz, G. (1987) EMBO J. 6, 1073-1077.

100 Chen, W.-J. and Douglas, M.G. (1987) Cell 49, 651-658.

101 Pfanner, N., Tropschug, M. and Neupert, W. (1987) Cell 49, $815-823$.

102 Hartl, F.-U., Ostermann, J., Pfanmar, N., Tropschug, M.. Guiard, B. and Neupert, W. (1987) in Cytochrome Systems: Molecular Biology and Energetics (Papa, S. et al., eds.), pp. 189-196. Plenum Press, New York.

103 Kleene, R., Pfanner, N., Pfaller, R., Link, T.A., Sebald, W., Neupert, W. and Tropschug, M. (1987) EMBO J. 6, 2627-2633.

104 Craig, E.A. (1985) Crit. Rev. Biochem. 18, 239-280.

105 Lindquist, S. (1986) A.nmu. Rev. Biochem. 55, 1151-1191. 
106 Pelham, H.R.B. (1986) Cell 46, 959-961

107 Deshaies, R.J., Koch, B.D., Werner-Washburne. M.. Craig. E.A. and Schekman, R. (1988) Nature 332, 800-805.

108 Chirico, W.J., Waters, M.G. and Blobel, G. (1988) Nature 332. 805-810.

109 Zimmermann, R., Sagstetter, M., Lewis, M.J. and Pelham. H.R.B. (1989) EMBO J. 7, 2875-2880.

110 iiut, E.C., Pesold-Hurt. B. and Schatz. G. (1984) FEBS Lett. 178. 306-310.

111 Horwich, A.L., Kalousek, F., Mellman. I. and Reser.verg. L.E (1985) EMBO J. 4, 1129-1135.

112 Maarse, A.C., Van Loon, A.P.G.M., Riezman. H., Gregor. J.. Schatz, G. and Grivell, L.A. (1984) EMBO J. 3, 2831-2837.

113 Hurt, E.C., Pesold-Hurt, B, and Schatz, G. (1984) EMBO J. 3. 3149-3156.

114 Hust, E. ., Pesold-Hurt, B., Suda. K.. Oppliger. W. and Schatz. G. (1985) EMBO J. 4, 2061-2068.

115 Horwich, A.L., Kalousek, F., Fenton, W.A., Furtak, K., Pollock. R.A. and Rosenberg, L.E. (1987) I Cell Biol. 105, 669-677.

116 Lingelbach, K.R., Graf, L.I., Dunn, A.R. and Hogenraad, N. (1986) Eur. J. Biochem. 161, 19-23.

117 Kraus, J.P., Novotny, I., Kalousek, F., Swaroop. M. and Rosenberg, L.E. (1988) J. Biol. Chem., in press.

118 Keng. T., Alani, E. and Guarente, L. (1986) Mol. Cell. Biol. 6. 355-364.

119 Douglas, M.G., Geller, B.L. and Emr. S.D. (1984) Proc. NatL. Acad. Sci. USA 81, 3983-3987.

120 Emr, S.D., Vassarotti, A., Garrett, J., Geller, B.L., Takeda, M. and Douglas, M.G. (1986) J. Cell. Biol. 102, S23-533.

121 Vasarotti, A., Chen, W., Smagula, C. and Douglas, M.G. (1987) J. Biol. Chem. 262, 411-418.

122 Bedwell, D.M., Klionsky, D.J. and Emr. S.D. (1987) Mol. Cell. Biol. 7, 4038-4047.

123 Van Loon, A.P.G.M. and Young, E.T. (1986) EMBO J. S, 161-165.

124 Surguchov, A.P. (1987) Trends Biochem. Sci. 12, 335-338.

125 Natsoulis, G., Hilger, F. and Fink, G.R. (1986) Cell 46, 235-243.

126 Chatton, B., Walter, P., Ebel, J.-P., Lacroute, F. and Fasiolo, F. (1988) J. Biol. Chem. 263, 52-57.

127 Myers, A.M. and Tzagoloff, A. (1985) J. Biol. Chem. 260, $15371-15377$.

128 Pape, L.K. and Tzagoloff, A. (1985) Nucl. Acids Res. 13. 6171-6183.

129 Pape, L.K., Koerner, T.J. and Tzagoloff. A. (1985) J. Biol. Chem. 260, 15362-15370.

130 Schneller, J.M., Schneider. C. and Stahl, A.J.C. (1987) Biochem. Biophys. Res. Commun. 85, 139?-1399.

131 Wu, M. and Tzagoloff, A. (1987) J. Biol. Chem. 262, 12275-12282.

132 Tropschug, M., Nicholson, D.W., Hartl, F.-U., Köhler, H., Pfanner, N., Wachter, E. and Neupert. W. (1988) J. Biol. Chem., in press.

133 Wierenga, R.K., Swinkels, B., Michels, P.A.M., Osinga, K., Misset, O., Van Beeumen, J., Gibson, W.C., Postma, J.P.M., Porst. P., Opperdoes, F.R. and Hol, W.G. (1987) EMBO J. 6. 215-221.

134 Riezman, H., Hase, T., Van Loon, A.P.G.M., Grivell, L.A., Suda, K. and Schatz, G. (1983) EMBO J. 2, 2161-2168.

135 Hase, T., Muller, U., Riezman, H. and Schatz, G. (1984) EMBO J. 3, 3157-3164.

136 Hase, T., Nakai, M. and Matsubara. H. (1986) FEBS Lett. 197. 199-203.

137 Hurt, E.C., Müller, U. and Schatz, G. (1985) EMBO J. 4. 3509-3518.

138 Adrian, G.S., McGammon, M.T., Montgomery, D.L. and Douglas, M.G. (1986) Mol. Cell. Biol. 6, 626-634.

139 Smagula, C. and Douglas, M.G. (1988) J. Biol. Chem. 263, 6783-6790.

140 Aquila, H., Misra, D., Eulitz, M. and Klingenberg. M. (1982) Hoppe Seyler's Z. Physiol. Chem. 363, 345-349.
141 Saraste. M. and Walker. J.E. (1982) FEBS Lett. 144, 250-254.

142 Aquila. H. Link. T.A. and Klingenberg. M. (1985) EMBO J. 4. 2369-2376.

143 Ito, A., Ogishima. T., Ou, W., Omura, T., Moyagi, H., Lee, S. Mihara. H. and Izumiya, N. (1985) J. Biochen! 98. :571-1582.

i44 Von Heijne, G. (1986) EMBO J. 5. 1335-1342. (a) Lennart-Nilsson, Y.G. and Von Heijne. G. (1988) FEBS Lett. 235. 173-177.

145 Pfanner, N., Hoeben, P., tropschug, M. and Neuper:, W. (1987) J Biol. Chem. 262, 14851-14854.

146 Stuart. R.A.. Neupert, W. and Tropschug. M. (1987) EMBO J. 6. 2131-2137.

14? Pfanner, N., Müller, H.K. Harmey, M.A. and Neupert, W. (1987) EMBO J. 5, 3449-3454.

148 Gay. N.J. and Walker, J.E. (1985) EMBO J. 4, 3519-3524

149 Van Loon, A.P.G.M., De Groot, R.J., De Haan. M., Dekkar. A. and Grivcll, L.A. (1984) EMBO J. 3. 1039-1043.

150 Horwich. A.L., Kalousek. F. and Rosenberg. L.E. (1985) Proc. Natl. Acad. Sci. USA 82, 4930-4933.

151 Horwich, A.L., Fenton, W.A.. Firgaira. F.A., Fox. J.E., Kolansky. D., Mellmann, I.S. and Rosenberg. L.E. (1985) J. Cell Biol. 100. 1515-1521.

152 Horwich, A.L., Kalousek. F., Fenton. W.A., Pollock, R.A. and Rosenberg. L.E. (1986) Cell 44, 451-459.

153 Chu. T.W., Grant, P.M. and Strauss, A.W. (1987) J. Biol. Chem. 262. $1280-12811$.

154 Vasarotti A., Stroud, R. and Douglas, M. (1987) EMBO J. 6, 705-711.

ISS Epand, R.M., Hui, S.-W., Argan, C.. Gillespie, L.L. and Shore. G. (1986) J. Biol. Chem. 261, $10017-10020$.

156 Roise, D. Horvath, S.J., Tomich, 3.M., Richards, J.H. and Schatz. G. (1986) EMBO J. S, 1327-1334.

157 Skerjank, I.S., Shore, G.C. and Silvius, I R (1987) EMi30 J. 6. 3117-3123.

158 Tamm, L.K. (1986) Biochemistry 25, 7470-7476.

159 Rietveld. A., Ponjec, G.A.E., Schiffers, P., Jordi, W., Van De Coclwijk. P.J.F.M., Demel, R.A., Marsh. D. and De Kruijfr, B. (1985) Biochim. Biophys. Acta 818, 398-409.

159(a) Ou. W.-J., Ito, A., Umedia. M.. Inoue. K. and Omura, T. (1988) J. Biochem. 103, 589-595.

160 Allison, D.S. and Sctatz, G. (1986) Proc. Natl. Acad. Sci. USA 83. 9011-9015.

161 Roise, D., Theiler. F., Horvath, S.J., Tomich, J.M.. Richards, J.H., Altuson. D.S. and Schatz, G. (1988) EMBO J. 7, 649-653.

162 Gillespie, L.L., Argan, C., Taneja, A.T., Hodges, R.S., Freeman. K.B. and Shore, G.C. (1985) J. Biol. Chem. 260, 16045-16048

163 Banroques, J., Perea, J. and Jacq. C. (1987) EMBO J. 6, 1085-1091.

164 Hurt, E.C. and Schatz, G. (1987) Nature 325, 499-503.

165 Hurt, E.C., Soltanifar. N., Goldschmidt-Clermont, M., Rochaix, J.-D. and Schatz, G. (1986) EMBO J. S, 1343-1350.

166 Baker. A. and Schatz. G. (1987) Proc. Nat. Acad. Sci. USA 84, 3117-3121.

167 Pfaller, R. and Neupert, W. (1987) EMBO J. 6, 2635-2642.

168 Zwizinski, C., Schleyer, M. and Neupert, W. (1984) J. Biol. Chem. 259, 7850-7856.

169 Pfaller, R., Steger, H.F., Rassow, J., Pfanner, N. and Neupert, W. (1Yة̈B) J. Gc!! Rinl., in press.

170 Pfanner, N.. Pfaller, R. and Neupert, W. (1988) Trends Biochem. Sci., in press.

171 Pfanner, N. and Neupert. W. (1985) EMBO J. 4, 2819-2825.

172 Schleyer M., Schmidt, B. and Neupert, W. (1982) Eur. J. Biochem. 125, 109-116.

173 Cheng, M.K., Pollock, R.A., Hendrick, J.R. and Horwich, A.L. (1987) Proc. Natt. Acad. Sci. USA 84, 4063-4067.

174 Tzagoloff, A. and Meagher, P. (1972) J. Biol. Chem. 247, 594-603.

175 Sierra, M.F. and Tzagoloff, A. (1973) Proc. Natl. Acad. Sci. USA 70, 3155-3159. 
176 Hensgen, L.A.M., Grivell, L.A., 3orst, P. and Bos, J.L. (1979) Pros. Natl. Acad. Sci. USA 76, 1663-1667.

177 Macino, G. and Tzagoioff, A. (1979) J. Biol. Chem. 254, $4617-4623$.

178 Sebald, W. and Wachter, E. (1980) FEBS Lett. 122, 307-311.

179 Nelson, N., nelson, H. and Schattz, G. (1980) Proc. Natl. Acad. Sci. (USA) 77, 1361-1364.

180 Schmidt, B., Hennig, B., Köhler, H. and Neupert, W. (1983) J. Biol. Chem. 258, 4687-4689.

181 Grossmann, A., Barthelt, S. and Chua, N.H. (1980) Nature 285 , 625-628.

132 Gasser, S.M., Daum, G. and Schatz, G. (1982) J. Biol. Chem. 257, 13034-13041.

183 Riezman, H., Hay, R., Gasser, S., Daum, G., Schneider, G. Witte, C. and Schatz, G. (1983) EMBO J. 2, 110S-1111.

184 Riezman, H., Hay, R., Witte, C., Nelson, N. and Schatz, G. (1983) EMBO J. 2, 1113-1118.

185 Schmidt, B., Pfaller, R., Pfanner, N., Schteyer, M. and Neupert, W. (1985) in Achievements and Perspectives in Mitochondrial Research (Quagliariello, E. et al., eds.). Vol. II, pp. 389-396, Eisevier, Amsterdam.

186 Pfaller, R., Pfanner, N. and Neupert, W. (1988) J. Biol. Chem., in press.

187 Hartl, F.-U., Ostermann, J., Guiard, B. and Neupert, W. (1987) Cell 51, 1027-1037.

188 Nicholsoin, D.W., Hergersberg. C. and Neupert, W. (1988) J. Biol. Chem., in press.

189 Ohba, M. and Schatz, G. (1987) EMBO J. 6, 2109-2115.

$190 \mathrm{Ohba}, \mathrm{M}$. and Schatz, G. (1987) EMBO J. 6, 2117-2122.

191 Zwizinski, C., Schleyer, M. and Neupert, W. (1983) J. Biol. Chem. 258, 4071-4074.

192 Hennig, B. and Neupert, W. (1981) Eur. J. Biochtin. 121, 203-212.

193 Hennig, B., Köhler, H. and Neupert, W. (1983) Proc. Natl. Acad. Sci. USA 80, 4963-4967.

194 Nicholson, D.W., Köhler, H. and Neupert, W. (1987) Eur. J. Biochem. 164, 147-157.

195 Basile, G., Di Bello, C. and Taniuchi, H. (1980) J. Biol. Chem. 255, 7181-7191.

196 Veloso, D., Basile, G. and Taniuchi, H. (1981) J. Binl. Chem. 256. 8646-8651.

197 Dumont, M.E., Ernst, J.F., Hampsey, D.M. and Sherman, F. (1987) EMBO J. 6, 235-241.

198 Nargang, F.E., Drygas, M.E., Kwong, P.L., Nicholson, D.W. and Neupert, W. (1988) J. Biol. Chem., in press.

199 Söllner, T., Pfanner, N. and Neupert, W. (1988) FEBS Lett. 229. 25-29.

200 Fujiki, Y., Hubhard, A.L., Fowler, S. and Lazarow, P.B. (1982) J. Cell Biol. 93, 97-102.

201 Fujiki, Y., Fowler, S., Shio, H., Hubbard, A.L. and Lazarow, P.B. (1982) J. Cell Biol. 93, 103-110.

202 Fisher, W.R., Taniuchi, H. and Anfinsen, C.B. (1973) J. Biol. Chem. 248, 3188-3195

(a) Hennig, B. and Neupert, W. (1983) Methods Enzymol. 97. 261-274.

203 Zimmermann, K., Hennig, B. and Neupert, W. (1981) Eur. J. Biochem. 116, 455-460.

204 Stellwagen, E., Rysavy, R. and Babul, G. (1972) J. Biol. Chem. 247, 8074-8077.

205 Berkhout, T.A., Rietveld, A.B. and De Kruijff, B. (1987) Biochim. Biophys. Acta 897, 1-4.

206 Nicholson, D.W., Ostermann, J. and Neupert. W. (1987) in Cytochrome Systems: Molecular Biology and Energetics (Papa, S. et al., eds.), pp. 197-208, Plenum Press, New York.

207 Nicholson, D.W. and Neupert, W. (1988) Proc. Natl. Acad. Sci. USA, in press.

208 Hackenbrock, C.R. (1968) Proc. Ni.ttl. Acad. Sci. USA 61, 589-602.

209 Kellems, R.E., Allison, V.F. and Butow, R.A. (1975) J. Cell Biol. 65, 1-14.
210 Ades, I.Z, and Butow, R.A. (1980) J. Biol. Chem. 255, 9925-9935.

211 Pain, D., Kanwar, Y.S. and Blobel, G. (1988) Nature 331, 232-237.

212 Nelson, N. and Schatz, G. (1979) Proc. Natl. Acad. Sci. USA 76. 4365-4369.

213 Kolansky, D.M., Conboy, J.G., Fenton, W.A. and Rosenberg. L.E. (1982) J. Biol. Chem. 257, 8467-8471.

214 Pfanner, N. and Neupert, W. (1988) in The Roots of Modern Biochemistry (Kleinkaut, H., Von Döhren, H. and Jaenicke, L., eds.), pp. 707-712, Walter de Gruyter, Berlin.

215 Kaput, J., Goltz, S, and Blobel, G. (1982) J. Biol. Chem. 257, 15054-15058.

216 Pfanner, N., Pfaller, R., Kleene, R. Ito, M., Tropschug. M. and Neupert. W. (1988) J. Biol. Chem. 263, 4049-4051.

217 Verner, K. and Schatz, G. (1987) EMBO J. 6, 2449-2456.

218 Ejlers, M., Hwang, S. and Schatz, G. (1988) EMBO J. 7. 1139-1145.

219 Chen, L. and Tai, P.C. (1985) Proc. Natl. Acad. Sci. USA 87 , 4384-4388.

220 Geller, B.L., Movva, N.R. and Wickner, W. (1986) Proc. Natl. Acad. Sci. USA 83, 4219-4222.

221 Yamane, K., Ichihara, S. and Mizushima, S. (1987) J. Biol. Chem. 262, 2358-2362.

222 Flügge, U.I., and Hinz, G. (1986) Eur. J. Biochem. 160, 563-570.

223 Pain, D. and Blobel, G. (1987) Proc. Natl. Acad. Sci. USA 84, 3288-3292.

224 Wiech, G., Sagstetter, M., Müller, G. and Zimmermann, R. (1987) EMBO J. 6, 1011-1016.

2.: Imanaka, T., Small, G.M. and Lazarow, P.B. (1987) J. Cell Biol. 105, 2915-2922.

(a) Bellion, E. and Goodman, J.M. (1987) Cell 48, 165-173.

226 Böhni, P., Gasser, S., Leaver, C. and Schatz, G. (1980) in The Organization and Expression of the Mitochondrial Genome (Kroon, A.M. and Saccone, C., eds.), pp. 423-433, Elsevier/ North-Holland, Amsterdam.

227 Conboy, J.G., Fenton, W.A. and Rosenberg, L.E. (1982) Biochem. Biophys. Res. Commun. 105, 1-7.

228 McAda, P.C. and Douglas, M.G. (1982) J. Biol. Chem. 257, 3177-3182.

229 Miura, S., Mori, M., Amaya, Y. and Tatibana, M. (1982) Eur. J. Biochem. 122, 641-647.

230 Böhni, P.C., Daum, G. and Schatz, G. (1983) J. Biol. Chem. 258, 4937-4943.

231 Schmidt, B., Wachter, E., Sebald, W. and Neupert, W. (1084) Eur. J. Biochem. 144, 581-588.

232 Cerletti, N., Böhni, P.C. and Suda, K. (1983) J. Biol. Chem. 258. 4944-4949.

233 Hawlitschek, G., Schneider, H., Tropschug, M., Hartl, F.-U. and Neupert, W. (1988) Cell 53, 795-806.

234 Yaffe, M.P. and Schatz, G. (1984) Proc. Natl. Acad. Sci. USA 81, 4819-4823.

235 Yaffe, M.P., Ohta, S. and Schatz, G. (1985) EMBO J. 4, 2069-2074.

236 Witte, C., Jensen, R.E., Yaffe, M.P. and Schatz, G. (1988) EMBO J. 7, 1439-1447.

(a) Pollock, R.A., Hartl, F.-U., Cheng. M.Y., Ostermann. J., Horwich, A. and Neupert, W. (1988) EMBO J., in press.

237 Zwizinski, C. and Wickner, W. (1980) J. Biol. Chem. 255. 7973-7977.

238 Watts, C., Wickner, W. and Zimmermann, R. (1983) Proc. Natl. Acad. Sci. USA 80, 2809-2813.

239 Robinson, C. and Ellis, R.J. (1984) Eur. J. Bicchern. 142. 337-342.

240 Sztul, E.S., Hendrick, J.P., Kraus, J.P., Wall, D., Kalousek, F. and Rosenberg, L.E. (1987) J. Cell Biol. 105, 2631-2639.

241 Ohashi, A., Gibson, J., Gregor, I. and Schatz, G. (1982) J. Biol. Chem. 257, 13042-13047.

242 Pratje, E., Mannhaupt, G., Michaelis, G. and Beyreuther, K. (1983) EMBO J. 2, 1049-1054.

243 Pratje, E. and Guiard, B. (1986) EMBO J. 5, 1313-1317. 
244 Kirwin. P.M.. Elderfield. P.D. and Robinson, C. (1987) J. Biol Chem. 262, 16386-16390.

245 Hurt, E.C., Allison, O.S., Müller, U. and Schatz, G. (1987) J. Biol. Chem. 262, 1420-1424.

246 Nguyen, M., Argan, C., Lusty, C.J. and Shore, G.C. (1986) J. Biol. Chem. 261, 800-805.

247 Nguyen, M., Argan, C., Sheffield, W.P., Bell, A.W., Shields, D. and Shore, G.C. (1987) J. Cell Biol. 104, 1193-1198.

248 Zwizinski, C. and Neupert, W. (1983) J. Biol. Chem. 258. 13340-13346.

249 Ou, W., Ito, A., Morohashi, K., Fuji-Kuriyama, Y, and Omura, T.J. (1986) Biochemistry 100, 1287-1296.

250 Wielburski, A., Kuzela, S. and Nelson, B.D. (1982) Biochem. J. 204, 239-245.

251 Werner, S., Schwab, A.J. and Neupert, W. (1974) Eur. J. Biochem. 49, 607-617.

252 Woodrow, G. and Schaty, G. (1979) J. Biol. Chem. 254. 6088-6093.

253 Taniuchi, H., Easile, G., Taniuchi, M. and Veloso, D. (1983) J. Biol. Chem. 258, 10963-10966.

254 Wold, F. (1981) Annu. Rev. Biochem. 50, 783-814.

255 Dickerson, R.E. and Timkovich, R. (1975) The Enzymes, Vol. II (Boyer, P., ed.), pp. 397-547, Academic Press, New York.

256 De Lange, R.J., Glazer, A.N. and Smith. E.L. (1969) J. Biol. Chem. 244, 1385-1388.

257 De Lange, R.J., Glazer, A.N. and Smith, E.L. (1970) J. Biol. Chem. 245, 3325-3327.

258 Park, K.S., Fros' R, Tuck, M., Ho, L.L., Kim, S. and Paik, W.K. (1987) J. Biol. Ch-m. 262, 14702-14708.

259 Kreb3, E.G. and Beavo, J.A. (1979) Annu. Rev. Biochen. 48, 923-959.

260 Richter, C., Winterhalter, K.H., Baumhüter, S., Lötscher, H.-R. and Moser, B. (1983) Proc. Natl. Acad. Sci. USA 80, 3188-3192.

261 Kun, E, Zimber, P.H., Chang, A.C.Y., Puschendorf, B. and Grunicke, H. (1975) Proc. Natl. Acad. Sci. USA 72, 1436-1440.

262 Ueda, K. and Hayaischi, O. (1985) Annu. Rev. Biochem. 54, 73-100.

263 Harnisch, U., Weiss, H. and Sebald, W. (1985) Eur. J. Biochem. 149, 95-99.

264 Schigger, H., Borchan, U., Machleidt, W., Link, T.A. and Von Jagow, G. (1987) FEBS Lett. 219, 161-168.

265 Hauska, G., Hurt, E. and Lockau, W. (1983) Biochim. Biophys. Acta 726, 97-133.

266 Gabellini, N. and Sebald, W. (1986) Eur. J. Biochem. 154. 569-579.

267 Gabellini, N., Harnisch, U., McCartny, J.E.G., Hauska, G. and Sebald, W. (1985) EMBO J. 4, 549-553.

268 Hartl, F.-U., Pfanner. N. and Neupert, W. (1987) Biochem. Soc. Trans. 5, 95-97.

269 Daum, G., Böhni, P.C. and Schatz, G. (1982) J. Biol. Chem. 257. $13028-13033$.

$270 \mathrm{Alt}$, J. and Hertmann, R.G. (1984) Curr. Genet. 8, 551-557.

271 Sadler, 1., Suda, K., Schatz, G., Kaudewitz, F. and Haid, A. (1984) EMBO J. 3, 2137-2143.

272 R8misch, J., Tropschug. M., Sebald, W. and Weiss, H. (1987) Eur. J. Biochem. 164, 111-115.

273 Duffaud, G.D. Lehnhardt, S.K., Marci, P.E. and Inouye, M. (1985) in Current Topics in Membranes and Transport. Vol. 24 (Bonner, F., ed.: P.A. Knauf and J.S. Cook. guest eds.). pp. 65-104. Academic Press, New York.

274 Kanazawa, H., Mabuchi, K., Kayano, T., Tamura, F. and Futai, M. (1981) Biochem. Biophys. Res. Commun. 100, 219-225.

275 Farrell, L.B., Gearing, D.P. and Nagley, P. (1988) Eur. J. Biochem. 173, 131-137.

276 Gearing. D.P. and Nagley, P. (1986) EMBO J. 5, 3651 - 3655.

277 Hurt, E.C. and Van Loon, A.P.G.M. (1986) Trends Biochem. Sci. 11, 204-207.
278 Van Loon, A.P.G.M., Brändli, A.W. and Schatz, G. (1986) Cell 44. $801-812$.

279 Van Loon, A.P.G.M., Brändii, A.W., Pesold-Hurt, B., Blank, D. and Schat., G. (1987) EMBO J. 6, 243,3-2439.

280 Van Loon, A.P.G.M. and Schatz, G. (1987) EMBO J, 6. 2441-2448.

281 Lubben. T.H., Bansberg. J. and Keegstra. K. (1987) Science 238. 1112-1113.

282 Nguyen, M, and Shore, G.C. (1987) J. Biol. Chem. 262. 3929-3931.

283 Nguyen, M., Bell, A.W. and Shore, G.C. (1988) J. Celi Biol. 106. 1499-1505.

284 Weiss, H. and Kolb. H.J. (1979) Eur. J. Bioshem. 99, 139-149.

285 Neupert. W. and Von Rücker, A. (1976) in Genetics and Biogenezis of Chloreplasts and Mitochondria (Bücher, T.. Neupert. W., Sebaic, W. and Werner, S., eds.), pp. 231-238, North-Holland. Amsterdam.

286 De Jong. L. Holtrop. M. and Kroon. A.M. (1979) Biochin. Biophys. Acta 548, 48-62.

287 Van Loon. A.P.G.M. Van Eijk, E. and Grivell, L.A. (1983) EMBO J. 2. i765- 1770.

288 Van Loon, A.P.G..M. Maarse, A.C. Riezman. H. and Grivell. L.A. (1983) Gene 26. 261-272.

289 Marzuki. S. and Linnane. A.W. (1985) in The Enzymes of Biological Membranes (Martonosi, A.N., ed.), Vol. 4. pp. 41 S-430. Plenum Press, New York.

290 Lustig, A., Padmanaban, G. and Rabinowitz, M. (1982) Biochemistry $21,309-316$.

291 Lustig, A., Levens, D. and Rabinowitz, M. (1982) J. Biol. Chem. 257, 5800-5808.

292 Faye, G. and Simon. M. (1983) Cell 32, 77-87.

293 Pillar, P., Lang, B.F., Steinberger, I., Vog!, B. and Kaudewitz, F, (1983) J. Biol. Chem. 258, 7954-7959.

294 McGraw, P. and Tzagolof, A. (198:) \& Biol. Chem. 258, 9453-9468.

295 Dieckmann. C.L., Koerner. T.J. and Tzagehni, A. (1984) J. Biol. Chem. 259, 4722-4731.

296 Muller, P.P., Reif, M.K., Zonghou, S Sxng̣staz, C., Mason, T.L. and Fox. T.D. (1984) J. Mol. Biol. 175. $43,-4 j 2$.

297 Dieckmann. C.L. and Tzagoloff. A. (1 85) J Biol. Chem. 260, 1513-1520.

298 Rödel, G., Körte, A. and Kaudewitz. F. (1985) Curr. Genet. 9. 641-648.

299 Fox. T.D. (1986) Trends Genet. 2, 97-100.

300 Lewin, A.S. and Norman. D.K. (1983) j. Biol. Chem. 258, 6750-6755.

301 Ellis, J. (1987) Nature 328, 378-379.

(a) Hemmingsen, S.M., Woolford, C.. Van der Vies, S.M., Tilly, K., Dennis, D.T., Georgopoulos, C.P., Hendrix, R.W. and Ellis, R.J. (1988) Nature 333, 330-333.

302 Hase, T., Riezman, H., Suda, K. and Schatz, G. (1983) EMBO J. 2, 2169-2172.

303 Mihara, K. and Sato, R. (1985) EMBO J. 5, 769-774.

304 Ono, H. and Tuboi, S. (1987) Eur. J. Biochem. 169, S09-514.

305 Kolarov, J. and Nelson, B.D. (1984) Eur. J. Biochem. 144, 387-392.

306 Sidhu, A. and Beattic. D.S. (1983) J. Biol. Chem. 258 , 10649-10656.

307 Beckmann, J.D.. Ljungdahl, P.O. Loper, J.L. and Trumpower, B.L. (1987) J. Biol. Chem. 262, 8901-8909.

308 De Haan, M., Van Loon, A.P.G.M., Kreike, J., Vaessen, R.T.M.J. and Grivell, L.A. (1984) Eur. J. Biochem. 138, 169-177.

309 Hatalova, I. and Kolarov, J. (1983) Biochem. Biophys. Res. Cummun. 110, 132-139.

310 Sthmeizer, E. and Heinrich, P.C. (1980) J. Biol. Chem. 255 , 7\$03-7506. 
311 Heinrich. P.C. (1982) Rev. Physiol. Biochem. Pharmacol, 93, 115-187.

312 Mihara, K. and Blobel. G. (1980) Proc. Natl. Acad. Sci. USA 77, 4160-4164.

313 Lewin, A.S., Gregor, 1., Mason, T.1., Nelson. N. and Schatz, G. (1980) Proc. Natl. Acad. Sci. USA 77, 3998-4002.

314 Koerner, T.J., Hill, J. and Tzagoloff, A. (1985) J. Biol, Chem. 260. 9513-9515.

315 Wright, R.M., Ko, C., Cumisky, M.G. and Poyton, R.O. (1984) J. Biol. Chem. 259, 15401-15407.

316 Takeda. M.. Vassarotti, A. and Douglas, M.G. (1985) J. Biol. Chem. 260, 15458-15465.

317 Kruse, B. and Sebald, W. (1984) in $\mathrm{H}^{+}$-ATPase (ATP Synthase): Structure, Function, Biogenesis. The $F_{0} F_{1}$ Complex of Coupling Membranes (Papa, S., Altendorf, K., Ernster, L. and Packer, L., eds.), pp. 67-75. ICSU Press, Adriatica Editrice, Bari, Italy.

318 Yoshida, Y.. Hashimoto, T. and Tagawa, K. (1983) J. Biochem. 94, 283-290.

319 Yoshida, Y., Hashimoto, T., Hase. T., Matsubara, H. and Tagawa, K. (1983) J. Biochem. 94, 291-297.

320 Michel, R., Wachter, E. and Scbald, W. (1979) FEBS Lett. 101, 373-376.

321 Morohashi, K., Fujii-Kuriyama, Y.. Okada, Y., Sogawa, K., Hirose. T., Inayama, S. and Omura, T. (1984) Proc. Natl. Acad. Sci. USA $81,4647-4651$.

322 Young, E.T. and Pilgrim. D.B. (1985) Mol. Cell. Biol. 5, 3024-3034.

323 Behra, R. and Christen, P. (1986) J. Biol. Chem. 261, 257-261.

324 Mori, M., Morita, T., Ikeda, F., Amaya, Y., Tatibana, M. and Cohen, P.P. (1981) Proc. Natl. Acad. Sci. USA 78, 6056-6060.

325 Morita, T., Mori, M., Ikeda, F. and Tatibana, M. (1982) J. Biol. Chem. 257, 10547-10550.

326 Bhat, N.K. and Avadhani, N.G. (1985) Biochem. J. 24, 8107-8113.

327 Nyunoya, H., Broglie, K.E., Widgren, E.E. and Lusty, C.J. (1985) J. Biol. Chem. 260, 9346-9356.

328 Harmey, M.A. and Neupert, W. (1979) FEBS Lett. 108, 385-389.

329 Ono, H. Yoshimura, N., Sato, M. and Tuboi, S. (1985) J. Biol. Chem. 260, 3402-3407.

330 Hunter, A. and Lindsay, J.G. (1986) Eur. J. Biochem. 155, 103-109.

331 Oda, T., Ichiyama, A., Miura, S. and Mori, M. (1984) J. Biochem. 95, 815-824.

332 Chien, S.-M. and Freeman, K.B. (1984) J. Biol. Chem. 259, 3337-3342.

333 Chien, S.-M., Patel, H.V. and Freeman, K.B. (1984) J. Biol. Chem. 259, 13633-13636.

334 Grant, P.M., Tellam, J., May, V.L. and Strauss, A.W. (1986) Nucl. Acids Res. 14, 6053-6065.

335 Mueckler, M.M. Himeno, M. and Pitot, H.C. (1982) J. Biol. Chem. 257, 7178-7180.

336 Simmaco, M., John, R.A., Barra, D. and Bossa, F. (1986) FEBS Leti. 199, 39-42.

337 Conboy, J. and Rosenberg, L.E. (1981) Proc. Natl. Acad. Sci. USA 78, 3073-3077.

338 Mori, M., Miura, S., Tatibana, M. and Cohen, P.P. (1980) Prr. Natl. Acad. Sci. USA 77, 7044-7048.

339 Kraus, J.P., Conboy, J. and Rosenberg, L.E. (1981) J. Biol. them. 256, 10739-10742.

340 McIntyre, P., Graf, L., Mercer, J., Peterson, G., Hudson, P and Hoogenraad, N. (1984) FEBS Lett. 177, 41-46.

341 Takiguchi, M., Miura, S., Mori, M., Tatibana, M., Nagata, S. and Kaziro, Y. (1984) Proc. Natl. Acad. Sci. USA 81, 7412-7416.

342 Kraus, J.P., Hodges, P.E., Williamson, C.L., Horwich, A.L., Kalousek, F., Williams, K.R. and Rosenberg, L.E. (1985) Nucl. Acids Res. 13, 943-952.

343 Horwich, A.L., Fenton, W.A., Williams, K.R., Kalousek, F., Kraus, J.P., Doolitte, R.F., Konigsberg, W. and Rosenberg, L.E. (1984) Science 224, 1068-1074.
344 Sachs, M.S., David, M. Werner, S. and RajBhendary, U.L. (1986) J. Biol. Chem. ?G1 869-873.

345 Lomax, M.I., Bashman, N.J., Nasof,, M.S., Carutivers, M.H. and Grossman, L.1. (1984) Proc. Natl. Acad. Sci. USA (USA) 81, 6295-6299.

146 Patterson, T. and Poyton, R.O. (1986) J. Biol. Chem. 261, 17192-17197.

347 Velours, J., Durrens, P., Aigle, M. and Guerin. B. (1988) Eur. J. Biochem. 170, 637-642.

348 Runswick, M.J., Powell, S.J., Nyren. P. and Walker, J.E. (1987) EMBO J. 6, 1367-1373.

349 Tzagoloff, A., Wu, M. and Crivellone, M. (1986) J. Biol. Chem. 261, 17163-17169.

350 Oudshoorn, P., Van Steeg. H., Swinkels, B.W., Schoppink, P. and Grivell, L.A. (1987) Eur. J. Biochem. 163. 97-103.

351 Takeda, M., Chen, W.-J., Saltzgaber, J. and Douglas, M.G. (1986) J. Biol. Chem. 261, 15126-1:133.

352 Boutry, M. and Chua, N.-H. (1985) EMBO J. 5, 2159-2165.

353 Ohta, S. and Kagawa, Y. (1986) J. Biochem. 99. 135-141.

354 Morohashi, K., Yoshioka. H., Gotoh, O., Ot.ada, Y., Yamamoto, K., Miyata, T., Sogawa, K., Fujiki-Kuriyama, Y. and Omura, T. (1987) J. Biochem. 102, 559-568.

355 Morohashi, K., Sogawa, K., Omura, T. and Fujiki-Kuriyama, Y. (1987) J. Biochem. 101, 879-887.

356 Suissa, M., Suda, K, and Schatz, G. (1984) EMBO J. 3, 1773-1781.

357 Dahl, H.H.M., Hunt, S.M., Hutchinson, W.M. and Brown, G.K. (1987) J. Biol. Chem. 262, 7398-7403.

(a) Koike. K., Ohta, S., Urata, Y., Kagawa, Y. and Koike, M. (1988) Proc. Natl. Acad. Sci. USA 85, 41-45.

(b) Henning, W.D., Upton, C., McFadden, G., Majumdar, R. and Bridger, W.A. (1988) Proc. Natl. Acad. Sci. USA 85. $1432-1436$.

358 Braun, T., Bober, E., Singh, S., Agarwal, D.P. and Goedde, w. (1987) FEBS Lett. 215, 233-236.

359 Kryzwicki, K.A. and Brandriss, M.C. (1984) Mol. Cell. Biol. 4, 2837-2842.

360 Jaussi, R., Cotton, B., Juresic, N., Christen, P. and Schïmperli, D. (1985) J. Biol. Chem. 260, 16060-16063.

361 Joh, T., Nomiyama, H., Maeda, S., Shimada, K. and Morino, Y. (1985) Proc. Natl. Acad. Sci. USA 82, 6065-6069.

362 Oda, T., Miyajima, H., Suzuki, Y. and Ichiyama, A. (1987) Eur. J. Biochem. 168, 537-542.

363 Urban-Grimal, D., Volland, C., Garnier, T., DeHoux, P. and Labbe-Bois, R. (1986) J. Biochem. 156, 511-519.

364 Kraus, J.P., Firgaira, F., Novotny, J., Kalousek, F., Williams, K.R., Williamson, C., Ohura, T. and Rosenberg. C.E. (1986) Proc. Natl., Acad. Sci. USA 83, 8049-8053.

365 Matsubara, Y., Kraus, J.P., Ozasa, H., Glassberg. R., Finocchiaro, G., Ikeda, Y., Mole, J., Rosenberg, L.E. and Tanaka, K. (1987) J. Biol. Chem. 262, 10104-10108.

366 Okamura, T., John, M.E., Zuber, M.X., Simpson, E.R. and Waterman, M.R. (1985) Proc. Natl. Acad. Sci. USA 82, S70S-\$709.

367 Okamura, T., Kagimoto, M., Simpson, E.R. and Waterman, M.R. (1987) J. Biol, Chem. 262, 10335-10338.

368 Ho, Y.-S. and Crapo, J.D. (1988) FEBS Lett. 229, 256-260.

369 Ho, Y.-S. and Crapo, J.D. (1987) Nucl. Acids Res. 15, 10070.

370 Hallewell, R.A., Mullenbach, G.T., Stempien, M.M. and Bell, G.I. (1986) Nucl. Acids Res. 14, 9539.

371 Nagata, S., Tseunetsugu-Yokata, Y., Naito, A. and Kaziro, Y. (1983) Proc. Natl. Acad. Sci. USA 80, 6192-6196.

372 Koerner, T.J., Myers, A.M., Lee, S. and Tzagoloff, A. (1987) J. Biol. Chem. 262, 3690-3696.

373 Ellis, S.R., Hopper, A.K. and Martin, N.C. (1987) Proc. Natl. Acad. Sci. USA 84, 5172-5176.

374 Myers, A.M., Crivellone, M.D. and Tzagoloff, A. (1987) J. Biol. Chem. 262, 3388-3397.

375 Foury. F. and Lahaye, A. (1987) EMBO J. 6, 1441-1449. 
376 Labouesse, M., Herbert, C.J., Dujardin, G. and Slonimski, P.P. (1987) EMBO J. 6, 713-721.

377 Maarse, A.C. and Grivell, L.A. (1987) Eur. J. Biochem. 165. 419-425.

378 Nakagawa, T., Maeshima, M. Muto, H., Kajiura, H., Hattori. H. and Ashi, T. (1987) Eur. J. Biochem. 165. 303-307.

379 Suski, G., Mengel, T., Cordingley, M. ard Kaden'sch, B. (1987) Eur J. Biochem. 168, 233-237.

380 Scl.usidt. G.W., De Villers-Thiery, Á., Desrui seaux. H., Blobel, G. and Chua, N.-H. (1979) J. Ceil Biol. 8?, 615-622.

381 Wright, R.M., Dircks, L.K. and Poyton. R.O. (1986) J. Biol. Chem. 262. 17183-17191.

382 Brandrier, wi.c: ad Kryzwick:, X.A. (1986) Mol Cell nt..i. b́, $3502-? ; i 2$.
383 Bhasker. C.R. Okamura. T. and Waterman. M. (1987) Eur. J. Biochem. 164, 21-25.

384 Farrell, L.B. and Nagley. P. (1987) Biochem. Biophys. Res. Commun. 144. 1257-1264.

385 Martes, C.A.M., Van Loon, A.P.G.M., Oudshoorn, P., Van Steeg. H., Grivell, L.A. and Slater. E.C. (1985) Eur. J. Biochem. 14. 153-161.

386 Mueckler. M.M. and Pitot, H.C. (1985) J. Biol. Chem. 260. 12993-12997.

387 Lederer, F. and Simon. A.M (1074) Rinchem. Ringhys. Res. Commen. 5o, 317-323.

388 Coruzzi. G. and Tzagoloff. A. (1979) J. Bioi. Chem. 254. 9324-9330. 